\title{
GEOPHYSICAL INVESTIGATIONS OF PYROCLASTIC DENSITY CURRENT PROCESSES AND DEPOSIT PROPERTIES AT MOUNT ST. HELENS, WASHINGTON (USA)
}

\author{
by \\ Andrew Cleveland Gase
}

\author{
A thesis \\ submitted in partial fulfillment \\ of the requirements for the degree of \\ Master of Science in Geophysics \\ Boise State University
}

August 2017 
(c) 2017

Andrew Cleveland Gase

ALL RIGHTS RESERVED 


\title{
DEFENSE COMMITTEE AND FINAL READING APPROVALS
}

\author{
of the thesis submitted by \\ Andrew Cleveland Gase
}

Thesis Title: Geophysical Investigations of Pyroclastic Density Current Processes and Deposit Properties at Mount St. Helens, Washington (USA)

Date of Final Oral Examination: 11 November 2016

The following individuals read and discussed the thesis submitted by student Andrew Cleveland Gase, and they evaluated his presentation and response to questions during the final oral examination. They found that the student passed the final oral examination.

John Bradford, Ph.D. Co-Chair, Supervisory Committee

Brittany D. Brand, Ph.D.

Co-Chair, Supervisory Committee

Lee M. Liberty, M.S.

Member, Supervisory Committee

The final reading approval of the thesis was granted by John Bradford, Ph.D., Chair of the Supervisory Committee. The thesis was approved by the Graduate College. 


\section{ACKNOWLEDGMENTS}

This thesis was supported by a National Science Foundation grant (NSF-EAR 0948588) and a Geological Society of America graduate student research grant. The Boise State Center for Geophysical Investigation of the Shallow Subsurface (CGISS) provided all geophysical equipment.

I am grateful to my peers Nicholas Pollock, Travis Nielson, Darin Schwartz, Alexander Miller, and Tate Meehan, who assisted with data collection. Without their support and perhaps most essentially their brawn this thesis would not exist. 


\begin{abstract}
Geophysical imaging has the potential to significantly improve investigations in pyroclastic deposits, either as a means of in situ property estimation or to provide geologic context where exposures do not exist. I perform two geophysical studies set in the deposits of the 1980 eruption at Mount St. Helens, Washington (USA); the aim is to investigate the physical properties and geology of pyroclastic deposits.

Joint petrophysical modeling reveals the dependence of seismic and electromagnetic velocities in pyroclastic deposits on two-phase porosity (vesicularity and intergranular porosity) and water-saturation. Seismic first arrival travel-time tomography, multi-channel analysis of surface waves, and multi-offset GPR reflection tomography inversions from coincident seismic and GPR surveys demonstrate that seismic and electromagnetic velocities are consistent with partially saturated and moderate to poorly sorted siliciclastic sediments. The anomalously high critical porosity of pumice allows pyroclastic deposits to maintain higher rigidity despite total deposit porosities on the order of 0.80 .
\end{abstract}

A GPR survey of the pumice plain reveals two broad pyroclastic density current (PDC) scour-and fill features interpreted as erosional channels-the most spatially extensive case of scouring by PDCs found to date. Both channels are $>200 \mathrm{~m}$ wide and $>500 \mathrm{~m}$ long; estimated eroded volumes are on the order of $10^{6} \mathrm{~m}^{3}$. Erosion appears to be promoted by moderate slope angle $\left(5-15^{\circ}\right)$, substrate pore-air retention, and pulses of increased flow energy. These findings are the first direct evidence of erosional self-channelization by sustained, waxing and waning PDCs, a phenomena 
that may increase flow velocity and run-out distance. 


\section{TABLE OF CONTENTS}

ACKNOWLEDGMENTS $\ldots \ldots \ldots \ldots \ldots \ldots \ldots \ldots$ iv

ABSTRACT $\ldots \ldots \ldots \ldots \ldots \ldots \ldots \ldots \ldots \ldots \ldots \ldots \ldots$

LIST OF TABLES $\ldots \ldots \ldots \ldots \ldots \ldots \ldots \ldots \ldots \ldots \ldots \ldots \ldots \ldots \ldots \ldots \ldots \ldots$

LIST OF FIGURES $\ldots \ldots \ldots \ldots \ldots \ldots \ldots \ldots \ldots \ldots \ldots \ldots \ldots \ldots$

LIST OF ABBREVIATIONS $\ldots \ldots \ldots \ldots \ldots \ldots \ldots \ldots \ldots \ldots \ldots$

LIST OF SYMBOLS $\ldots \ldots \ldots \ldots \ldots \ldots \ldots \ldots \ldots \ldots \ldots \ldots \ldots \ldots \ldots$

1 Introduction to Thesis $\ldots \ldots \ldots \ldots \ldots \ldots \ldots \ldots \ldots \ldots$

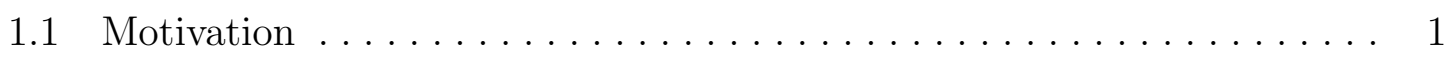

1.2 Pyroclastic Density Currents . . . . . . . . . . . . . . . . . . 1

1.3 Near-Surface Geophysics.......................... . 3

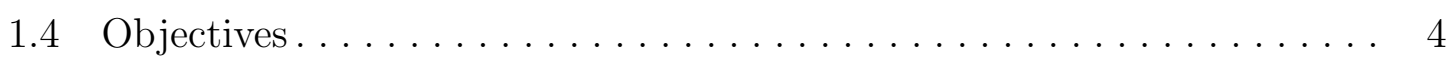

2 In Situ Constraints on Porosity and Water-Saturation of Pyroclastic Deposits From Electromagnetic and Seismic Velocities......... 6

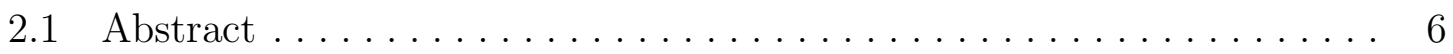

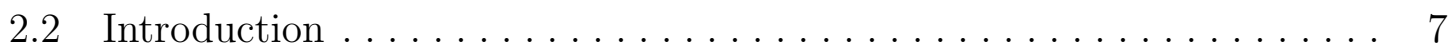

2.2.1 Petrophysical Background $\ldots \ldots \ldots \ldots \ldots \ldots \ldots \ldots \ldots$

$2.2 .2 \quad$ Survey Setting ............................ 11 
2.3 Methods .................................. 12

2.3.1 GPR Acquisition and Data Processing . . . . . . . . . . 12

2.3.2 Seismic Acquisition and Data Processing ............. 13

2.4 Results and Interpretations $\ldots \ldots \ldots \ldots \ldots \ldots \ldots \ldots \ldots \ldots \ldots$

2.4.1 GPR Reflectivity...................... 14

2.4.2 Complete P-wave Tomogram $\ldots \ldots \ldots \ldots \ldots \ldots \ldots \ldots$

2.4.3 Outcrop Scale Tomograms $\ldots \ldots \ldots \ldots \ldots \ldots \ldots \ldots \ldots$

2.5 Discussion . . . . . . . . . . . . . . . . . . . . . . . 19

2.5.1 Geophysical Velocities of Pyroclastic Deposits ............ 19

2.5.2 Petrophysical Inversion for Water-Saturation and Porosity . . . . 20

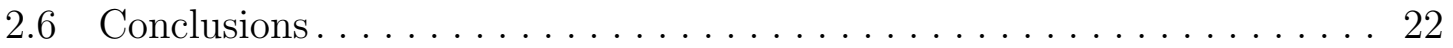

2.7 Equations for Electromagnetic and Seismic Properties............. 23

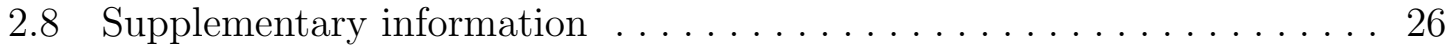

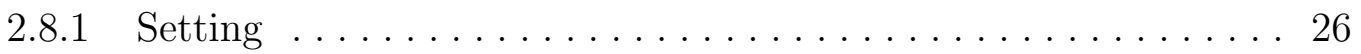

2.8.2 GPR Reflectivity Results and Interpretations . . . . . . . . 27

2.8.3 Complete Line P-wave velocity tomogram $\ldots \ldots \ldots \ldots \ldots 27$

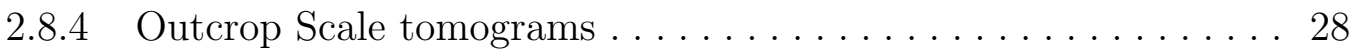

2.8.5 Petrophysical Inversion . . . . . . . . . . . . . . . . . . . 29

2.9 Tables . . . . . . . . . . . . . . . . . . . . . . . . . . . . . . 29

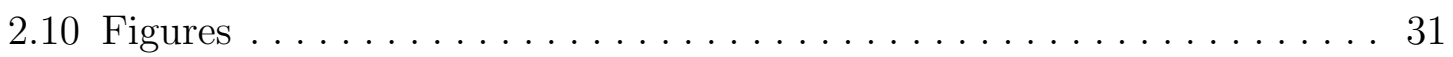

3 Evidence of erosional self-channelization of pyroclastic density currents revealed by ground-penetrating radar imaging at Mount St. Helens, Washington (USA) $\ldots \ldots \ldots \ldots \ldots \ldots \ldots \ldots \ldots$

$3.1 \quad$ Abstract ................................. 45 


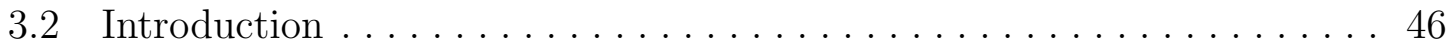

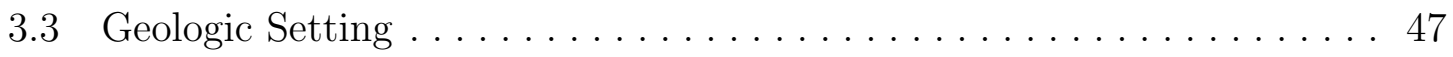

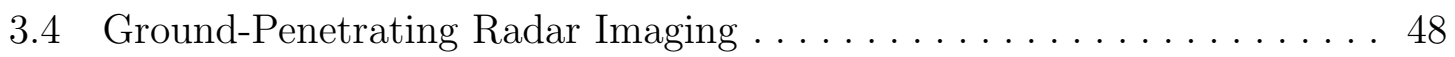

3.5 Radargram Descriptions and Interpretations . . . . . . . . . . . 49

3.5.1 Description Strategy . . . . . . . . . . . . . . . . . . . 49

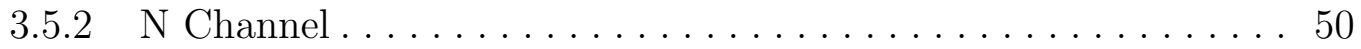

$3.5 .3 \quad$ S Channel . . . . . . . . . . . . . . . . . . . . . . . 51

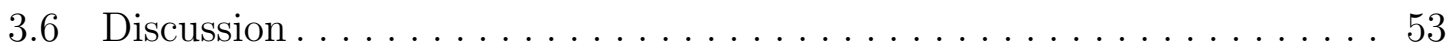

3.7 Conclusion $\ldots \ldots \ldots \ldots \ldots \ldots \ldots \ldots \ldots \ldots \ldots \ldots \ldots \ldots \ldots$

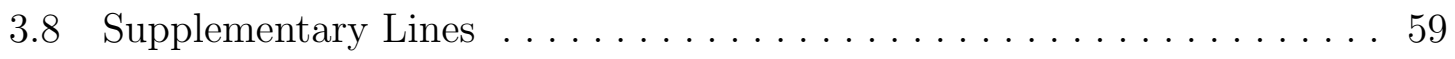

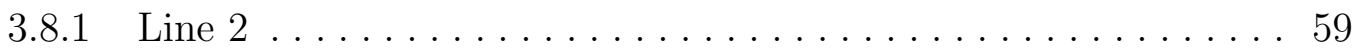

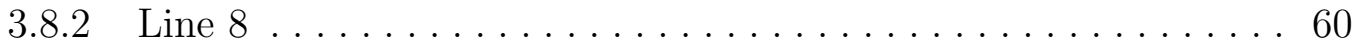

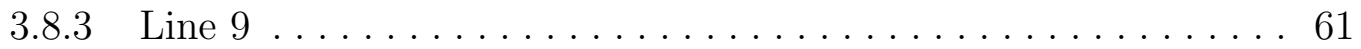

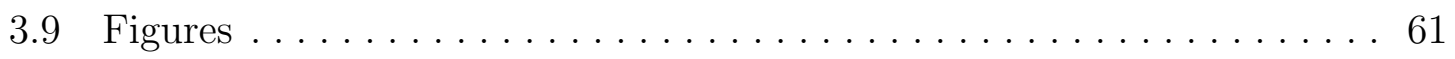

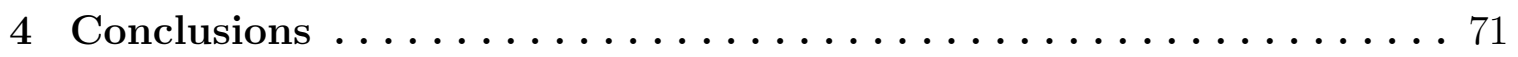

REFERENCES........................... 73 


\section{LIST OF TABLES}

2.1 Parameters are listed for GPR (Table 2.1a) and seismic (Table 2.1b)

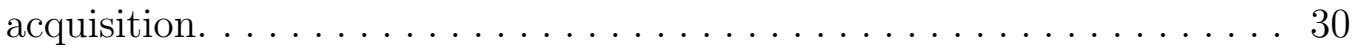

2.2 Densities $\left(\rho_{i}\right)$, bulk moduli $\left(K_{i}\right)$, shear moduli $\left(G_{i}\right)$ and volumetric proportions of mineral phases within dacite from 18 May 1980 PDC

deposits of Mount St. Helens. . . . . . . . . . . . . . . . . . . . 30 


\section{LIST OF FIGURES}

2.1 Electromagnetic and seismic velocities are modeled for pyroclastic deposits for given intergranular water-saturation $\left(S_{g}\right)$ and porosity $\left(\phi_{g}\right)$ at $10 \mathrm{~m}$ depth. a) Electromagnetic velocity is primarily sensitive to $S_{g}$ and secondarily sensitive to $\phi_{g}$. b) S-wave velocity is weakly anticorrelated with $S_{g}$ and inversely related to $\phi_{g}$. c) P-wave velocity increases rapidly at $S_{g}>0.95$ and is otherwise inversely related to $\phi_{g}$. d) The root-mean squared misfit from joint petrophysical minimization of $V_{P}, V_{S}$, and $V_{E M}$ modeled for pyroclastic deposits with $\phi_{g}$ of 0.4 and $S_{g}$ of 0.25 . Dotted contours indicate RMS misfit at 0.25 intervals. Note that seismic and electromagnetic velocity contours (dashed lines) are near perpendicular. Neither seismic nor electromagnetic velocities

alone can resolve unique solutions for $S_{g}$ or $\phi_{g} \ldots \ldots \ldots \ldots$. . . . . 31

2.2 a) Mount St. Helens digital elevation model. b) Satellite image of the study site in the pumice plain, $5 \mathrm{~km}$ northwest of Mount St. Helen's crater. The survey line is $>20 \mathrm{~m}$ offset from the adjacent outcrop (blue). The survey line section with seismic data only is red; overlapping GPR and seismic data are yellow; outcrops are colored blue. Grid-lines are $1 \mathrm{~km}$ UTM, northern hemisphere, zone 10. . . . . . 32 
2.3 a) Panorama of the outcrop adjacent to the survey line. b) Panorama with flow-unit interpretations from Brand et al. [2014]. All flow-units (indicated by Roman numerals) were deposited during the 18 May 1980 eruption. The outcrop contains a large scour-and-fill feature, where the pyroclastic density currents deposited Units I and II, scoured into Unit II, then filled the scour with Units III and IV. Two breccia lenses comprised of meter-scale boulders are present in Units III and IV. The approximate horizontal extent of the line is shown below the panorama with the identical color scheme as in Figure $2.2 \ldots \ldots \ldots \ldots \ldots$

2.4 GPR reflectivity was used to estimate subsurface $V_{E M}$ and correlate tomography results with underlying stratigraphy. a) Representative common-midpoint gathers show hyperbolic reflections. b) Time-stack after normal move-out correction, F-K migration, and depth conversion at $0.092 \mathrm{~m} \mathrm{~ns}^{-1}$. c) PSDM radargram with horizons selected for reflection tomography. d) PSDM radargram with stratigraphic interpretations. The Unit I-II horizon is weak and relatively horizontal. Dipping reflections in Unit III truncate Unit II reflections. Lenses of weak signal are attributed to breccias. . . . . . . . . . . . . 34 
2.5 a) A representative seismic shot gather shows first-arrivals (red line) and significant ground-roll (purple). Shot gathers have clear watertable refractions (first-arrivals beyond $40 \mathrm{~m}$ offset) and a water-table reflection (yellow dashed curve). b) Rayleigh-waves are isolated for MASW. For example, Shot 122 is windowed to offsets 12-78 m. Data are muted before the ground-roll to limit body-wave noise. c) A dispersion curve depicts Rayleigh-wave frequency versus phase-velocity of Shot 122. Dispersion curve picks are shown in red. . . . . . . . . . 35

2.6 P-wave velocity spanning the entire horizontal extent of the seismic line. Contours are drawn at 300, 500, 1000, and $1500 \mathrm{~m} \mathrm{~s}^{-1}$. P-wave velocity increases gradually with depth in the shallowest $20 \mathrm{~m}$ from 300 $\mathrm{m} \mathrm{s}^{-1}$ to $500 \mathrm{~m} \mathrm{~s}^{-1}$. The $1500 \mathrm{~m} \mathrm{~s}^{-1}$ contour follows the relief of the stream below. An additional $400 \mathrm{~m} \mathrm{~s}^{-1}$ contour highlights a lenticular region of with slightly elevated $V_{P}$ in the upper $10 \mathrm{~m}$. The $300 \mathrm{~m}$ $\mathrm{s}^{-1}$ contour at the top left side of the tomogram accentuate a low $V_{P}$ area attributed to poorly consolidated sediments within a secondary phreatic explosion crater at the beginning of the line. P-wave velocity is also reduced along the hill-slope at the right end of the line. . . . . . 36 
2.7 EM-wave velocity model from reflection tomography of GPR data. EM-wave velocity is greatest near the ground surface. Two broad regions of low $V_{E M}$ are centered at horizontal positions $100 \mathrm{~m}$ and 200 m. b) P-wave velocity model from inversion of first-arrival travel times. P-wave velocity increases gradually with depth. A lens of high $V_{P}\left(>350 \mathrm{~m} \mathrm{~s}^{-1}\right)$ at $4 \mathrm{~m}$ depth and horizontal position $100 \mathrm{~m}$ is centered over the Unit IV breccia lens (Figure 2.3). P-wave velocity is lowest $\left(<300 \mathrm{~m} \mathrm{~s}^{-1}\right)$ at the northern end of the line. c) S-wave model from inversion of Rayleigh-wave dispersion curves at off-end shot mid-points. A lens of high $V_{S}\left(225 \mathrm{~m} \mathrm{~s}^{-1}\right)$ at $5 \mathrm{~m}$ depth overlaps the high $V_{P}$ zone (b) and the Unit IV breccia lens (Figure 2.3). S-wave velocity is lowest in the top $1 \mathrm{~m}$ and at the northern end of the line. . . . . . . . 37

2.8 Intergranular porosity $\left(\phi_{g}\right)$ and water-saturation $\left(S_{g}\right)$ results from joint Monte Carlo inversion of seismic and electromagnetic velocities. a) Intergranular porosity ranges between $0.28-0.42$. A zone of low $\phi_{g}$ corresponds to the location of the upper breccia lens in the outcrop. b) Intergranular porosity errors $\left(e_{\phi}\right)$ do not exceed 0.03. c) Intergranular water-saturation ranges between $0.25-0.35$ and mirrors the morphology of the $V_{E M}$ tomogram (Figure 2.7a). d) Intergranular water-saturation

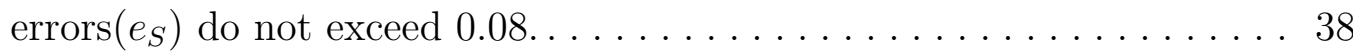

2.9 Southeast facing photographs of multifold GPR and active seismic acquisition along outcrop AD-3. a) Multifold GPR was acquired with two sources and four receivers, mounted on six sleds connected by rope. In this photograph offsets range from 8-15 m. b) Active seismic acquisition using a hammer source, and $10 \mathrm{~Hz}$ geophones at $2 \mathrm{~m}$ intervals.39 
2.10 a) Mount St. Helens digital elevation model. b) Map of seismic and GPR lines in the central pumice plain. Line 1 (i.e., line discussed in chapter 2) is parallel to outcrop AD-3. Line 2 (i.e., supplementary line) is parallel to outcrop D-4. Lengths with seismic data only are red; overlapping GPR and seismic data are yellow; outcrops are blue. The $1 \mathrm{~km}$ grid is UTM, northern hemisphere, zone 10 . . . . . . . . . 40

2.11 a) Panorama of outcrop D-4 and b) flow-unit interpretations from Brand et al. [2014]. Outcrop D-4 contains deposits from the 18 May 1980 eruption, mantled by subsequent June PDC and lahar deposits. Unit III contains large levees comprised of decimeter scale cobbles. A helicopter is approximately $100 \mathrm{~m}$ beyond the outcrop. The approximate extent of Line 2 is shown below with identical color scheme as in

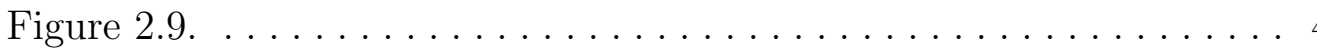

2.12 Line 2 radargram after reflection tomography, PSDM and stacking. Line 2 contains three dominant radar-facies. Deep, sub-parallel and horizontal reflections to the west correspond to Unit III. Scattering from levee breccias may be responsible for signal loss at the center and east of Unit III. The deepest horizon separates Units III and IV. Two mounds of irregular reflections at 5-7 $\mathrm{m}$ depth are attributed to lithic levees, although the features are not well-defined. Wavy reflections above the levees are attributed to Unit IV. Lahar and June PDCs deposits in outcrop D-4 (Figure 2.11) are either non-existent along the line or indistinguishable in the image. . . . . . . . . . . . . . 41 
2.13 P-wave velocity tomogram of Line 2, spanning the entire horizontal extent of the seismic line and up to depths of $30 \mathrm{~m}$. Shallow subsurface $V_{P}$ irregularities do not clearly resemble the levees in outcrop D-4

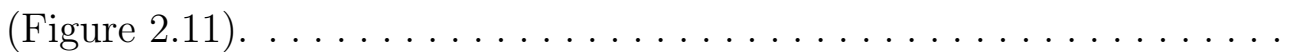

2.14 Line 2 velocity tomograms. Note three times vertical exaggeration. a) Electromagnetic velocity model from reflection tomography of GPR data. Electromagnetic velocity gradually decreases with depth, suggesting a slight increase in volumetric water-content with depth. b) P-wave velocity tomogram from inversion of first-arrival times. Laterally continuous zones of elevated $V_{P}\left(>300 \mathrm{~m} \mathrm{~s}^{-1}\right)$ roughly correspond to the locations of the lithic levees, although the morphologies of these zones are not well resolved. P-wave velocity increases significantly with depth. c) S-wave velocity model from inversion of Rayleigh-wave dispersion curves. S-wave velocity variations are horizontally smoothed. Thin, laterally continuous zones of elevated $V_{S}$ in the top $2 \mathrm{~m}$ are suspected to result from picking errors. S-wave velocity increases with depth. The $250 \mathrm{~m} \mathrm{~s}^{-1} V_{S}$ contour broadly overlaps with the elevated $V_{P}$ zones.) $\ldots \ldots \ldots \ldots \ldots \ldots \ldots \ldots \ldots \ldots \ldots \ldots \ldots \ldots \ldots$ 
2.15 Intergranular porosity and water saturation results for Line 2. a) Intergranular porosity ranges between 0.2-0.34. A zone of low $\phi_{g}$ corresponds to the location of a breccia lens in outcrop D-4 (Figure 2.11), which suggests poor sorting and compositional changes can be detected with seismic and electromagnetic velocities. b) Integranular porosity errors do not exceed 0.025. c) Intergranular water saturation ranges between $0.22-0.31$ and resembles the morphology of the $V_{E M}$ tomogram (Figure 2.14a). d) Intergranular water saturation errors do not exceed $0.08 \ldots \ldots \ldots \ldots \ldots \ldots \ldots \ldots \ldots \ldots \ldots \ldots$

3.1 Maps of the study site show debris avalanche and PDC deposits, and the survey design. Site maps (b and c) have identical coordinates. (a) Digital elevation model of the northern slope of MSH with debris avalanche hummock locations and major PDC trajectories [Brand et al., 2014]. (b) Combined map of elevation and surficial PDC units from 1980 [Kuntz et al., 1990]. Flow directions are derived from the surface morphology; lower unit flow directions may deviate significantly. (c) Map of GPR lines, outcrops, and subsurface channel boundaries. . . . . 62 
3.2 Radargram and outcrop locations are shown in Figure 3.1. Sub-sections of Figures 3.2-3.4 are generally presented in the up-flow direction, from northwest to southeast. The scour-and-fill exposed in outcrop AD-3 (a) is validated in Line 1 (b) and traced up-flow (c). Channel boundaries are defined by the locations of truncation horizons. T4 is the southern boundary of $\mathrm{N}$ Channel. (a) Photograph of outcrop AD-3, $180 \mathrm{~m}$ wide. (b) Radargram of Line 1. (c) Radargram of Line 5 . Note 3 times vertical length exaggeration on all radargrams. . . . . . . . . . 63

3.3 Three cross-lines show $\mathrm{S}$ Channel and the point of inception of $\mathrm{N}$ Channel (exposed scour-and-fill at outcrop AD-3) between Lines 6 and 7. N Channel does not appear in Lines 4 or 7. (a) Radargram of Line 4. (b) Radargram of Line 6. (c) Radargram of Line 7. Line crossings are marked by orange lines. $\ldots \ldots \ldots \ldots \ldots \ldots \ldots \ldots$. . . . . . 64

3.4 S Channel is exposed at outcrop AD-2b, where Line 3 is used to correlate reflectivity within Figure 3.3 to mapped stratigraphy. Lahar erosion to the south obscures the southern boundary of S Channel.(a) Panorama of outcrop AD-2b with corresponding flow units. Note that east and west directions are flipped to aid in comparison with all radargrams. (b) Radargram of Line $3 . \ldots \ldots \ldots \ldots$. . . . . . . . . 65

3.5 Line 2 confirms the GPR reflectivity of an exposed debris avalanche hummock and reveals scouring down-flow from S Channel. (a) Radargram of Line 2. (b) The debris avalanche hummock reflection is corroborated at outcrop AD-2a. (c) Slumping sediments prevent stratigraphic verification of the northern half of the radargram and T1c. . . . . . . 65 
3.6 Radargram of Line 8. Note the Units II-V are exposed along the surface of the ground and truncation of Unit III by Unit IV at $60 \mathrm{~m}$ (T5) may represent scouring up-flow from $\mathrm{S}$ Channel. $\mathrm{V}: \mathrm{H}$ is $3: 1$ for all radargrams. Line 8 crosses Line 7 along the orange line. . . . . . . . 66

3.7 Radargram one Line 9 with cross-point to Line 8 marked in orange. Flow direction is left and slightly into the page . . . . . . . . 66

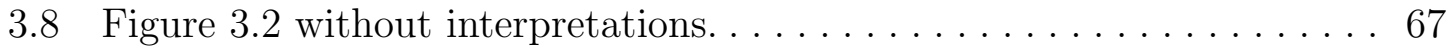

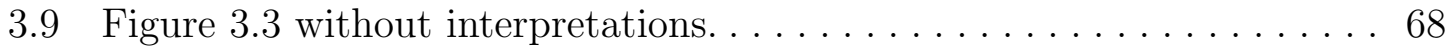

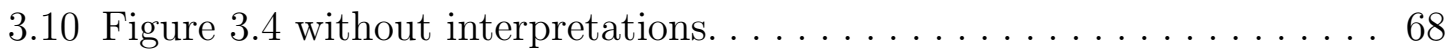

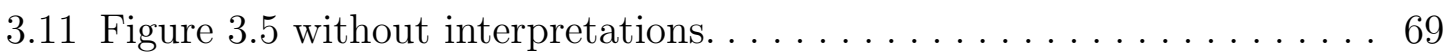

3.12 Figure 3.6 without interpretations. . . . . . . . . . . . . . . . . . . 69

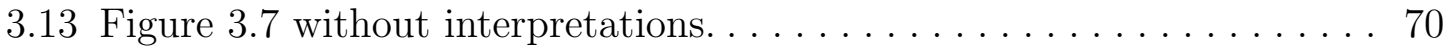




\title{
LIST OF ABBREVIATIONS
}

\author{
AGC - Automatic gain control \\ CMP - Common mid-point \\ F-K - Frequency-wavenumber \\ GPR - Ground-penetrating radar \\ GPS - Global positioning system \\ H1 - Horizon 1 \\ H2 - Horizon 2 \\ H2.5 - Horizon 2.5 \\ H3 - Horizon 3 \\ H4 - Horizon 4 \\ MASW - Multichannel analysis of surface waves \\ MSH - Mount St. Helens \\ NMO - Normal move-out \\ PDC - Pyroclastic density current \\ PSDM - Prestack depth migration \\ RMS - Root mean square
}




\title{
LIST OF SYMBOLS
}

\author{
c Speed of light in a vacuum \\ $G \quad$ Shear modulus \\ $K \quad$ Bulk modulus \\ $S \quad$ Water-saturation \\ $V_{E M}$ Electromagnetic wave velocity \\ $V_{P} \quad \mathrm{P}$-wave velocity \\ $V_{S} \quad$ S-wave velocity \\ $\varepsilon \quad$ Relative permittivity \\ $\theta \quad$ Volumetric water-content \\ $\mu \quad$ Magnetic permeability \\ $\rho \quad$ Density \\ $\sigma \quad$ Electrical conductivity \\ $\phi \quad$ Porosity
}




\section{CHAPTER 1}

\section{INTRODUCTION TO THESIS}

\subsection{Motivation}

Approximately one in ten people live within $100 \mathrm{~km}$ of an active volcano [Small and Naumann, 2001; Sparks et al., 2013]. Volcanoes have a significant impact on surrounding communities; seasonal snow-melt and nutrient rich volcanic soils sustain agriculture, geothermal heat is an alternative to fossil fuels, pyroclastic deposits are quarried for construction materials, and tourists are drawn to volcanic regions.

Perhaps most notably, geo-hazards, including volcanic mass-flows, ash-fall, and earthquakes, threaten lives and infrastructure. At least 91,724 lives were lost as

direct result of volcanic eruptions in the $20^{\text {th }}$ century [Witham, 2005]. Pyroclastic density currents (PDCs) and lahars are responsible for the majority of these fatalities during several tragic eruptions. As human populations continue to grow in regions surrounding active-volcanoes so does the value of understanding volcanic processes and products.

\subsection{Pyroclastic Density Currents}

PDCs generated by explosive volcanic eruptions are among the most hazardous of all volcanic phenomena. The destructive capability of these swift, ground hugging, 
inhomogeneous mixtures of heated gas and volcanic particles is exemplified by historic eruptions at Mount St. Helens (Washington, USA), El Chichon (Mexico), and Mount Pelee (Martinique) [Venzke et al., 2002]. Understanding the processes that control PDC dynamics is crucial for accurate hazard assessment in regions with explosive volcanism.

PDCs are produced by a wide range of eruption styles that include block and ash-flows from dome collapses, boil over PDCs, Plinian column collapse PDCs, and lateral blasts. By each style, PDCs can have markedly different volumes and flow dynamics (i.e., mobility, run-out distance, duration) [c.f., Branney and Kokelaar, 2002]. Additionally, PDC transport depends on external factors, such as topography and the nature of the basal substrate, which can influence flow trajectory and processes including substrate erosion, entrainment of air, and deposition. The numerous factors which control PDC dynamics result in unsteady flows that are subject to swift transformation in flow regime. For this reason, PDC deposits often display tremendous vertical and lateral variability in sedimentary facies and granulometry.

Direct observation of processes within PDCs remains intangible due to their destructive and visually opaque nature, and the short timescales over which processes occur. PDCs are often studied through analysis of their deposits, which can be used to (1) constrain depositional conditions, substrate erosion, flow run-out distance, and general flow dynamics [e.g., Sparks et al., 1997; Calder et al., 2000; Brown and Branney, 2004; Pittari et al., 2006; Brand et al., 2014]; (2) develop hypotheses to be tested with laboratory experiments [e.g., Girolami et al., 2008; Roche et al., 2013; Chedeville et al., 2015; Breard et al., 2016]; and (3) provide constraints to validate numerical models [e.g., Dufek, Wexler, and Manga, 2009; Kelfoun et al., 2009; Benage et al., 2016]. However, field techniques and interpretations of 3D sedimentary 
features are limited by the quality of the deposits (i.e., primary versus reworked) and the degree of exposure. These constraints motivate the need for methods that non-destructively image and measure the properties of unexposed PDC deposits.

\subsection{Near-Surface Geophysics}

Exploration geophysics can be broadly defined as the measurement of physical parameters to investigate the earth's subsurface. Each geophysical method is sensitive to one or more material property (e.g., density, Poisson's ratio, electrical conductivity), and is inherently limited in resolution by the acquisition parameters. By employing multiple techniques at a single exploration site, it is possible to account for the strengths and weaknesses of each method and improve interpretations.

For more than a century, the search for economic hydrocarbons and ores, as well as national defense programs, have made vast improvements to geophysical techniques and computation [Lawyer, Bates, and Rice, 2001]. Although natural resource identification remains the primary application of exploration geophysics, geophysicists are increasingly adapting existing techniques to problems in the nearsurface, including hydrology [e.g., Bradford, 2008; Giustiniani et al., 2008; Miller et al., 2008], glaciology [e.g., Bradford and Harper, 2005], microbiology [e.g., Beaver et al., 2016], and sedimentology [e.g., Bristow, Bailey, and Lancaster, 2000; Rozar, 2015].

While exploration geophysics techniques are commonly used to image the deep magmatic and hydrothermal systems of volcanoes [e.g., Nagaoka et al., 2012; Kiser et al., 2016; Wynn et al., 2016], near-surface investigations of shallow volcanic deposits are less prevalent. Notable ground-penetrating radar applications in pyroclastic 
deposits include stratigraphic imaging [e.g., Russell and Stasiuk, 1997; Cagnoli and Russell, 2000; Cagnoli and Ulrych, 2001; Gomez et al., 2008 ; Cassidy et al., 2009; Courtland et al., 2012] and porosity estimation via electromagnetic velocity measurements [Rust, Russell, and Knight, 1999; Rust and Russell, 2000; Rust and Russell., 2001]. Studies using active-source seismology are limited to p-wave tomography of partially welded deposits [Bais et al., 2003], and reflection imaging in complex volcanic environments [Bruno and Castiello, 2009; Bruno, 2015].

\subsection{Objectives}

The aim of this thesis is to apply geophysical imaging techniques to improve our understanding of the physical properties and geology of shallow, unconsolidated pyroclastic deposits. The thesis is comprised of two studies set at Mount St. Helens, Washington (USA).

Geophysical measurements and rock property estimation have the potential to significantly improve interpretations of lithology and hydrologic processes in volcanic environments. However, few measurements exist for seismic and electromagnetic velocities in unconsolidated pyroclastic deposits, and no existing studies resolve the effects of dual porosity (i.e., pumice vesicles and intergranular pores) within seismic and electromagnetic rock property models. In the first study, In situ constraints on porosity and water-saturation of pyroclastic deposits from electromagnetic and seismic velocities, investigates the unique geophysical properties of pyroclastic deposits. This study represents the first joint multi-fold GPR and active-source seismic surveys in pyroclastic deposits. The objectives are: (1) to image and better constrain electromagnetic and seismic velocities of shallow, unconsolidated pyroclastic deposits; and 
(2) to investigate the effects of porosity and water-content on electromagnetic and seismic velocities in a two phase porosity system.

Erosion and its effects on PDC dynamics remains one of the most poorly understood aspect of PDCs [Dufek, 2016]. In the second study, Evidence of erosional self-channelization of pyroclastic density currents revealed by ground-penetrating radar imaging at Mount St. Helens, Washington (USA), I perform GPR imaging to investigate erosional self-channelization of PDCs. The objective of this study is to test whether a large, scour-and-fill feature exposed in the 18 May 1980 pyroclastic flow deposits are Mount St Helens is the result of sustained, axial erosion and thereby an example of erosional self-channelization [Brand et al., 2014]. 


\section{CHAPTER 2}

\section{IN SITU CONSTRAINTS ON POROSITY AND WATER-SATURATION OF PYROCLASTIC DEPOSITS FROM ELECTROMAGNETIC AND SEISMIC VELOCITIES}

\section{$2.1 \quad$ Abstract}

Measurements of in situ porosity and water saturation have the potential to improve interpretations of geology and hydrology in volcanic regions. However, rock property models must consider the unusual dual porosity structure of pyroclastic deposits (vesicles within pumices and intergranular pores). Additionally, partial saturation conditions require coincident seismic and electromagnetic measurements to resolve unique solutions for porosity and water-saturation. The goals of this

study are to (1) measure the electromagnetic and seismic velocities of well-exposed pyroclastic deposits, and (2) constrain porosity and water-saturation from real seismic and electromagnetic velocity measurements. I conduct the first joint active seismic and multi-offset ground penetrating radar survey in pyroclastic deposits and apply Monte Carlo petrophysical inversions to constrain water-saturation and porosity from seismic and electromagnetic velocities. Despite total deposit porosities between 0.720.83 , seismic and electromagnetic velocities of pyroclastic deposits are comparable to 
the velocities of well-sorted beach sand and alluvial conglomerates. Differentiation between intergranular porosity and vesicular porosity in real geophysical data remains non-unique and highly dependent on a priori information. Our results demonstrate that in order to extract rock properties from geophysical measurements investigators must carefully consider lithology.

\subsection{Introduction}

Active seismic and ground-penetrating radar (GPR) methods are among the most robust means of imaging the shallow subsurface. When paired with accurate rock-physics models, seismic and electromagnetic velocities can be used to estimate porosity and/or water-content [e.g. Greaves et al. 1996; Bradford, Clement, and Barrash, 2009; Holbrook et al., 2014; Pasquet et al., 2016]. However, deposits with unique porosity structure require adapted rock physics models that differ from typical sediments.

Porosity within pyroclastic deposits derives from both pumice vesicles and intergranular pores. This dual porosity structure violates a common assumption that pores exist only between grains and produces unusual physical properties. Nur et al. [1998] note that pumice maintain elevated seismic velocities at porosities higher than any other natural rock (as much as 0.8). Pumices are often so porous that they float in water [Whitham and Sparks, 1986]. Additionally, sedimentary characteristics of pyroclastic deposits such as grain-size, sorting, welding (i.e., fusion of grains at high temperature), and grain angularity can vary significantly over relatively short distances. Yet, how textural and granulometric properties affect in situ seismic and electromagnetic velocities in pyroclastic deposits remains untested. 
In situ property estimation has the potential to improve interpretation of geologic and hydrologic processes in volcanic terrains. Notable studies in pyroclastic deposits include 1D electromagnetic velocity $\left(V_{E M}\right)$ estimates with ground-penetrating radar [Rust and Russell, 2001] and P-wave velocity $\left(V_{P}\right)$ traveltime tomography [Bais et al., 2003]. However, existing studies lack overlapping electromagnetic and seismic measurements that are required to isolate water-saturation and porosity in partially saturated conditions.

The objectives of this study are to:

1. Measure the electromagnetic and seismic velocities of well-exposed pyroclastic deposits.

2. Constrain porosity and water-saturation with seismic and electromagnetic velocities in a two-phase porosity system (i.e., vesicles and intergranular pores).

To address these goals, I develop a joint electromagnetic and seismic petrophysical model for pyroclastic deposits and conduct the first joint multi-offset GPR and activesource seismic survey in pyroclastic deposits.

\subsubsection{Petrophysical Background}

Assuming relative magnetic permeability is equal to that of free-space $(\mu=1)$ and negligible electrical conductivity $(\sigma=0), V_{E M}$ is

$$
V_{E M}=\frac{c}{\sqrt{\varepsilon}}
$$

where $\varepsilon$ is the relative permittivity and $c$ is the speed of light in a vacuum. Air-filled pores within a sediment will reduce $\varepsilon$ and thereby increase $V_{E M}$. Rust et al. [1999] 
determine empirical equations to estimate $V_{E M}$ of dry volcanic rocks with known total porosity $(\phi)$ and composition. Yet, water in partially-saturated deposits can significantly reduce $V_{E M}$ and prevent application of these solid-air empirical equations due to the high relative permittivity of water $\left(\varepsilon_{w}=81\right)$ with respect to the relative permittivity of volcanic rocks, such as dacite $\left(\varepsilon_{d}=6.79\right)$ [Rust et al., 1999; Rust and Russell, 2001]. While changes in dry porosity have a theoretical effect on $V_{E M}$ [Rust and Russell, 2000], $V_{E M}$ and GPR reflections are primarily controlled by volumetric water-content $\left(\theta_{W}\right)$ [Topp, Davis, and Annan, 1980; Van Dam and Schlager, 2000]. Therefore, attempts to calculate $\phi$ from $V_{E M}$ that ignore present water will underestimate $\phi$.

GPR can be solely applied to estimate $\theta_{W}$ in soils with the equation of Topp et al. [1980][e.g., Greaves et al., 1996; Huisman et al., 2003; Bradford 2008]. Alternatively, Bradford et al. [2009] estimate $\phi$ for water-saturated alluvial sediments with the complex refractive index method (CRIM) [Wharton et al., 1980]. However, an earthmodel with pore-spaces occupied by both water and air cannot be resolved with GPR alone because $V_{E M}$ depends on both water-saturation (i.e. $S$ ) and $\phi$ (Figure 2.1a). A second geophysical parameter that is sensitive to $\phi$ or $S$ is required constrain a unique solution.

At similar depths, active seismic methods can match the resolution of GPR data. First-arrival traveltime tomography and Rayleigh-wave inversion are common techniques for estimating $\mathrm{P}$-wave velocity $\left(V_{P}\right)$ and S-wave velocity $\left(V_{S}\right)$. P- and S-wave velocities are

$$
V_{P}=\sqrt{\frac{K_{b}+4 / 3 G_{b}}{\rho_{b}}} \quad V_{S}=\sqrt{\frac{G_{b}}{\rho_{b}}}
$$


where $K_{b}$ is the bulk modulus, $G_{b}$ is the shear modulus, and $\rho_{b}$ is density. In unconsolidated and unsaturated materials $(S<0.99), V_{P}$ and $V_{S}$ are primarily sensitive to stiffness of the sediment matrix, grain size, degree of compaction, and $\rho_{b}$, and are secondarily sensitive to capillary and pore pressure effects of water along grain-contacts [c.f., Santamarina et al., 2005 and references therein]. Thus, $V_{P}$ and $V_{S}$ are more sensitive to $\phi$ than to $S$ in partial saturation conditions (Figure 2.1b and c).

The total deposit porosity in pyroclastic deposits is related to vesicle porosity $\left(\phi_{v}\right)$ and intergranular porosity $\left(\phi_{g}\right)$ as

$$
\phi=\phi_{v}\left(1-\phi_{g}\right)+\phi_{g}
$$

Attempts to calculate seismic velocities of pyroclastic deposits must combine separate porosity distributions with distinct physical properties (equations detailed in Section 2.7). I model pyroclastic deposits as uniform vesicular pumice grains nested within a porous sedimentary matrix with the following steps:

1. Calculate the bulk and shear moduli for pumice of known mineralogy, vesicularity $\left(\phi_{v}\right)$, and vesicle saturation $\left(S_{v}\right)$ with the critical porosity equation of Nur et al. [1998] and Gassman's equations [Gassman, 1951].

2. Calculate the dry bulk modulus $\left(K_{d r y}\right)$ and shear modulus $\left(G_{d r y}\right)$ of a pumice sediment with known intergranular porosity $\left(\phi_{g}\right)$ and effective stress with HertzMindlin contact theory [Mindlin, 1949].

3. Calculate bulk and shear moduli with intergranular pore saturation $\left(S_{g}\right)$ as in Santamarina et al [2005]. 
4. Compute electromagnetic velocities for dacite pumice nested within a sediment matrix using the CRIM equation.

Electromagnetic and seismic velocity data can be used to estimate deposit porosity and water content. However, it is not possible to distinguish between intergranular pores and vesicles with real geophysical measurements. Instead, I assume pumices have constant vesicularity, and that intergranular pores and vesicles have identical volumetric water content. Thus, through joint-petrophysical minimization I simulta-

neously estimate $S_{g}$ and $\phi_{g}$ of pyroclastic deposits from seismic and electromagnetic measurements (Figure 2.1d).

\subsubsection{Survey Setting}

I acquired GPR and active seismic data at Mount St. Helens, Washington (USA), $5 \mathrm{~km}$ north of the crater (Figure 2.2). I chose this location because the deposits are recently mapped [Brand et al., 2014; Gase, Brand, and Bradford, 2017] and well exposed, allowing for stratigraphic comparison.

A $30 \mathrm{~m}$ thick outcrop described by Brand et al. [2014] is adjacent to the survey line. The underlying sequence contains four chronological flow-units deposited by column-collapse pyroclastic density currents from the 18 May 1980 eruption (Figure 2.3). Unit I is uniform, massive and capped by a $\sim 50 \mathrm{~cm}$ thick layer of ash. Unit II is diffusely stratified and thickest at the southern end of the outcrop. The Unit II-III boundary is sharp and unconformable; the PDCs responsible for Unit III scoured at channel $~ 8 \mathrm{~m}$ into Unit II before becoming depositional [Brand et al., 2014; Gase, Brand, and Bradford, 2017]. Unit III fills the scour with a massive lapilli tuff and a lithic breccia with meter-scale boulders. The transition between Units III and IV is 
gradational, although in places Unit IV caps Unit III with a lithic breccia lens and massive lapilli tuff.

The juvenile material is dacitic tephra and accidental blocks within pyroclastic deposits are composed of basaltic-andesite, andesite, dacite, and rhyodacite [Kuntz et al., 1981]. The water-table is assumed to mimic the adjacent north descending stream gradient, approximately $30 \mathrm{~m}$ beneath the survey line.

\subsection{Methods}

\subsubsection{GPR Acquisition and Data Processing}

I collected a $234 \mathrm{~m}$ long line of common-source GPR data according to the acquisition parameters in Table 2.1a with the goal of imaging the underlying stratigraphy to the depth of the adjacent outcrop. Maximum reflection traveltimes range between 150-400 ns (Figure 2.4a). Initial GPR processing included time-zero correction, bandpass frequency filtering (12-25-200-300 MHz), and AGC (30 ns time-gate). Eigenvector filtering removed laterally continuous background noise at the bottom of the time-window. The data were corrected for normal move-out (NMO), stacked, and frequency-wavenumber (F-K) migrated at $0.092 \mathrm{~m} \mathrm{~ns}^{-1}$ (Figure 2.4b).

Advanced processing followed the methodology of Bradford [2006]. I performed Kirchoff prestack depth migration (PSDM) with an initial velocity of $0.092 \mathrm{~m} \mathrm{~ns}^{-1}$, followed by two-dimensional reflection tomography in the post-migration domain to invert for a $V_{E M}$ model that minimized residual move-out of selected horizons (Figure 2.4c). I repeated PSDM with the inverted $2 \mathrm{D} V_{E M}$ model. The migration results were sorted to common image point gathers, top muted to remove stretched signal from PSDM, and stacked to produce the final reflection image (Figure 2.4d). 


\subsubsection{Seismic Acquisition and Data Processing}

I chose seismic acquisition parameters to record first-arrivals for traveltime tomography, and Rayleigh waves for multi-channel analysis of surface-waves (MASW) at a resolution and depth comparable to the GPR data (Table 2.1b). I recorded 168 shots for the $324 \mathrm{~m}$ long seismic line. After 24 shots, the first 24 geophones were rolled to the end of the seismic line. I repeated this procedure until the 24 final stations were placed, after which the line was shot through to the final receiver station.

The shot gathers are of excellent quality (Figure 2.5a). Given the remote location and decent geophone coupling, noise is largely limited to movement of the survey team and the fan of the field computer. First-arrival velocity increases slightly at near-offsets $(<24 \mathrm{~m})$. A more abrupt increase in first-arrival velocity from $\sim 400 \mathrm{~m}$ $\mathrm{s}^{-1}$ to $\sim 1500 \mathrm{~m} \mathrm{~s}^{-1}$ at intermediate offsets is likely caused by the water-table refraction. Ground-roll is strong across the spread and separates into distinct modes after the first dozen receiver stations. A water-table reflection overlaps with ground-roll within the noise cone. Several deep reflections are present in the reflection envelope between the ground-roll and water-table refraction.

I band-pass frequency filtered (12-25-100-200 Hz) the seismic data and picked first-arrivals for each shot. Special attention was required to pick first-arrivals at near-offsets, which were often slower than the air-wave $\left(\sim 340 \mathrm{~m} \mathrm{~s}^{-1}\right.$; Figure 2.5a). Using Rayfract ${ }^{T M}$ first-arrival traveltime tomography software, I constructed blocky initial $V_{P}$ models from the first-arrival picks. The initial model was modified by a wave-path Eikonal traveltime inversion for 150 iterations, resulting in the final 2D $V_{P}$ model (Figure 2.6a). Near-vertical ray-paths of deep-refracted arrivals, shallow refracted arrivals $(\sim 5 \mathrm{~m})$, and moderate ray-densities in the near-surface $(\sim 50-750$ 
rays per cell) ensure adequate sensitivity in the upper $20 \mathrm{~m}$ for comparison with GPR reflection tomography results (Figure $2.6 \mathrm{~b}$ ).

I performed MASW with the approach of Gribler et al. [2016], which requires isolated Rayleigh waves across off-end shot gathers. Offsets nearer than $\sim 20 \mathrm{~m}$ often contain high-amplitude noise. I used only positive offsets to ensure a uniform distribution of mid-points. A top mute was applied to limit contamination by body-waves and noise. To improve signal quality and lateral resolution, shot-gathers were windowed to 24 channels equidistant from the shot station and maximum station on the survey line (Figure 2.5b).

I generated dispersion curves and picked fundamental modes between 10-80 Hz (Figure 2.5c). Weak dispersion curve semblance below $10 \mathrm{~Hz}$ is likely due to the inability of the hammer-source to generate lower frequencies, limiting depths achieved by MASW to $\sim 10 \mathrm{~m}$. I inverted dispersion curves for 1D $V_{S}$ versus depth profiles using SurfSeis $2^{T M}$ Rayleigh-wave inversion software. Each inverted $V_{S}$ vertical profile was binned at the mid-point and horizontally smoothed across four midpoints to produce a pseudo-2D $V_{S}$ model.

\subsection{Results and Interpretations}

\subsubsection{GPR Reflectivity}

I interpret reflectivity in stratigraphic order and compare reflectivity with the adjacent outcrop (Figure 2.2). Reflections are described by their amplitude (i.e., faint or coherent) and geometry (i.e., continuity, shape, relation to adjacent reflections). Areas of geometrically similar reflectivity are referred to as units. Horizons are 
referred to as the laterally coherent boundaries of broad areas of similar reflectivity (i.e., unit boundaries).

The GPR reflectivity contains three major horizons that divide four units of contrasting reflectivity (Figure $2.4 \mathrm{~d}$ ). Horizon 1 gradually descends from $\sim 12 \mathrm{~m}$ depth at the southern end of the GPR line to $\sim 14 \mathrm{~m}$ depth at horizontal position $\sim 200$ m. Reflections beneath Horizon 1 are faint. Reflections above Horizon 1 along the southern half of the GPR line are sub-parallel and increase in amplitude at shallower depths. Horizon 2 appears at $\sim 4 \mathrm{~m}$ depth at horizontal position $40 \mathrm{~m}$. From the north, Horizon 2 undulates slightly and descends abruptly, truncating $\sim 8 \mathrm{~m}$ of lower reflections until it converges with Horizon 1 at $~ 150 \mathrm{~m}$. Along the northern half of the GPR line, reflections above Horizons 1 and 2 vary from concordant along Horizon 2, to sub-parallel and chaotic between horizontal positions 150-200 m. Horizon 3 is faint, begins at $\sim 2.5 \mathrm{~m}$ depth at $50 \mathrm{~m}$, and extends across most of the GPR line, separating lower coherent reflections from weak and chaotic reflections in the near-surface.

The three horizons correspond to the locations and nature of the flow-unit boundaries in the adjacent outcrop (Figure 2.3b). Horizon 1 separates Units I and II. Horizon 2 separates Units II and III, and truncates Unit II reflections. Units III and IV are separated by Horizon 3.

The massive facies of Unit IV and the diffuse nature of its contact with Unit III may explain why reflectivity is poor in the near surface and Horizon 3 is faint. The phreatic explosion crater at the southern end of the GPR line produces a shallow, cup-shaped horizon. Lenticular zones of chaotic reflections coincide with the locations of lithic breccias in AD-3, suggesting scattering by the blocks. Gase et al. [2017] provide similar interpretations with single-offset, $50 \mathrm{MHz}$ GPR with less signal-tonoise and poorer resolution. The radargram herein demonstrates that multi-offset 
GPR is a more effective tool for identifying dominant sedimentary fabric associated with stratification, unit transitions, and scattering lithologies (i.e., breccias).

\subsubsection{Complete P-wave Tomogram}

P-wave tomograms reveal the approximate location of the water-table, and broad $V_{P}$ variations in the near-surface (i.e., depth $<15 \mathrm{~m}$ ). The seismic line contains four zones of broad $V_{P}$ heterogeneity (Figure 2.6a). From the ground surface, $V_{P}$ gradually increases with depth from velocities near or below the speed of sound in air $(\sim 350 \mathrm{~m}$ $\left.\mathrm{s}^{-1}\right)$ to $>500 \mathrm{~m} \mathrm{~s}^{-1}$. The slight increase in $V_{P}$ with depth is most plausibly controlled by increased effective-stress. At greater depths $(\sim 20-30 \mathrm{~m}), V_{P}$ increases to $>1500$ $\mathrm{m} \mathrm{s}^{-1}$, likely caused by the water-table, given that $V_{P}$ typically increases by a factor of three or more as sediments become water-saturated. The depth at which the $V_{P}$ exceeds $1500 \mathrm{~m} \mathrm{~s}^{-1}$ coincides with the approximate depth of the stream below the adjacent outcrop.

At $<15 \mathrm{~m}$ depth a bowl shaped zone of low $V_{P}$ at the southern end of the seismic line corresponds to the location of the phreatic explosion crater (Figure 2.2). A lens of slightly elevated $V_{P}$ at mid-line $\left(>400 \mathrm{~m} \mathrm{~s}^{-1}\right)$ is centered over the lithic breccias in outcrop(Figure 2.3), which suggests that poorly-sorted deposits with large, low vesicularity clasts produce detectable $V_{P}$ contrasts. A reduced $V_{P}$ zone along the slope at the northern end of the seismic line may comprise of slumped sediments with reduced $V_{P}$. I do not identify any clear lithologic causes from outcrop other than the absence of large clasts (Figure 2.3). The complete $V_{P}$ tomogram demonstrates that water-saturation, effective stress, and lithology produce detectable effects on $V_{P}$. P-wave velocity in the upper 20 meters appears to be controlled primarily by 
lithology and effective stress; whereas $V_{P}$ is influenced by water-saturation below the water-table.

\subsubsection{Outcrop Scale Tomograms}

In contrast to $V_{P}$, the $V_{E M}$ and $V_{S}$ results are more depth-limited. GPR signal penetration was constrained by signal attenuation with depth. The MASW results estimate $V_{S}$ at depths $<10 \mathrm{~m}$, controlled by the lowest recorded Rayleigh-wave frequencies. In addition, both $V_{S}$ and $V_{E M}$ data are horizontally limited compared to $V_{P}$. I interpret $V_{E M}, V_{P}$, and $V_{S}$ tomograms windowed to match the depth and horizontal extent of the $V_{E M}$ and $V_{S}$ results. This allows qualitative comparison of the three velocities at scales close to the exposed area in the nearby outcrops.

Each velocity inversion technique produces tomograms gridded with variable horizontal and vertical spacing. GPR tomograms are horizontally gridded at the GPR CMP bin (0.29 m), whereas seismic tomograms are horizontally gridded at the station spacing $(\sim 2 \mathrm{~m})$. The vertical grids for each tomogram is limited by the acquisition geometry and resolution of the inversion technique. Results were linearly interpolated to a $0.25 \mathrm{~m}$ horizontal and vertical interval grid to improve comparison between results.

Electromagnetic velocities range from $0.083 \mathrm{~m} \mathrm{~ns}^{-1}$ to $0.1 \mathrm{~m} \mathrm{~ns}^{-1}$ with an average $V_{E M}$ of $0.092 \mathrm{~m} \mathrm{~ns}^{-1}$ (Figure 2.7a). Electromagnetic velocities are greatest at the ground surface on the northern half of the line. Two areas of low $V_{E M}(<0.09 \mathrm{~m}$ $\mathrm{ns}^{-1}$ ) spread across the depth range and are split horizontally by higher velocity $\left(>0.095 \mathrm{~m} \mathrm{~ns}^{-1}\right)$ zone mid-line. P-wave velocity in the upper $15 \mathrm{~m}$ ranges from $\sim 250$ $\mathrm{m} \mathrm{s}^{-1}$ to $450 \mathrm{~m} \mathrm{~s}^{-1}$, increasing gradually with depth (Figure 2.7b). A lenticular region of elevated $V_{P}\left(>350 \mathrm{~m} \mathrm{~s}^{-1}\right)$ extends from horizontal positions $50-150 \mathrm{~m}$ at 
depths less than $7 \mathrm{~m}$. P-wave velocity beneath this lens is reduced but eventually increases at $\sim 10 \mathrm{~m}$ depth. P-wave velocity is lowest $\left(<300 \mathrm{~m} \mathrm{~s}^{-1}\right)$ on the northern third of the line in the upper $10 \mathrm{~m}$. S-wave velocity is low $\left(<150 \mathrm{~m} \mathrm{~s}^{-1}\right)$ in the upper meter and increases gradually with depth (Figure 2.7c). A similar lens of elevated $\left(>225 \mathrm{~m} \mathrm{~s}^{-1}\right) V_{S}$ is present between $50 \mathrm{~m}$ and $150 \mathrm{~m}$ at depths between 3 and $7 \mathrm{~m}$. As with $V_{P}, V_{S}$ is reduced beneath the lens and again increases at $\sim 10 \mathrm{~m}$ depth. S-wave velocity is also reduced $\left(<200 \mathrm{~m} \mathrm{~s}^{-1}\right)$ on the northern third of the line.

The three tomograms contain broad trends in velocity that relate to the interaction of the respective waves with subsurface properties. Electromagnetic velocity is distinct from $V_{P}$ and $V_{S}$ because it is primarily influenced by water-content, even in unsaturated conditions. Electromagnetic velocity is greatest in the very near surface where the deposits are driest. Low $V_{E M}$ areas, underlain by zones of higher $V_{E M}$ may suggest variations in deposit water-content. Electromagnetic velocity variations do not correspond simply to stratigraphy. P- and S-wave velocity tomograms (Figures $2.7 \mathrm{~b}$ and $2.7 \mathrm{c}$ ) show similarities including increasing velocity with depth, a mid-line lens of elevated velocity, and reduced velocity along the northern third of the line. Increasing velocity with depth can be explained by effective stress. The mid-line lens of elevated velocity corresponds to the size and location of the upper lithic breccia shown in the outcrop (Figure 2.3), which suggests that the boulders impart greater rigidity on the deposit. This also explains why velocities are reduced at the northern third of the line where no large lithics are present in outcrop (Figure 2.3c). 


\subsection{Discussion}

\subsubsection{Geophysical Velocities of Pyroclastic Deposits}

Comparisons to the adjacent outcrops show $V_{E M}$ is a poor indicator of stratigraphy, but PSDM reflectivity accurately resolves flow-unit contacts and the characteristics of stratigraphic facies. Overlap between zones of high $V_{P}$ and $V_{S}$ and breccia lenses demonstrate seismic sensitivity to changes in grain-size elevated $V_{P}$ and $V_{S}$, but it is unclear how reduced volumetric water-content expected of poorly sorted, mixed sediments would lower $V_{E M}$.

Electromagnetic velocity can vary greatly for unconsolidated sediments $(\sim 0.15-0.03$ $\mathrm{m} \mathrm{ns}^{-1}$ ) depending on the volumetric water-content. Our results for both lines fall within the reasonable range $\left(0.08-0.1 \mathrm{~m} \mathrm{~ns}^{-1}\right)$ for partial-saturation conditions with $\varepsilon$ between 9 -14. The range of velocities is slightly above the $\sim 10 \%$ margin of error that is typical of GPR reflection tomography results. A day of heavy rain preceded the survey, and weather was hot $(\sim 35 \mathrm{C})$ and sunny during acquisition. Elevated $V_{E M}$ at depths $<5$ m may reflect a combination of either drying in the near-surface or vertical flow.

In the upper $10 \mathrm{~m}$, seismic velocities $\left(\sim 200-550 \mathrm{~m} \mathrm{~s}^{-1}\right.$ for $V_{P} ; \sim 100-500 \mathrm{~m} \mathrm{~s}^{-1}$

for $\left.V_{S}\right)$ for pyroclastic deposits fall within the typical values $\left(<100-800 \mathrm{~m} \mathrm{~s}^{-1}\right.$ for $V_{P} ;<100-500 \mathrm{~m} \mathrm{~s}^{-1}$ for $\left.V_{S}\right)$ for near-surface, partially-saturated soils [Santamarina et al., 2005] and sands [Bachrach, Dvorkin, and Nur, 2000]. However, the range of $V_{P}$ I measure in the unconsolidated Mount St. Helens pyroclastic deposits is approximately half the $V_{P}$ of the loose to partially welded pyroclastic deposits of the Neapolitan Yellow Tuff (Italy) [Bais et al., 2003], and $~ 20-30 \%$ of $V_{P}$ for tuff [Wohletz and Heiken, 1992 and references therein]. Exceptionally low grain density may offset 
reduction of the bulk and shear moduli that is expected to result from vesicularity. Alternatively poor-sorting (typical of PDC deposits) will reduce intergranular porosity [e.g., Rogers and Head, 1961; Beard and Weyl, 1973], and increase seismic velocities [Zimmer et al., 2007]. Our data show evidence of sorting effects where $V_{P}$ and $V_{S}$ are elevated near poorly-sorted breccia lenses (Figure 2.7).

\subsubsection{Petrophysical Inversion for Water-Saturation and Porosity}

It is possible to extract greater detail by transforming geophysical parameters into rock properties with petrophysical equations. Such equations are most accurate in homogenous environments (e.g., uniform grain size, limited compositional variability). Despite their limiting assumptions, petrophysical relationships can remove the effects of stress, and reveal material property heterogeneity in geophysical data.

Many factors control the porosity of pyroclastic deposits. Vesicles within pumices vary in spatial distribution, size, shape, tortuosity, and permeability [e.g., Klug and Cashman, 1994; Bouvet de Maisonneuve, Bachmann, and Burgisser, 2009], which also affect water-content within individual pyroclasts [e.g., Whitham and Sparks, 1986; Manville et al., 1998]. Intergranular pore-space is controlled by the shape and packing of the grains. Poorly sorted sediments are less porous than well-sorted or fine-grained sediments [Rogers and Head, 1961; Beard and Weyl, 1973]. Mixed lithologies, such as river conglomerates exhibit reduced intergranular porosity, and the porosity of near-surface, sandy river sediments can range between $~ 0.1-0.4$ [Barrash and Clemo, 2002]. Both vesicles and intergranular pore spaces reduce the expected bulk and shear moduli and the bulk density of the deposits.

I assume (1) constant $\phi_{v}=0.71$, which is the average vesicularity of pyroclasts produced by the PDCs during the 18 May, 1980 eruption of Mount St. Helens 
[Kuntz et al., 1981; Klug and Cashman, 1994], and (2) equal volumetric water-content within the intergranular and vesicular pore-spaces. Given pyroclastic materials can contain isolated, non-connected vesicles [e.g., Rust et al., 1999], the latter assumption accounts for lower expected water-saturation within vesicles relative to intergranular pores.

I estimate $\phi_{g}$ and $S_{g}$ by modeling pyroclastic deposits as a three-phase, dielectric and elastic system, with vesicular, partially-saturated clasts. Seismic and electromagnetic velocities are estimated for all combinations of $\phi_{g}(0-.999)$ and $S_{g}(0-1)$ at 0.001 intervals. The solution space shows that $V_{P}$ is controlled by $\phi_{g}$ at $S_{g}<0.95, V_{S}$, is controlled by $\phi_{g}$ and insensitive to $S_{g}$, and $V_{E M}$ primarily controlled by $S_{g}$ and is moderately dependent on $\phi_{g}$ when $S_{g}$ is negligible (Figure 2.1).

Similar to Bradford et al. [2015], I estimate $\phi_{g}$ and $S_{g}$ by performing a Monte Carlo simulation with 50,000 realizations drawn from a uniform distribution spanning the range of plausible $\phi_{g}$ and $S_{g}$ for each grid-cell. I evaluate realizations by a normalized RMS misfit, where the modeled and observed velocity difference is divided by the observed velocity. I consider realizations with $<0.02$ RMS misfit to be valid solutions. I accept the median $\phi_{g}$ and $S_{g}$ values as the global solution. Uncertainties $\left(e_{\phi}\right.$ for $\phi_{g}$ and $e_{S}$ for $S_{g}$ ) are taken as half the range of valid solutions. The inversion procedure was repeated for each grid-cell containing a $V_{P}, V_{S}$, and $V_{E M}$ value.

The inversion results in physically plausible values of $\phi_{g}, S_{g}$, and their associated uncertainties (Figure 2.8). Intergranular porosity ranges between 0.28-0.42 and is lowest in the vicinity of the Unit IV breccia lens (Figure 2.8a). The morphology of the low $\phi_{g}$ region appears to combine the morphologies of the high $V_{P}$ and high $V_{S}$ lenses in Figures 2.7a and 2.7b. Otherwise, $\phi_{g}$ is roughly uniform and between 0.350.4 across the line. Intergranular water-saturation ranges between $\sim 0.25-0.35$ and is 
morphologically similar to the $V_{E M}$ inversion results (Figure 2.8c). The morphologies of these results demonstrate that $V_{E M}$ is primarily sensitive to water-content, whereas seismic velocities are better suited to detect variations in porosity and granulometry.

Uncertainties associated with both $\phi_{g}$ and $S_{g}$ are greatest where $V_{S}$ and $V_{P}$ data disagree, possibly due to unequal resolutions and sensitivities of MASW and first-arrival traveltime tomography results (Figures $2.8 \mathrm{~b}$ and 2.8d). Further work considering how unequal resolutions and sensitivities introduce error could improve joint petrophysical minimizations.

The moderate to low $\phi_{g}$ suggests that poor-sorting and compositional variations within the breccia lenses reduce the expected $\phi_{g}$. Regardless of the relatively low $\phi_{g}$, Equation 3 shows that the total porosity range of the deposits in this study is extremely high $(0.76-0.83)$. Such high porosity may create a unique hydrologic environment where saturated pyroclastic deposits can hold twice as much water as saturated sands.

\subsection{Conclusions}

Active seismic and GPR methods are effective tools for investigating the geology and hydrology of shallow pyroclastic deposits. I acquired coincident GPR and active seismic surveys to measure electromagnetic and seismic velocities of pyroclastic deposits, and to investigate the influence of dual porosity and water-saturation geophysical measurements. Petrophysical modeling reveals that seismic velocities are more predictive of porosity, whereas $V_{E M}$ relates more strongly to volumetric water-content. I show that joint Monte Carlo inversion of seismic and electromagnetic velocities is a means to estimate subsurface water-saturation and porosity in partially 
saturated conditions. Finally, our results reveal that despite total deposit porosities between $0.72-0.83$, seismic and electromagnetic velocities of pyroclastic deposits are comparable to the velocities of well-sorted beach sand or alluvial conglomerates. Our results demonstrate that investigators must carefully consider the effects unique lithology in order to estimate rock properties from geophysical measurements.

\subsection{Equations for Electromagnetic and Seismic Properties}

I use the CRIM equation [Wharton et al., 1980] to estimate the relative permittivity of pumice $\left(\varepsilon_{p}\right)$, with the relative permittivities of dacite $\left(\varepsilon_{d}=6.79\right)$ [Rust et al., 1999], water $\left(\varepsilon_{w}=86\right)$, and air $\left(\varepsilon_{a}=1\right)$, vesicularity as measured from the 18 May 1980 PDC deposits $\left(\phi_{v}=0.71\right)$ [Kuntz et al., 1981], and vesicle water-saturation $\left(S_{v}\right)$ as

$$
\varepsilon_{p}=\left[\sqrt{\varepsilon_{d}}+\left(\phi_{v}-\phi_{v} S_{v}\right)\left(\sqrt{\varepsilon_{a}}-\sqrt{\varepsilon_{d}}\right)+\phi_{v} S_{v}\left(\sqrt{\varepsilon_{w}}-\sqrt{\varepsilon_{d}}\right)\right]^{2}
$$

Volumetric water-content is assumed equal inside the vesicles and in the intergranular pores,

$$
S_{v} \phi_{v}=S_{g} \phi_{g}
$$

The bulk relative permittivity is calculated as

$$
\varepsilon=\left[\sqrt{\varepsilon_{p}}+\left(\phi_{g}-\phi_{g} S_{g}\right)\left(\sqrt{\varepsilon_{a}}-\sqrt{\varepsilon_{p}}\right)+\phi_{g} S_{g}\left(\sqrt{\varepsilon_{w}}-\sqrt{\varepsilon_{p}}\right)\right]^{2}
$$

Finally, I model $V_{E M}$ for given $S_{g}$ and $\phi_{g}$ with equation 2.1.

To estimate seismic velocities for given $S_{g}$ and $\phi_{g}$, I first calculate the average grain density $\left(\rho_{g}\right)$, and estimate the elastic moduli the grains $\left(K_{m a}, G_{d}\right)$ with the averaging formula of Hill [1952]. Mineral proportions from 18 May 1980 eruption include pyroxene, hornblende, plagioclase feldspar, and volcanic glass (Table 2.2) 
[Kuntz et al., 1981]; isotropic elastic constants are from Bass [1995], and Mavko et al. [1998].

I use Gassmann's equations [Gassmann, 1951; Biot, 1956] to calculate the bulk and shear moduli of pumice grains with vesicles and pore-fluids ( $K_{P}$ and $G_{P}$, respectively) as

$$
\begin{gathered}
K_{p}=K_{d}+\frac{(1-b)^{2}}{\frac{1-\phi_{v}-b}{K_{m a}}+\frac{\phi_{v}}{K_{f}}} \\
G_{p}=G_{d}
\end{gathered}
$$

where $b=K_{d} / K_{m a}$. The bulk modulus of the pore water is $K_{f}$. The bulk modulus of the rock skeleton $\left(K_{d}\right)$ and the shear modulus of the rock skeleton $\left(G_{d}\right)$ relate to the bulk and shear moduli of the mixed mineral phases $\left(K_{m a}\right)$ by equations of Nur et al. [1998] with a critical porosity of 0.80 .

I follow the formulation of Bachrach et al. [2000] to estimate the elastic moduli of the sediment matrix with Hertz-Mindlin contact theory [Mindlin, 1949]. The bulk modulus $\left(K_{d r y}\right)$ and shear modulus $\left(G_{d r y}\right)$ for a dry, randomly packed, unconsolidated matrix of identical, elastic spheres are

$$
\begin{gathered}
K_{H M}=\frac{n\left(1-\phi_{g}\right)}{12 \pi r} \sigma_{n} \\
G_{H M}=\frac{n\left(1-\phi_{g}\right)}{20 \pi r}\left(\sigma_{n}+1.5 \sigma_{s}\right)
\end{gathered}
$$

as shown in Walton [1987], where $\sigma_{n}$ is the normal stiffness, $\sigma_{s}$ is the shear stiffness, $n$ is the average number of contacts per grain, and $r$ is grain radius (assumed as 2 mm to model fine lapilli). Mavko and Mukerji [1998] show that

$$
\sigma_{n}=\frac{4 a G_{p}}{1-v}
$$




$$
\sigma_{s}=\frac{8 a G_{p}}{2-v}
$$

where $v$ is Poisson's ratio. The grain contact area, $a$, is related to confining force $(F)$, the contact curvature radius $R, v$, and $G_{p}$ :

$$
a=\frac{3 F R(1-v)^{1 / 3}}{8 G_{p}}
$$

The radius of curvature is related to the grain-size, assuming the angularity of sand found in Bachrach et al. [2000]:

$$
R=0.086 r
$$

Confining force is related to the grain properties, matrix properties, and the lithostatic pressure, $P$ :

$$
F=\frac{4 \pi r^{2} P}{n\left(1-\phi_{g}\right)}
$$

Lithostatic pressure is treated as

$$
P=\rho g D
$$

Where $D$ is the depth and $g$ is the acceleration due to gravity $\left(9.81 \mathrm{~m} \mathrm{~s}^{-1}\right)$.

As in Holbrook et al. [2014], I use the formulation of the upper and lower Hashin-Shtrikman bounds equations of Helgerud, [1999] to calculate the bulk and shear moduli of the dry frame $\left(K_{d r y}\right.$ and $\left.G_{d r y}\right)$. Finally, I account for intergranular pore-saturation to produce bulk elastic constants $\left(K_{b u l k}\right.$ and $\left.G_{b u l k}\right)$ as described by Santamarina et al. [2005], in which the bulk moduli of the fluid phases $\left(K_{f l}\right)$, and a fluid and particle suspension $\left(K_{\text {sus }}\right)$, and dry matrix $\left(K_{d r y}\right)$ are combined as

$$
\begin{aligned}
K_{f l} & =\left(\frac{S_{g}}{K_{w}}+\frac{1-S_{g}}{K_{a}}\right)^{-1} \\
K_{\text {sus }} & =\left(\frac{\phi_{g}}{K_{f l}}+\frac{1-\phi_{g}}{K_{d r y}}\right)^{-1}
\end{aligned}
$$




$$
K_{\text {bulk }}=K_{d r y}+K_{\text {sus }}
$$

where $K_{a}$ and $K_{w}$ are the bulk moduli of air and water, respectively. The shear modulus of the partially saturated matrix is unaffected by pore-fluids:

$$
K_{\text {bulk }}=G_{d r y}
$$

Finally, I model $V_{P}$ and $V_{S}$ using equations 2.2 and 2.3 .

\subsection{Supplementary information}

An additional figure is included to demonstrate data acquisition (Figure 2.9).

An additional line of overlapping GPR and seismic data (referred to as Line 2) was collected and processed in order to test the reproducibility of the results in the body of chapter 2 . We include the results for Line 2 below.

\subsubsection{Setting}

Line 2 is located $1.5 \mathrm{~km}$ to the southeast of Line 1 along D-4, which exposes several pyroclastic density current flow-units and lahar deposits (Figures 2.10 and 2.11). The line is situated so that the seismic data extend well beyond the GPR data on both ends.

Unit II is a massive lapilli tuff exposed locally at the western edge of D-4. Unit III grades from massive lapilli tuff to diffusely stratified lapilli tuff. Unit IV is normally graded with two lenses comprised of imbricated, decimeter scale lithics, interpreted as levees [Brand et al., 2014]. The tops of the levees undulate and transition to a massive lapilli tuff. A younger lahar deposit and pyroclastic density current deposit from June 1980 overlie the 18 May 1980 flow-unit sequence. The water-table is approximately 
$20 \mathrm{~m}$ below the top of the outcrop and assumed to mimic the east to west descending stream profile.

\subsubsection{GPR Reflectivity Results and Interpretations}

Line 2 contains two major horizons that separate three distinct units (Figure 2.12). Horizon 1 begins near the western end of the line at $12 \mathrm{~m}$ depth and gradually ascends to $10 \mathrm{~m}$ depth at the southern end of the line. Horizon 1 separates deep sub-parallel reflections that range from strong to faint and above lower frequency reflections that range in continuity from high at the ends of the line to poor at mid-line. The low frequency reflections are bounded above by the undulating Horizon 2 , which is mantled by high frequency, chaotic reflections.

The two horizons in Line 2 correlate with stratigraphy in D-4 (Figure 2.11b). The lowest unit of sub-parallel reflections corresponds to the depth and extent of the Unit III massive lapilli tuff. The low frequency reflections above the Horizon 1 coincide with the $1-5 \mathrm{~m}$ thick lenticular and imbricated lithic breccias within the lower portion of Unit IV. This interpretation is further supported by the undulatory shape of and the ambiguous facies transition along Horizon 2, which separates low frequency reflections from above chaotic reflections and matches the upward facies transition from an imbricated breccia to a massive lapilli tuff within Unit IV. We note that this interpretation would be difficult to make without the adjacent outcrop.

\subsubsection{Complete Line P-wave velocity tomogram}

Line 2 contains two major zones of $V_{P}$ heterogeneity (Figure 2.13). As in Line $1, V_{P}$ increases gradually with depth in the very near surface and eventually reaches velocities in excess of $1500 \mathrm{~m} \mathrm{~s}^{-1}$ at depths greater than $20 \mathrm{~m}$, corresponding to 
the depth of the water-table. Again, the gradual increase of $V_{P}$ with depth reflects increased effective stress with depth. Several areas of irregular and low $V_{P}$ are also evident in the very near surface. The wedge shaped reduced $V_{P}$ zone at the western end of the line coincides with the extent of a June PDC deposit exposed in outcrop D-4 (Figure 2.11). These low $V_{P}$ areas may also result from very poorly consolidated sediments at the surface.

\subsubsection{Outcrop Scale tomograms}

Line $2 V_{E M}$ ranges from $0.082 \mathrm{~m} \mathrm{~ns}^{-1}$ to $0.093 \mathrm{~m} \mathrm{~ns}^{-1}$ (Figure 2.14a). Electromagnetic wave velocity is highest in the upper $3 \mathrm{~m}$ along the eastern end of the line and elevated in the very near surface, while $V_{E M}$ is lowest along the line ends at depths greater than $5 \mathrm{~m}$. The outcrop scale Line $2 V_{P}$ tomogram displays greater heterogeneity in the upper $10 \mathrm{~m}$ (Figure 2.14b). P-wave velocity exceeds $500 \mathrm{~m} \mathrm{~s}^{-1}$ below depths $10 \mathrm{~m}$. Above the $500 \mathrm{~m} \mathrm{~s}^{-1}$ contour, horizontal lenticular zones of elevated $V_{P}\left(>300 \mathrm{~m} \mathrm{~s}^{-1}\right)$ extend across the line at shallow depths. The lowest $V_{P}$ zones are in the upper 1-2 m. S-wave velocity in Line 2 increases gradually with depth from $150 \mathrm{~m} \mathrm{~s}^{-1}$ to $300 \mathrm{~m} \mathrm{~s}^{-1}$ (Figure 2.14c). Isolated zones of $V_{S}$ heterogeneity appear throughout the line at moderate and very shallow depths ( $7 \mathrm{~m}$ and $1 \mathrm{~m}$, respectively).

Line 2 outcrop scale tomograms contains broad trends in $V_{E M}$ and more spatially isolated velocity heterogeneity in $V_{P}$ and $V_{S}$ (Figure 2.14). Both $V_{P}$ and $V_{S}$ are vertically influenced by effective stress, whereas water-content may increase with depth, which would reduce $V_{E M}$. The $0.090 \mathrm{~m} \mathrm{~ns}^{-1} V_{E M}$ contour appears to have a shape similar to the levees exposed in outcrop D-4 (Figures 2.11), which could reflect a hydrologic response to changes in the porosity or permeability along a lithologic contact. The lenses of high $V_{P}\left(>300 \mathrm{~m} \mathrm{~s}^{-1}\right)$ and high $V_{S}\left(>250 \mathrm{~m} \mathrm{~s}^{-1}\right)$ at 
depths of $5 \mathrm{~m}$ also appear to qualitatively match the morphology and location of the levees. S-wave velocity appears to be more irregular, possibly due to picking error or topographic effects that are not accounted by the Rayleigh-wave inversion.

\subsubsection{Petrophysical Inversion}

Line $2 \phi_{g}$ ranges between 0.18 and 0.32 (Figure 2.15a), which is at times below the range of physically plausible $\phi_{g}$ values of gravels (0.25-0.4) [Santamarina et al., 2005] or mixed materials such as alluvial conglomerates (0.1-0.4) [Barrash and Clemo, 2002]. However, our model does not account for the higher velocities expected of accidental clasts (primarily basaltic-andesite) that are common throughout Unit IV in D-4. A low $\phi_{g}$ zone between horizontal positions 50-100 m agrees with the western extent of a levee breccia, although this low $\phi_{g}$ is not apparent for eastern extent of the levee breccia. Intergranular water-saturation mirrors the morphology of the Line $2 V_{E M}$ model (Figure 2.15c). Again, uncertainty shows lack of correlation between the $V_{P}$

and $V_{S}$ models (Figure 2.15b and 2.15d), possibly due to the 1D and highly smoothed nature of MASW results.

\subsection{Tables}


Table 2.1: Parameters are listed for GPR (Table 2.1a) and seismic (Table 2.1b) acquisition.

\begin{tabular}{|c|c|c|c|}
\hline \multicolumn{2}{|c|}{ Table 2.1a GPR acquisition } & \multicolumn{2}{|c|}{ Table 2.1b Seismic acquisition } \\
\hline GPR system & $\begin{array}{l}\text { Sensors } \\
\text { Software } \\
\text { Pro, } 100 \mathrm{PE} \\
\text { unshielded } \\
\text { antennas, } 2400 \\
\mathrm{~V} \text { transmitters, } \\
4 \text { receivers }\end{array}$ & Seismograph & $\begin{array}{l}\text { Geometrics, } \\
3 \text { Geodes, } \\
24 \text {-channel }\end{array}$ \\
\hline Survey Type & $\begin{array}{l}\text { Transverse elec- } \\
\text { tric, 2D }\end{array}$ & Geometry & In-line \\
\hline $\begin{array}{l}\text { Minimum/ Max- } \\
\text { imum offset [m] }\end{array}$ & $1 / 15.5$ & Source & $\begin{array}{lr}3.6 \mathrm{~kg} & \text { sledge } \\
\text { hammer }\end{array}$ \\
\hline CMP fold & $\begin{array}{l}16 \text { (double } 8.5 \mathrm{~m} \\
\text { offset) }\end{array}$ & Receivers & $\begin{array}{l}10 \mathrm{~Hz} \text { vertical } \\
\text { pin geophones }\end{array}$ \\
\hline $\begin{array}{l}\text { CMP bin size } \\
{[\mathrm{m}]}\end{array}$ & 0.29 & $\begin{array}{l}\text { Number of chan- } \\
\text { nels }\end{array}$ & 72 \\
\hline $\begin{array}{l}\text { Receiver interval } \\
{[\mathrm{m}]}\end{array}$ & 0.5 & $\begin{array}{l}\text { Receiver interval } \\
{[\mathrm{m}]}\end{array}$ & 2 \\
\hline $\begin{array}{l}\text { Source interval } \\
{[\mathrm{m}]}\end{array}$ & 0.16 & $\begin{array}{l}\text { Source interval } \\
{[\mathrm{m}]}\end{array}$ & 2 \\
\hline $\begin{array}{l}\text { Sample interval } \\
{[\mathrm{ns}]}\end{array}$ & 0.8 & $\begin{array}{l}\text { Sample interval } \\
{[\mathrm{ms}]}\end{array}$ & 0.5 \\
\hline $\begin{array}{l}\text { Recording time } \\
{[\mathrm{ns}]}\end{array}$ & 400 & $\begin{array}{l}\text { Recording time } \\
\text { [ms] }\end{array}$ & 500 \\
\hline Stacks/source & 8 & Stacks/source & 4 \\
\hline
\end{tabular}

Table 2.2: Densities $\left(\rho_{i}\right)$, bulk moduli $\left(K_{i}\right)$, shear moduli $\left(G_{i}\right)$ and volumetric proportions of mineral phases within dacite from 18 May 1980 PDC deposits of Mount St. Helens.

\begin{tabular}{|c|c|c|c|c|}
\hline \hline Component & $\rho_{i}\left[\mathrm{~kg} \mathrm{~m}^{-3}\right]$ & $K_{i}[\mathrm{GPa}]$ & $G_{i}[\mathrm{GPa}]$ & Volume fraction [\%] \\
\hline Volcanic glass (obsidian) & 2331 & 37.8 & 30.1 & 62.1 \\
\hline Plagioclase-feldspar & 2630 & 75.6 & 25.6 & 30 \\
\hline Orthopyroxene & 3310 & 111.2 & 63.7 & 4.2 \\
\hline Hornblende & 3120 & 87 & 43 & 2.5 \\
\hline Fe-Ti oxide & 5009 & 161.1 & 91.4 & 1.2 \\
\hline
\end{tabular}




\subsection{Figures}
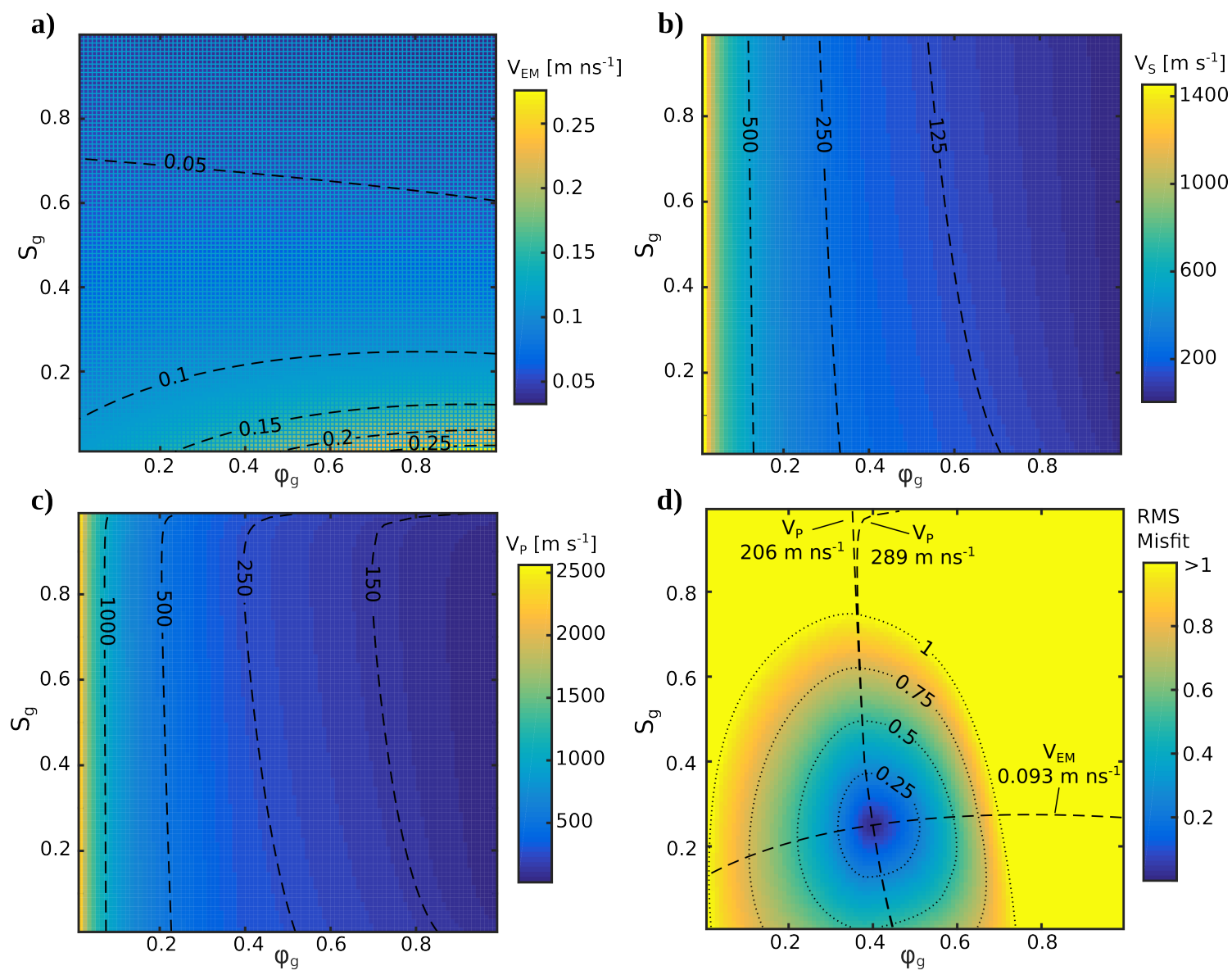

Figure 2.1: Electromagnetic and seismic velocities are modeled for pyroclastic deposits for given intergranular water-saturation $\left(S_{g}\right)$ and porosity $\left(\phi_{g}\right)$ at $10 \mathrm{~m}$ depth. a) Electromagnetic velocity is primarily sensitive to $S_{g}$ and secondarily sensitive to $\phi_{g}$. b) S-wave velocity is weakly anticorrelated with $S_{g}$ and inversely related to $\phi_{g}$. c) P-wave velocity increases rapidly at $S_{g}>0.95$ and is otherwise inversely related to $\phi_{g}$. d) The root-mean squared misfit from joint petrophysical minimization of $V_{P}, V_{S}$, and $V_{E M}$ modeled for pyroclastic deposits with $\phi_{g}$ of 0.4 and $S_{g}$ of 0.25 . Dotted contours indicate RMS misfit at 0.25 intervals. Note that seismic and electromagnetic velocity contours (dashed lines) are near perpendicular. Neither seismic nor electromagnetic velocities alone can resolve unique solutions for $S_{g}$ or $\phi_{g}$. 
a)

b) $561000 \quad$ UTM Easting [m] 562000
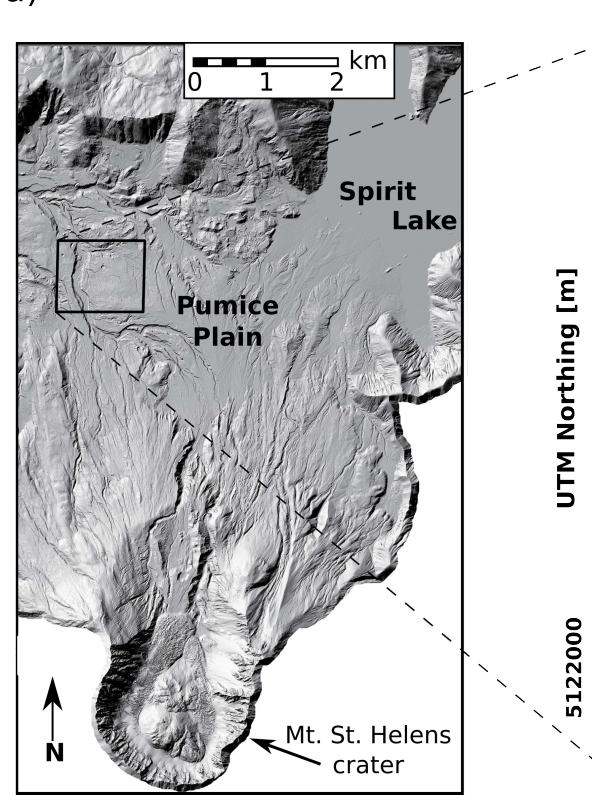

(b)

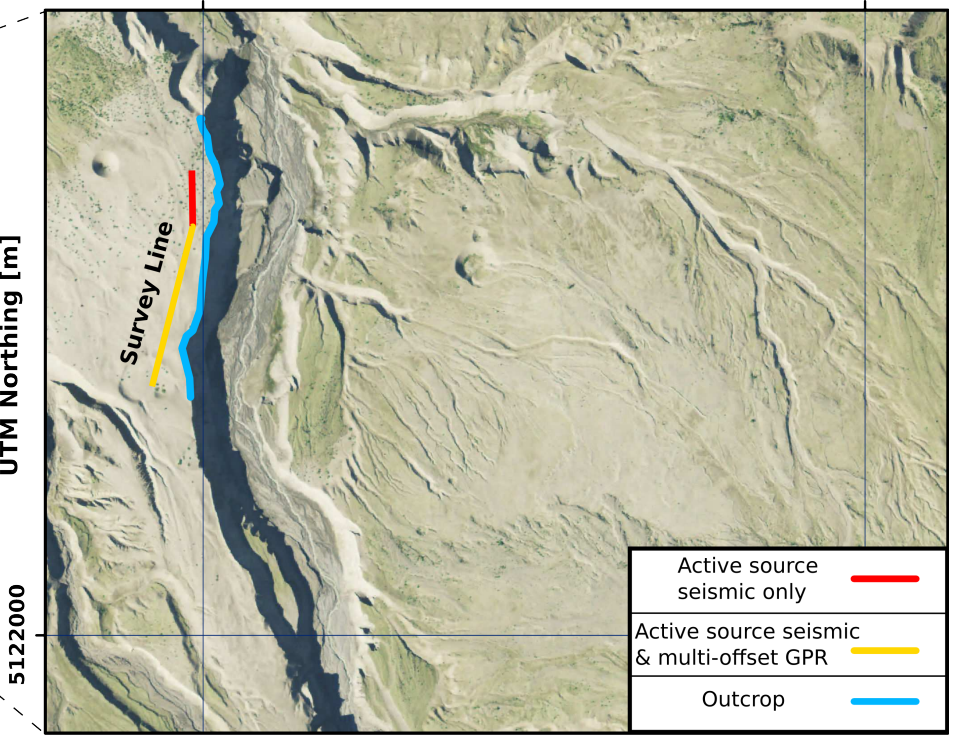

]

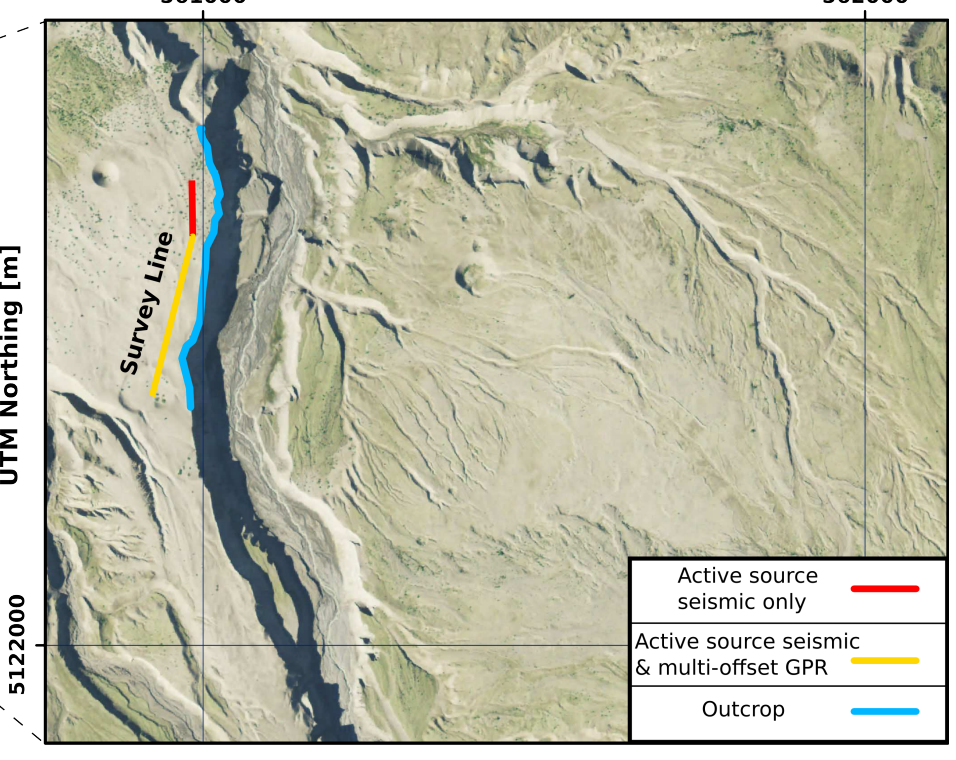

Figure 2.2: a) Mount St. Helens digital elevation model. b) Satellite image of the study site in the pumice plain, $5 \mathrm{~km}$ northwest of Mount St. Helen's crater. The survey line is $>20 \mathrm{~m}$ offset from the adjacent outcrop (blue). The survey line section with seismic data only is red; overlapping GPR and seismic data are yellow; outcrops are colored blue. Grid-lines are $1 \mathrm{~km}$ UTM, northern hemisphere, zone 10. 
a) $s$

$\mathrm{N}$

b)
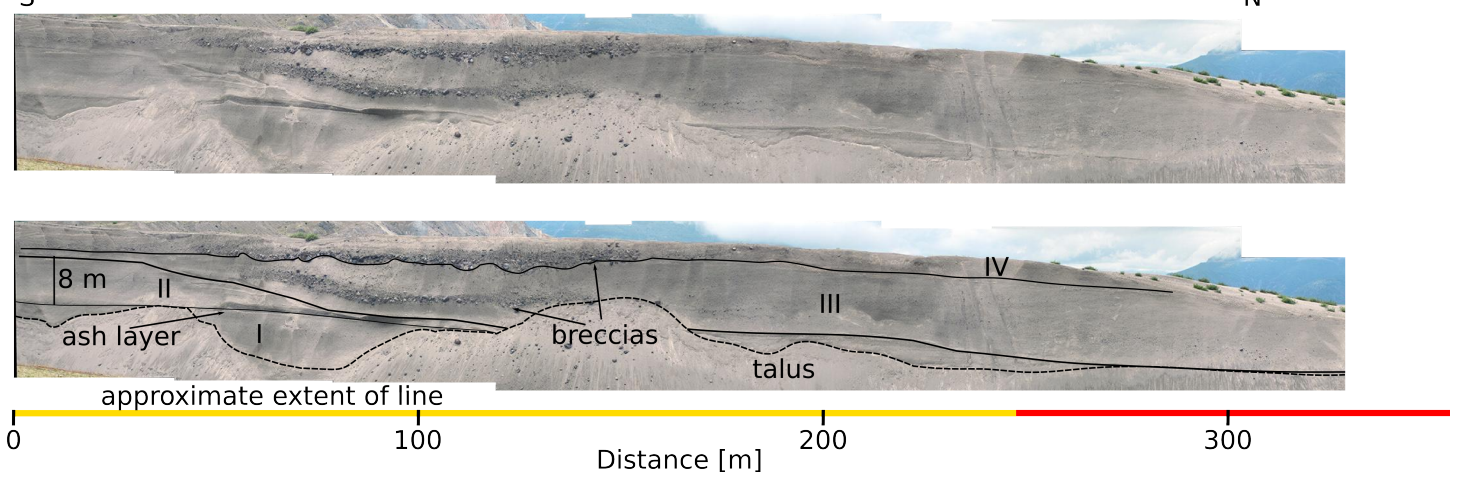

Figure 2.3: a) Panorama of the outcrop adjacent to the survey line. b) Panorama with flow-unit interpretations from Brand et al. [2014]. All flow-units (indicated by Roman numerals) were deposited during the 18 May 1980 eruption. The outcrop contains a large scour-and-fill feature, where the pyroclastic density currents deposited Units I and II, scoured into Unit II, then filled the scour with Units III and IV. Two breccia lenses comprised of meter-scale boulders are present in Units III and IV. The approximate horizontal extent of the line is shown below the panorama with the identical color scheme as in Figure 2.2. 
a)
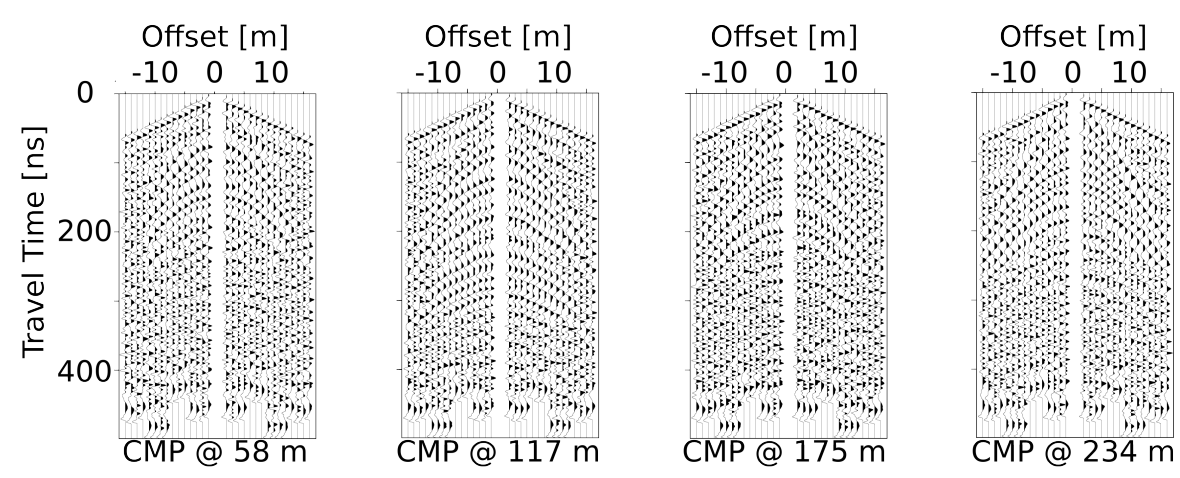

b)

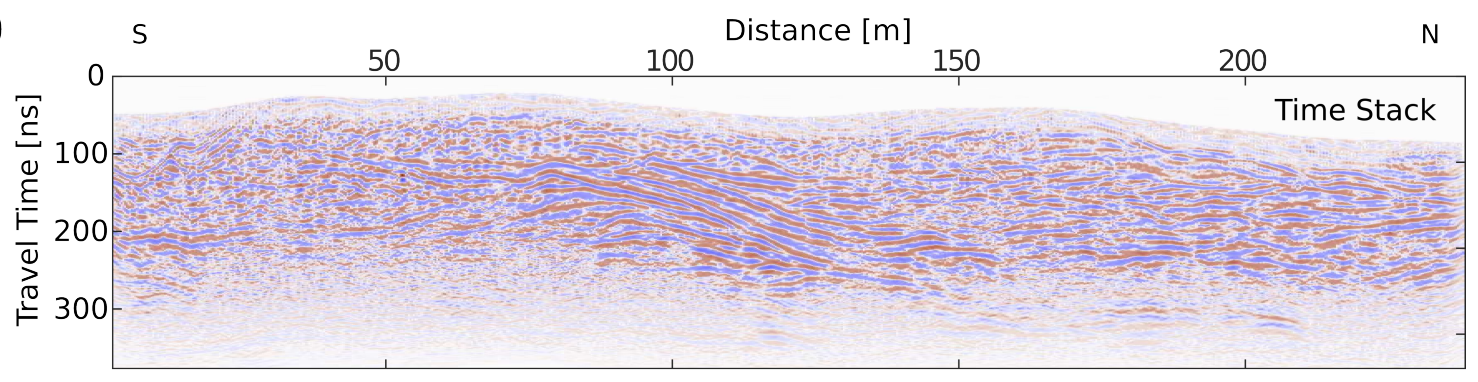

c)

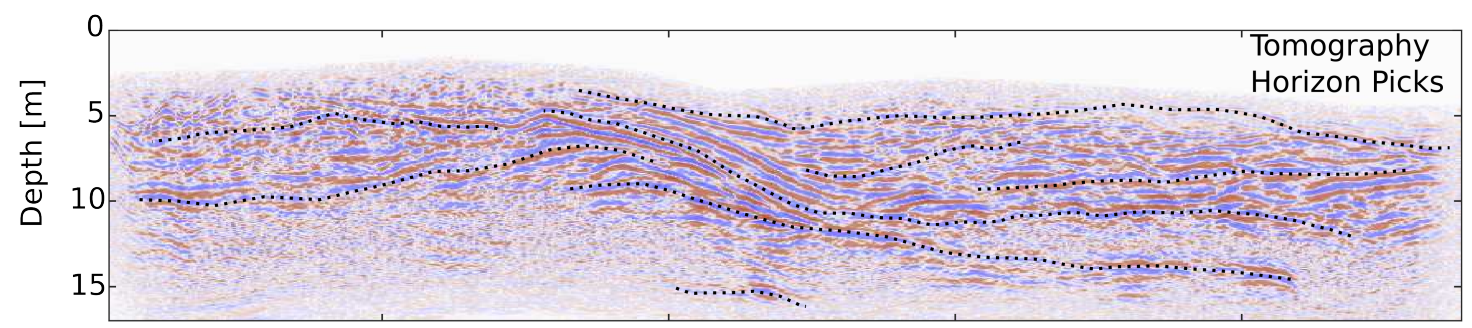

d)

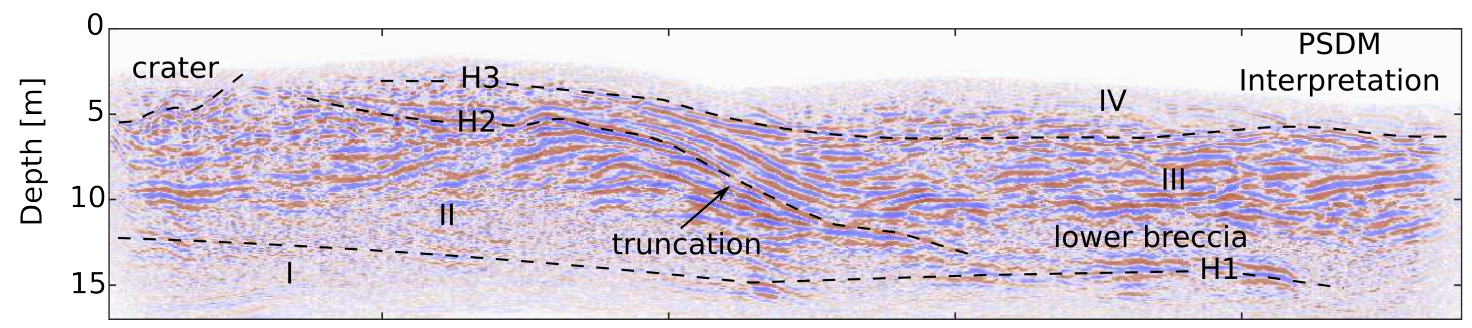

Figure 2.4: GPR reflectivity was used to estimate subsurface $V_{E M}$ and correlate tomography results with underlying stratigraphy. a) Representative common-midpoint gathers show hyperbolic reflections. b) Time-stack after normal move-out correction, F-K migration, and depth conversion at $0.092 \mathrm{~m} \mathrm{~ns}^{-1}$. c) PSDM radargram with horizons selected for reflection tomography. d) PSDM radargram with stratigraphic interpretations. The Unit I-II horizon is weak and relatively horizontal. Dipping reflections in Unit III truncate Unit II reflections. Lenses of weak signal are attributed to breccias. 

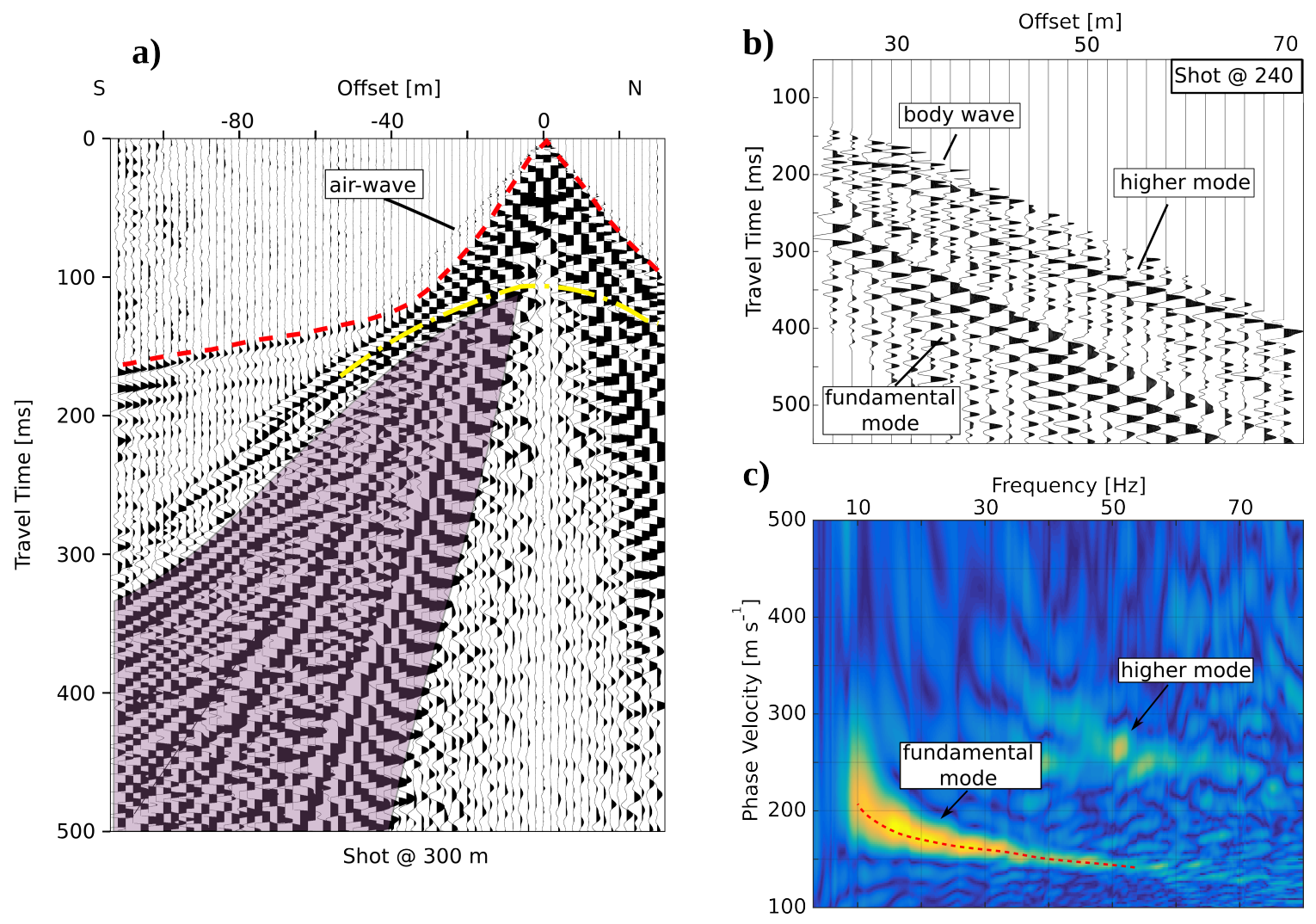

Figure 2.5: a) A representative seismic shot gather shows first-arrivals (red line) and significant ground-roll (purple). Shot gathers have clear water-table refractions (first-arrivals beyond $40 \mathrm{~m}$ offset) and a watertable reflection (yellow dashed curve). b) Rayleigh-waves are isolated for MASW. For example, Shot 122 is windowed to offsets 12-78 m. Data are muted before the ground-roll to limit body-wave noise. c) A dispersion curve depicts Rayleigh-wave frequency versus phase-velocity of Shot 122. Dispersion curve picks are shown in red. 
a)

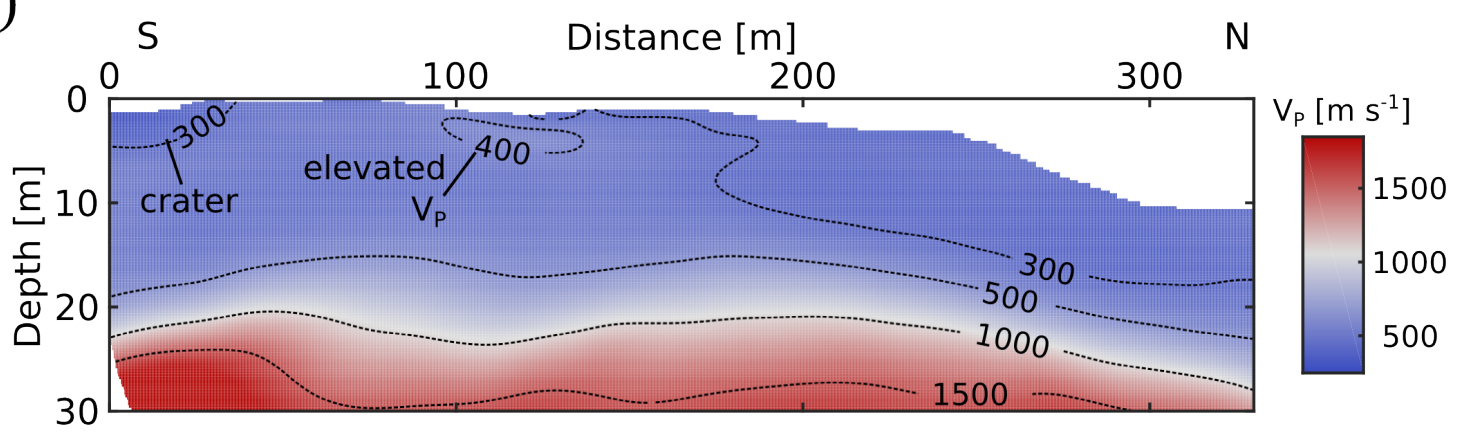

b)

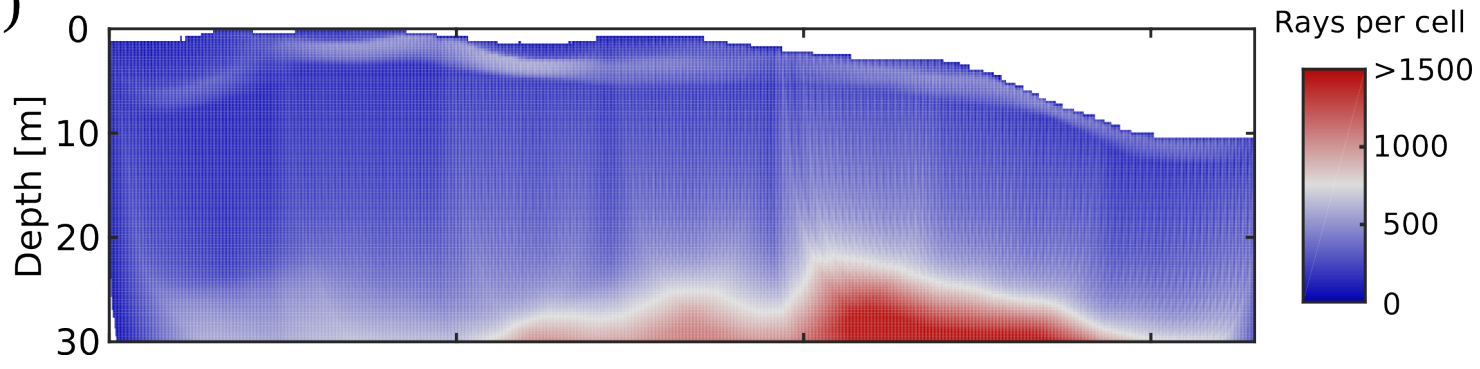

Figure 2.6: $\mathrm{P}$-wave velocity spanning the entire horizontal extent of the seismic line. Contours are drawn at 300, 500, 1000, and $1500 \mathrm{~m} \mathrm{~s}^{-1}$. P-wave velocity increases gradually with depth in the shallowest $20 \mathrm{~m}$ from $300 \mathrm{~m}$ $\mathrm{s}^{-1}$ to $500 \mathrm{~m} \mathrm{~s}^{-1}$. The $1500 \mathrm{~m} \mathrm{~s}^{-1}$ contour follows the relief of the stream below. An additional $400 \mathrm{~m} \mathrm{~s}^{-1}$ contour highlights a lenticular region of with slightly elevated $V_{P}$ in the upper $10 \mathrm{~m}$. The $300 \mathrm{~m} \mathrm{~s}^{-1}$ contour at the top left side of the tomogram accentuate a low $V_{P}$ area attributed to poorly consolidated sediments within a secondary phreatic explosion crater at the beginning of the line. P-wave velocity is also reduced along the hill-slope at the right end of the line. 

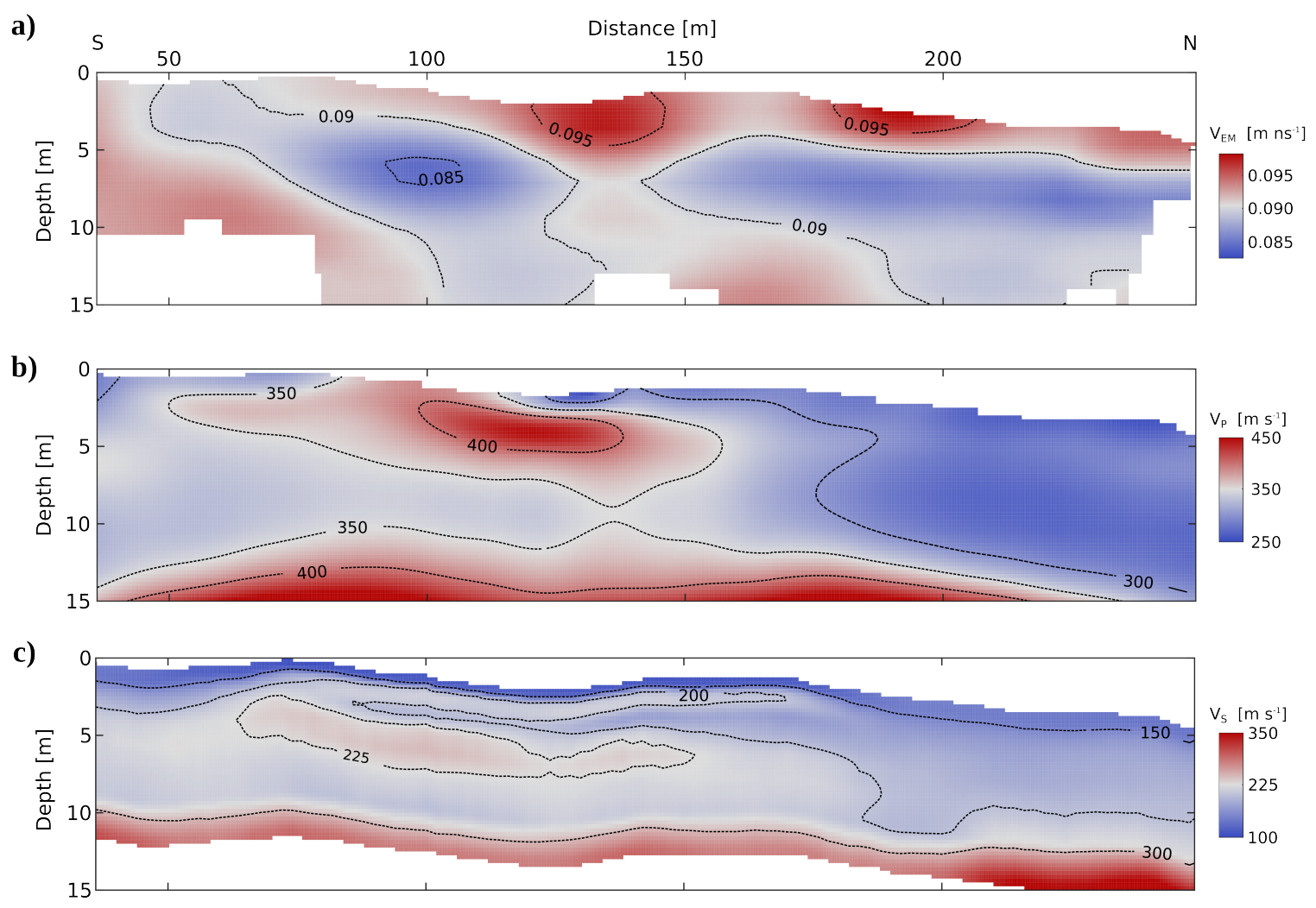

Figure 2.7: EM-wave velocity model from reflection tomography of GPR data. EM-wave velocity is greatest near the ground surface. Two broad regions of low $V_{E M}$ are centered at horizontal positions $100 \mathrm{~m}$ and 200 m. b) P-wave velocity model from inversion of first-arrival travel times. $\mathrm{P}$-wave velocity increases gradually with depth. A lens of high $V_{P}(>350 \mathrm{~m}$ $\mathrm{s}^{-1}$ ) at $4 \mathrm{~m}$ depth and horizontal position $100 \mathrm{~m}$ is centered over the Unit IV breccia lens (Figure 2.3). P-wave velocity is lowest $\left(<300 \mathrm{~m} \mathrm{~s}^{-1}\right)$ at the northern end of the line. c) S-wave model from inversion of Rayleigh-wave dispersion curves at off-end shot mid-points. A lens of high $V_{S}\left(225 \mathrm{~m} \mathrm{~s}^{-1}\right)$ at $5 \mathrm{~m}$ depth overlaps the high $V_{P}$ zone (b) and the Unit IV breccia lens (Figure 2.3). S-wave velocity is lowest in the top $1 \mathrm{~m}$ and at the northern end of the line. 
a)

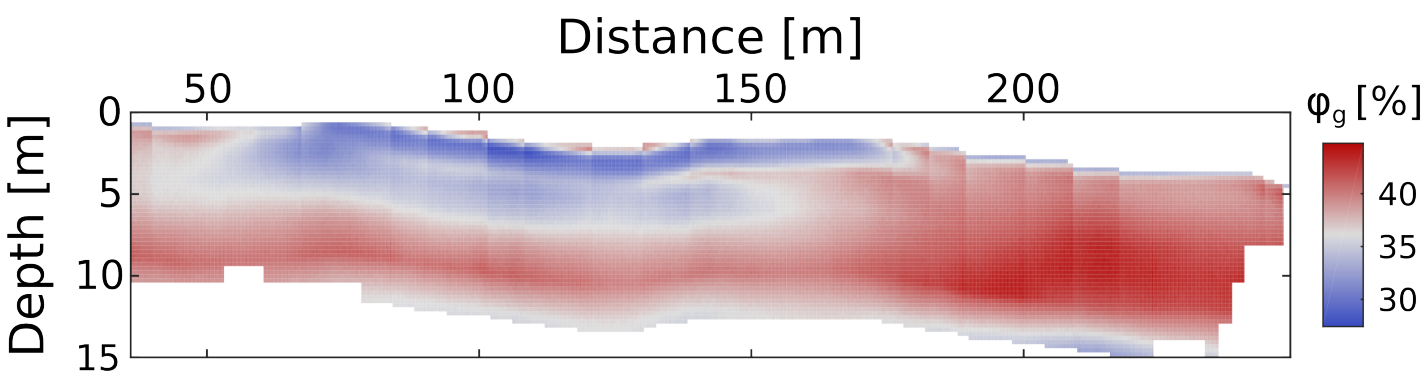

b)

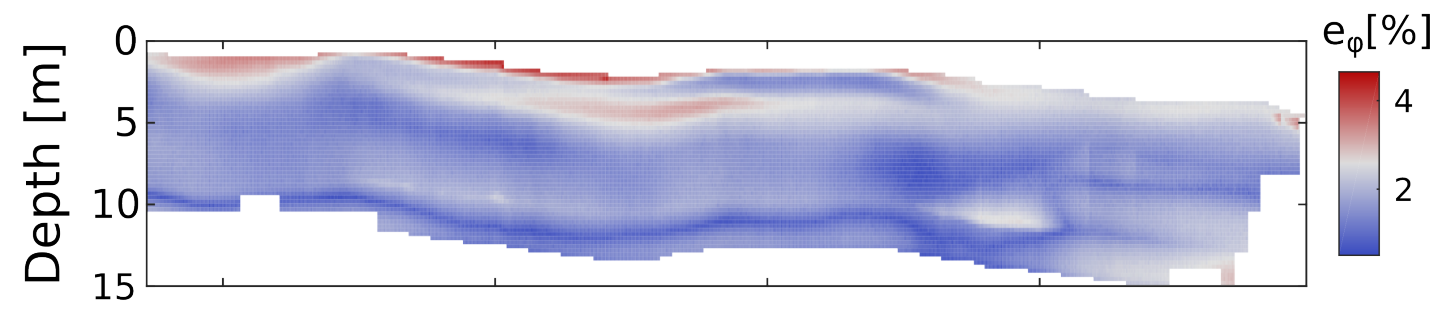

c)

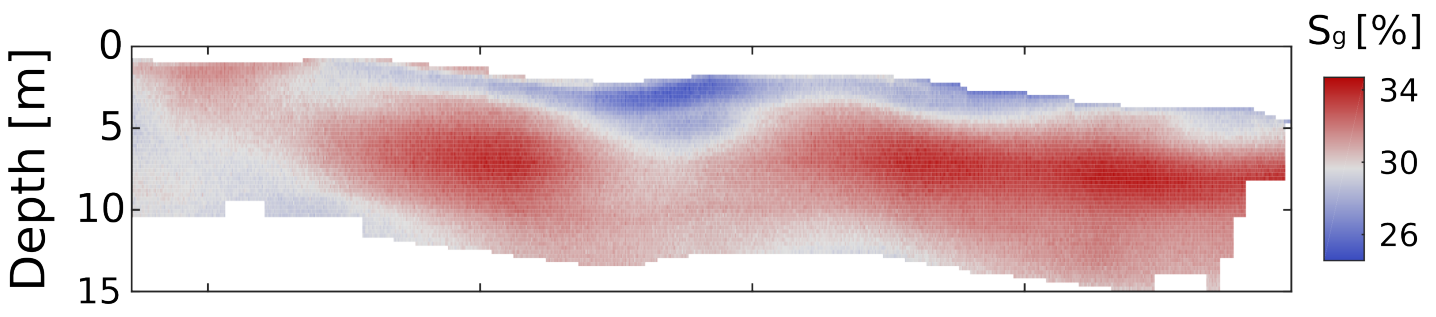

d)

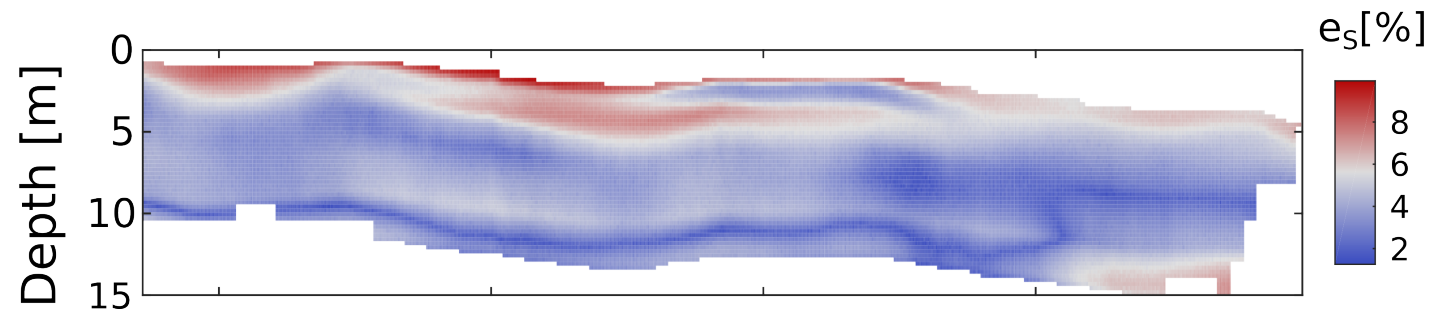

Figure 2.8: Intergranular porosity $\left(\phi_{g}\right)$ and water-saturation $\left(S_{g}\right)$ results from joint Monte Carlo inversion of seismic and electromagnetic velocities. a) Intergranular porosity ranges between 0.28-0.42. A zone of low $\phi_{g}$ corresponds to the location of the upper breccia lens in the outcrop. b) Intergranular porosity errors $\left(e_{\phi}\right)$ do not exceed 0.03. c) Intergranular water-saturation ranges between $0.25-0.35$ and mirrors the morphology of the $V_{E M}$ tomogram (Figure 2.7a). d) Intergranular water-saturation $\operatorname{errors}\left(e_{S}\right)$ do not exceed 0.08 . 

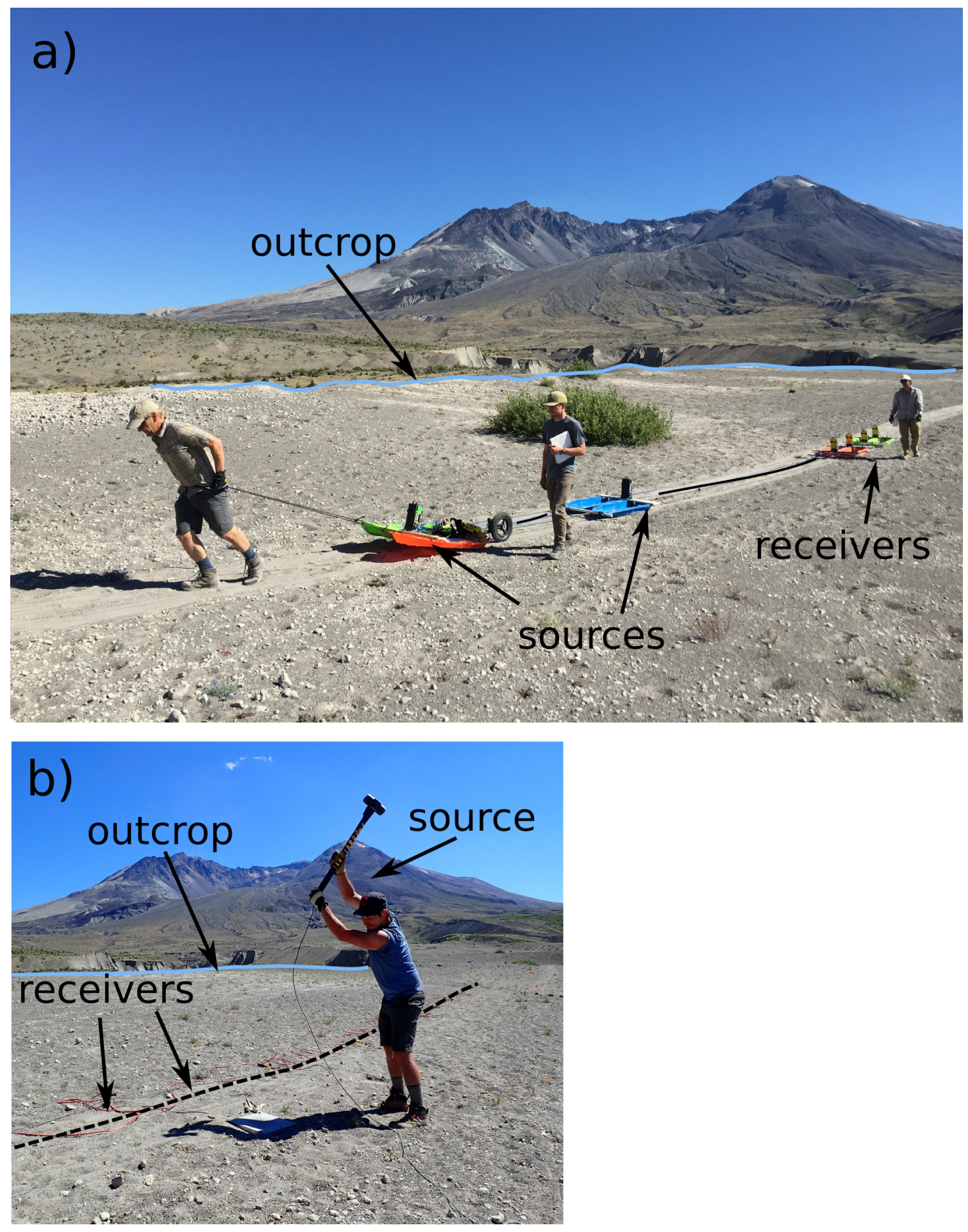

Figure 2.9: Southeast facing photographs of multifold GPR and active seismic acquisition along outcrop AD-3. a) Multifold GPR was acquired with two sources and four receivers, mounted on six sleds connected by rope. In this photograph offsets range from 8-15 m. b) Active seismic acquisition using a hammer source, and $10 \mathrm{~Hz}$ geophones at $2 \mathrm{~m}$ intervals. 


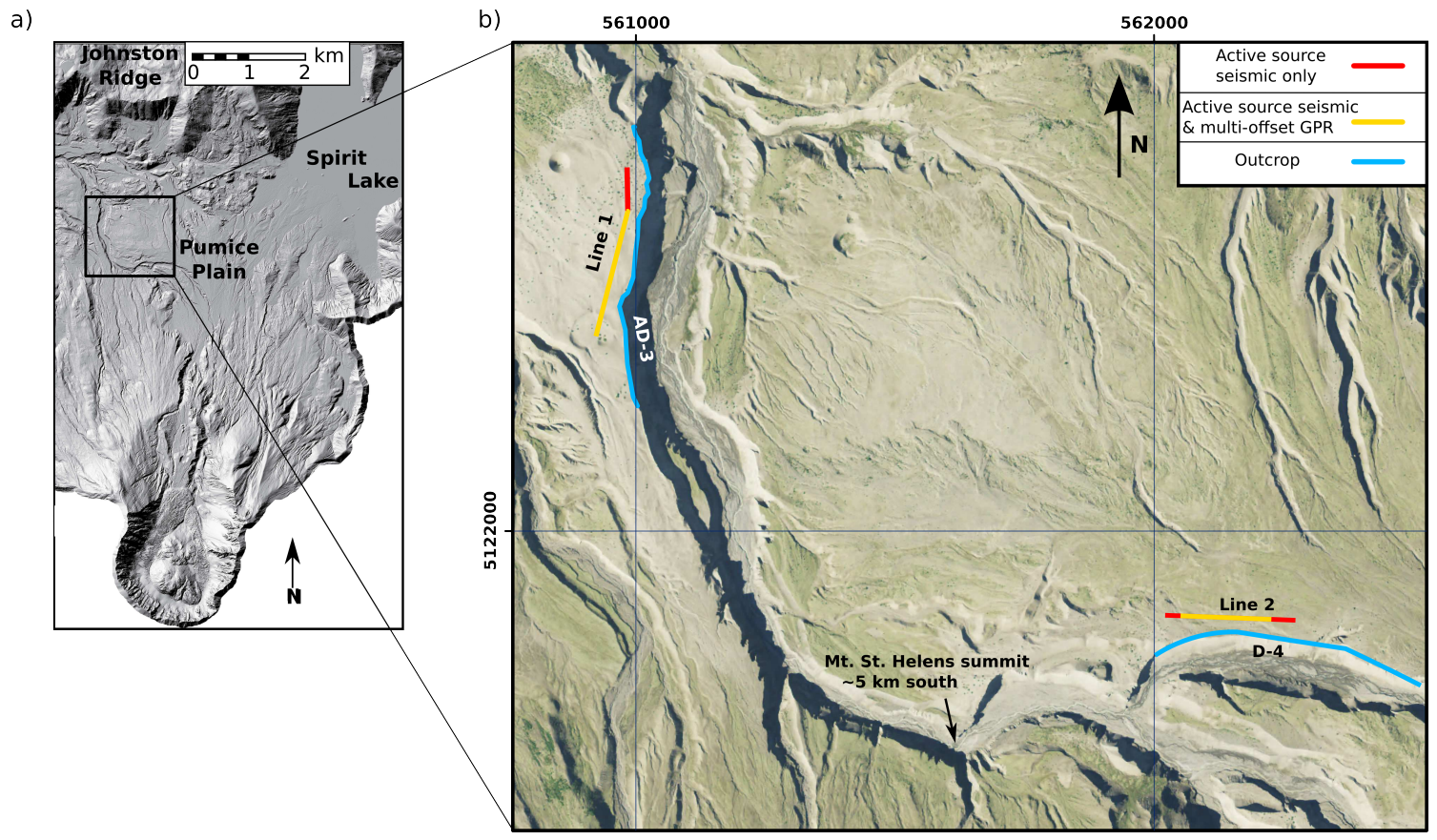

Figure 2.10: a) Mount St. Helens digital elevation model. b) Map of seismic and GPR lines in the central pumice plain. Line 1 (i.e., line discussed in chapter 2) is parallel to outcrop AD-3. Line 2 (i.e., supplementary line) is parallel to outcrop D-4. Lengths with seismic data only are red; overlapping GPR and seismic data are yellow; outcrops are blue. The $1 \mathrm{~km}$ grid is UTM, northern hemisphere, zone 10. 
a) $\mathrm{W}$

D-4

E

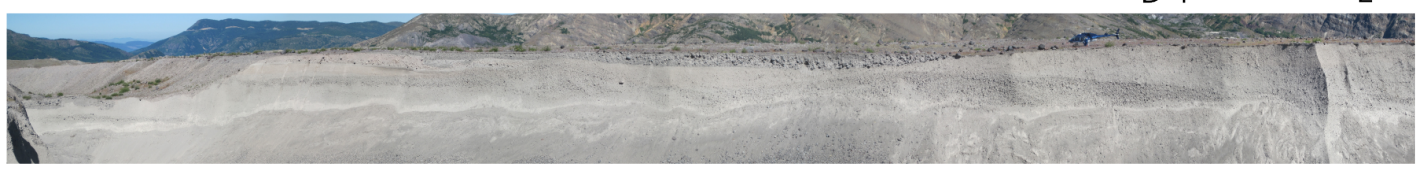

b)

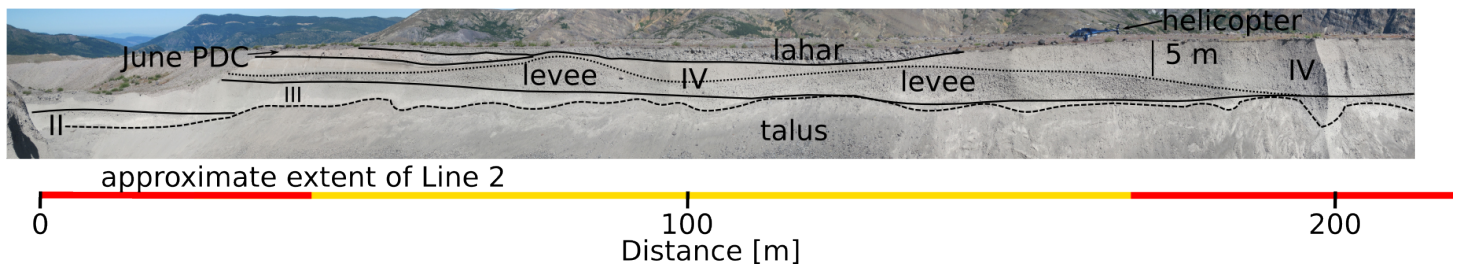

Figure 2.11: a) Panorama of outcrop D-4 and b) flow-unit interpretations from Brand et al. [2014]. Outcrop D-4 contains deposits from the 18 May 1980 eruption, mantled by subsequent June PDC and lahar deposits. Unit III contains large levees comprised of decimeter scale cobbles. A helicopter is approximately $100 \mathrm{~m}$ beyond the outcrop. The approximate extent of Line 2 is shown below with identical color scheme as in Figure 2.9.

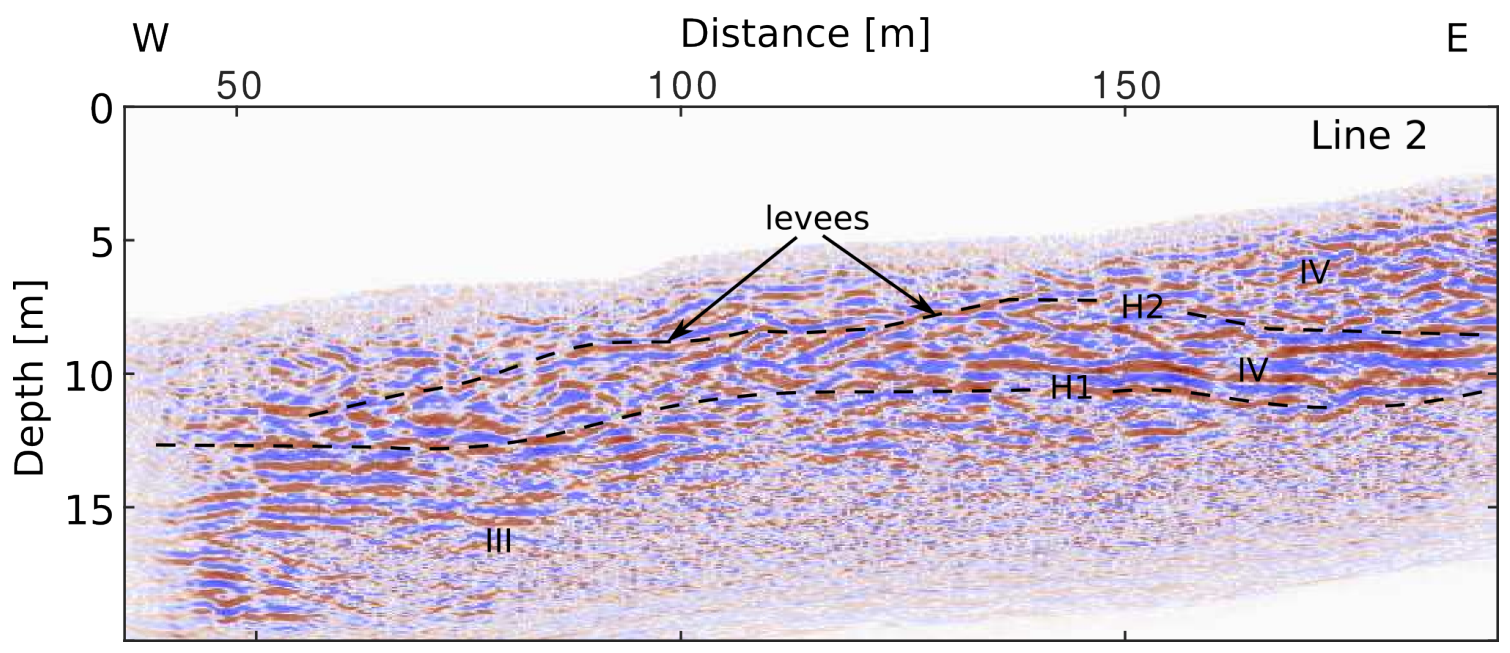

Figure 2.12: Line 2 radargram after reflection tomography, PSDM and stacking. Line 2 contains three dominant radar-facies. Deep, sub-parallel and horizontal reflections to the west correspond to Unit III. Scattering from levee breccias may be responsible for signal loss at the center and east of Unit III. The deepest horizon separates Units III and IV. Two mounds of irregular reflections at 5-7 m depth are attributed to lithic levees, although the features are not well-defined. Wavy reflections above the levees are attributed to Unit IV. Lahar and June PDCs deposits in outcrop D-4 (Figure 2.11) are either non-existent along the line or indistinguishable in the image. 


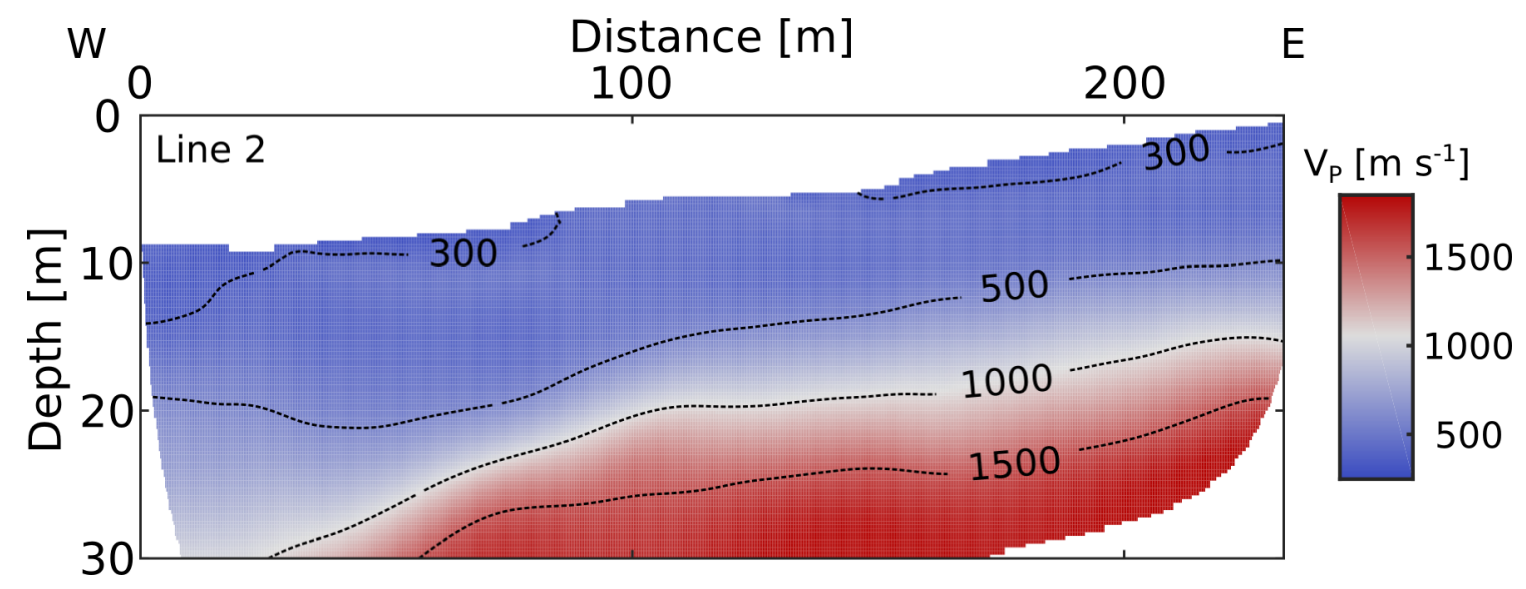

Figure 2.13: P-wave velocity tomogram of Line 2, spanning the entire horizontal extent of the seismic line and up to depths of $30 \mathrm{~m}$. Shallow subsurface $V_{P}$ irregularities do not clearly resemble the levees in outcrop D-4 (Figure 2.11). 

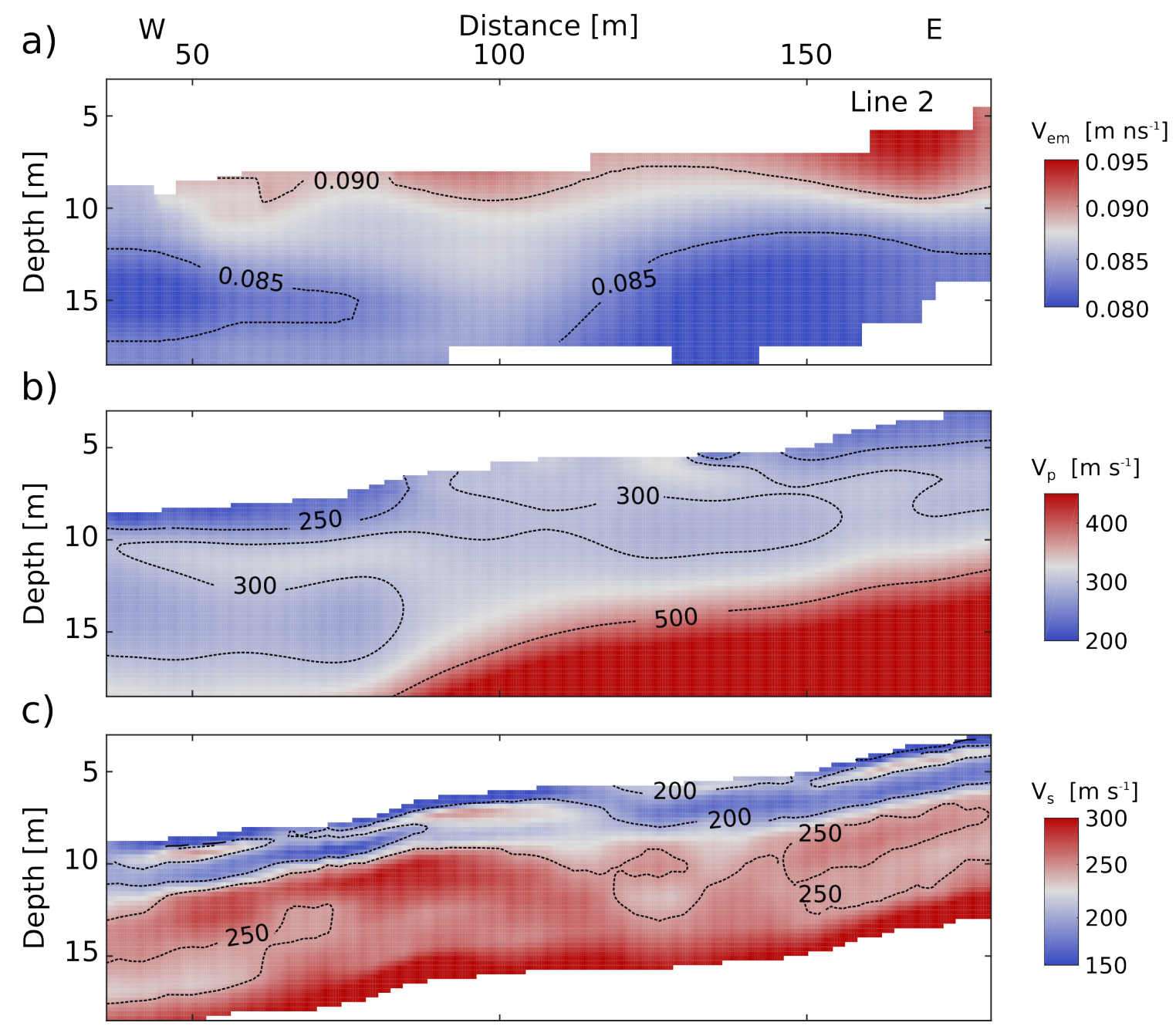

Figure 2.14: Line 2 velocity tomograms. Note three times vertical exaggeration. a) Electromagnetic velocity model from reflection tomography of GPR data. Electromagnetic velocity gradually decreases with depth, suggesting a slight increase in volumetric water-content with depth. b) $\mathrm{P}$-wave velocity tomogram from inversion of first-arrival times. Laterally continuous zones of elevated $V_{P}\left(>300 \mathrm{~m} \mathrm{~s}^{-1}\right)$ roughly correspond to the locations of the lithic levees, although the morphologies of these zones are not well resolved. P-wave velocity increases significantly with depth. c) $\mathrm{S}$-wave velocity model from inversion of Rayleigh-wave dispersion curves. S-wave velocity variations are horizontally smoothed. Thin, laterally continuous zones of elevated $V_{S}$ in the top $2 \mathrm{~m}$ are suspected to result from picking errors. S-wave velocity increases with depth. The $250 \mathrm{~m} \mathrm{~s}^{-1}$ $V_{S}$ contour broadly overlaps with the elevated $V_{P}$ zones.) 

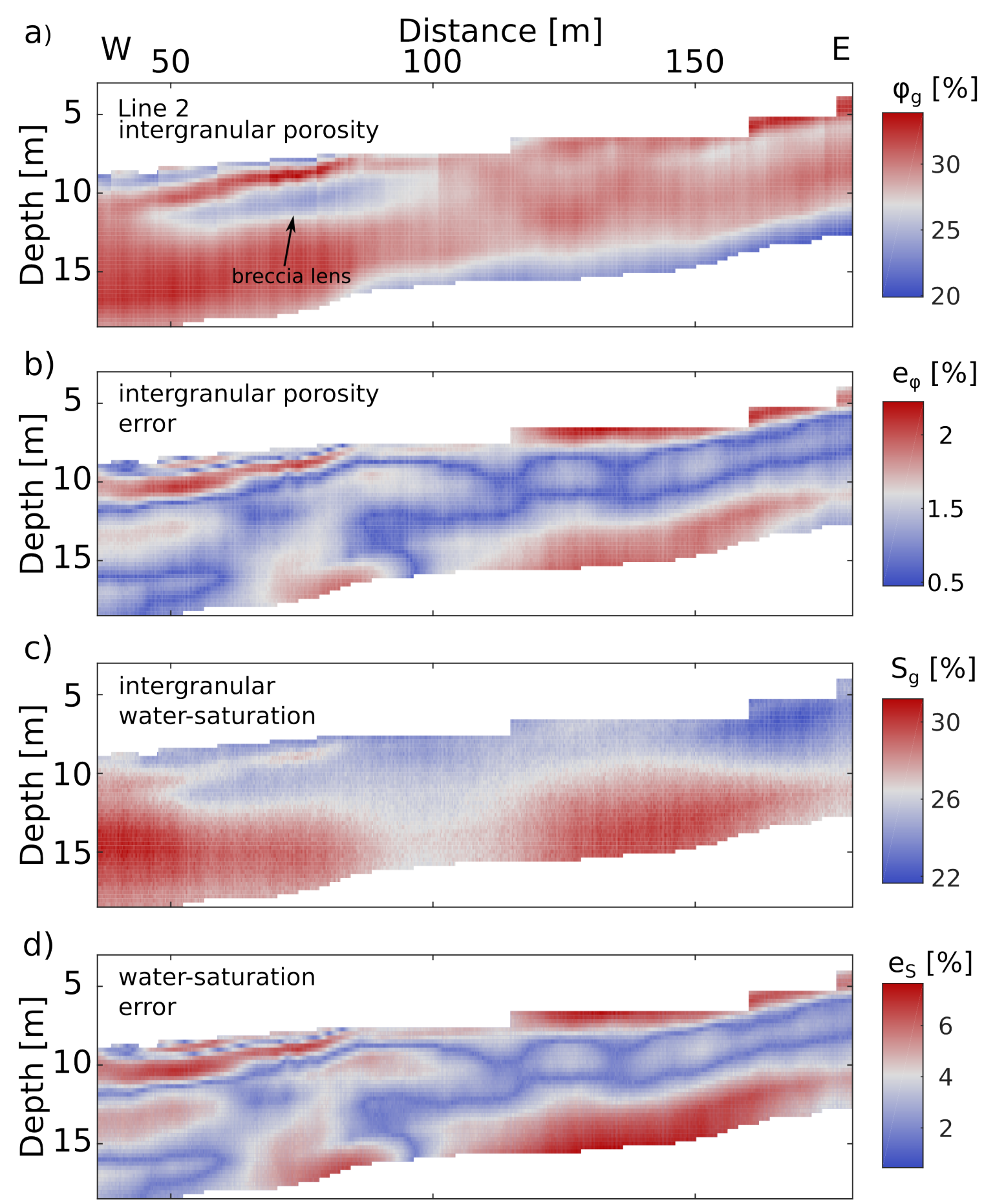

Figure 2.15: Intergranular porosity and water saturation results for Line 2. a) Intergranular porosity ranges between 0.2-0.34. A zone of low $\phi_{g}$ corresponds to the location of a breccia lens in outcrop D-4 (Figure 2.11), which suggests poor sorting and compositional changes can be detected with seismic and electromagnetic velocities. b) Integranular porosity errors do not exceed 0.025. c) Intergranular water saturation ranges between $0.22-0.31$ and resembles the morphology of the $V_{E M}$ tomogram (Figure 2.14a). d) Intergranular water saturation errors do not exceed 0.08 . 


\section{CHAPTER 3}

\section{EVIDENCE OF EROSIONAL SELF-CHANNELIZATION OF PYROCLASTIC DENSITY CURRENTS REVEALED BY GROUND-PENETRATING RADAR IMAGING AT MOUNT ST. HELENS, WASHINGTON (USA)}

\subsection{Abstract}

The causes and effects of erosion are among the least understood aspects of pyroclastic density current (PDC) dynamics. Evidence is especially limited for erosional self-channelization, a process whereby PDCs erode a channel that confines the body of the eroding flow or subsequent flows. I use ground-penetrating radar imaging to trace a large PDC scour-and-fill from outcrop to its point of inception, and discover a second, larger PDC scour-and-fill. The scours are among the largest PDC erosional features on record, at >200 m wide and at least $500 \mathrm{~m}$ long; estimated eroded volumes are on the order of $10^{6} \mathrm{~m}^{3}$. The scours are morphologically similar to incipient channels carved by turbidity currents. Erosion may be promoted by a moderate slope $\left(5-15^{\circ}\right)$, substrate pore-pressure retention, and pulses of increased flow energy. These finding are the first direct evidence of erosional self-channelization by PDCs, a phenomenon that may increase flow velocity and run-out distance through confinement and substrate erosion. 


\section{$3.2 \quad$ Introduction}

Pyroclastic density current (PDC) deposits from flows of moderate volume $\left(\sim 10^{6}\right.$ $\mathrm{m}^{3}$ ) are often mantled by intertwined pumice lobes with lateral levees and depressed central channels [e.g., Wilson and Head, 1981; Calder et al., 2000]. The morphological similarity of pumice lobes to self-channelized granular flows implies that in certain conditions, PDCs from discrete or waning eruptions can self-channelize [Jessop et

al., 2012; Kokelaar et al., 2014]. Self-channelization is commonly observed as levee formation and/or axial erosion (i.e., scouring) in sediment-laden flows, including but not limited to, granular flows [e.g., Pouliquen, Delour, and Savage, 1997; Félix and Thomas 2004] and turbidity currents [e.g., Clark and Pickering, 1996]. Experimental self-channelized flows have increased run-out distance in granular flows [Kokelaar et al., 2014] and increased axial velocity in subaqueous flows [de Leeuw, Eggenhuisen, and Cartigny, 2016] when compared to non-channelized flows of equal volume. Therefore, understanding the mechanisms and consequences of PDC self-channelization is critical for hazard prediction.

The role of self-channelization is poorly constrained in sustained, concentrated, fluidized PDCs generated by Plinian column-collapse. Brand et al. [2014] identify a broad scour-and-fill feature ( 300 m wide, 12 m deep) within the 18 May 1980 PDC deposits at Mount St. Helens (MSH). The scour-and-fill feature is interpreted as evidence of PDC self-channelization, where PDCs scoured into fresh PDC deposits from earlier phases of the eruption, and subsequently deposited within the scour. Yet, even well-exposed PDC deposits fail to capture 3D sedimentary architecture. Constraining the conditions that promoted erosion and the nature of scouring is limited without complementary subsurface imaging. 
Our objective is to test whether the scour-and-fill feature is an expression of sustained, axial erosion and thereby an example of erosional self-channelization, or erosion promoted by irregular pre-flow topography. I use ground-penetrating radar (GPR) to image the scour-and-fill feature up-flow from exposure to the point of inception and to search for subsurface topographic irregularities (e.g., debris avalanche hummocks).

\subsection{Geologic Setting}

The historic 18 May 1980 MSH eruption began when a massive landslide removed the volcano's upper northern edifice and deposited large hummocks from the break in slope $\sim 3.5 \mathrm{~km}$ north of the vent, to Johnston Ridge and beyond to the west (Figure 3.1a). The following 9-hour eruption generated a Plinian column that began to collapse midday. Numerous column-collapse PDCs flowed northward through the breached crater and deposited up to $8 \mathrm{~km}$ from the vent (Figure 3.1a). PDC activity began around $1215 \mathrm{hrs}$, waxed to the climactic phase between 1500-1715 hrs, and continued for a short waning phase. PDC deposits in the pumice plain are up to $\sim 40 \mathrm{~m}$ thick. Post-eruption erosion by the glacier-fed headwaters of the Toutle River exposes tens of kilometers of deposits in the pumice plain.

Brand et al. [2014] identify five chronological PDC flow-units (Units I-V) deposited by concentrated PDCs capable of retaining elevated pore-pressure over the majority of their flow paths. Units I and II, are diffusely-stratified to massive, and are often capped by $\sim 0.25-0.5 \mathrm{~m}$ thick layers of coignimbrite ash. Units III and IV are the most voluminous flow-units exposed in the pumice plain. These climactic flow-units are often massive with lithic breccias containing both vent and local eroded blocks 
[Pollock, Brand, and Roche, 2016]. The scour-and-fill feature, introduced above, is found at the Unit II-III flow-contact in outcrop AD-3 (Figure 3.2a). Units III and IV fill the scour-and-fill feature. The surficial pumice-lobe deposits of Unit V correspond to the waning phase of the eruption (Figure 3.1b).

Our study covers $\sim 2 \mathrm{~km}^{2}$ of the pumice plain, $\sim 5 \mathrm{~km}$ northwest of the vent (Figures 3.1b and 3.1c). The topography descends regionally to the northwest with a maximum dip of $\sim 15^{\circ}$ and total relief of $\sim 125 \mathrm{~m}$. Trajectories derived from the post-eruption surface morphology show that PDCs from the waning phase of the eruption followed the northwest topographic gradient [Kuntz, Rowley, and MacLeod, 1990] (Figure 3.1b). Debris avalanche hummocks are clustered along the margins of the site (Figures 3.1a and 3.1b) with no exposures upstream from the scour-and-fill. Our survey is designed to search up-flow from the scour-and-fill for buried debris avalanche hummocks and evidence of PDC erosion.

\subsection{Ground-Penetrating Radar Imaging}

Data were acquired in common-offset mode with a Sensors and Software PulseEKKO Pro GPR. Two sleds with $50 \mathrm{MHz}$ antennas at a fixed offset of $2 \mathrm{~m}$ were dragged over the deposit surface. A wheel odometer controlled the $0.5 \mathrm{~m}$ trace interval. Simultaneously, we recorded real time kinematic GPS data for topographic correction. Generally, we could image within Units II-V ( 20 m deep). The vertical resolution of $50 \mathrm{MHz}$ electromagnetic waves (i.e., $0.46 \mathrm{~m}$ at $0.09 \mathrm{~m} \mathrm{~ns}^{-1}$ ) is suitable for interpreting flow-unit contacts and broad stratigraphic trends.

Processing included time-zero correction and bandpass frequency filtering (1225-400-800 MHz). Automatic gain control (AGC) was applied to Line 5, and true 
amplitude recovery was performed on all other data. Finally, we migrated the data (frequency-wavenumber) to collapse diffractions and move dipping reflections to their true subsurface positions, then applied topographic correction at $0.09 \mathrm{~m} \mathrm{~ns}^{-1}$. A prior multi-offset reflection tomography GPR survey found $0.09 \mathrm{~m} \mathrm{~ns}^{-1}$ to be the average velocity for the MSH pyroclastic deposits [Gase, Bradford, and Brand 2015].

\subsection{Radargram Descriptions and Interpretations}

\subsubsection{Description Strategy}

I select six key radargrams for their relevance to PDC erosion (Figures 3.2, 3.3, 3.4). Unmarked radargrams and radargrams from several other lines that further support our interpretations are available in the supplementary material. Reflections are described by their amplitude (i.e., faint or coherent) and geometry (i.e., continuity, shape, relation to adjacent reflections). Areas of geometrically similar reflectivity are referred to as units. Horizons are referred to as the boundaries of broad areas of similar reflectivity (i.e., units boundaries). In the case that these boundaries result from a geologic boundary (i.e., flow-unit boundary) or hydrologic boundary (i.e., water-table), a horizon can be a laterally continuous reflection. Horizons are described in stratigraphic order across the entire dataset (WT for water-table and H1-H5 for lithologic horizons). WT is a strong, laterally continuous reflection that corresponds to the depth of standing water in adjacent streams. Truncation surfaces are segments of horizons that terminate lower reflections. Regionally continuous truncation surfaces traced between radargrams are named by superposition (T1-T5), followed by a lowercase letter corresponding to proximity the vent ( $a$ is most proximal). 


\subsubsection{N Channel}

To validate the GPR data, we compare the reflectivity of Line 1 with outcrop AD-3 (Figure 3.2a). The adjacent stream bed is $\sim 35 \mathrm{~m}$ below the top of the outcrop. Reflections in Line 1 are above the water-table and include three horizons that correlate with stratigraphic features in outcrop. The depth and morphology of H1 corresponds to the flow Unit I-II contact in outcrop AD-3 (Figure 3.2a). Above, H2.5 begins to the south at $\sim 1012 \mathrm{~m}$ elevation, dips northward at $6^{\circ}$, truncates $\sim 13$ m of lower reflections (T4c), and eventually converges with $\mathrm{H} 1$ mid-line. H3, at $~ 3$ $\mathrm{m}$ depth to the south, separates lower reflections that are concordant to T4c from near-surface horizontal reflections. To the north, a second truncation surface (T5) terminates Unit III reflections along H3 with relief of $12 \mathrm{~m}$. The wedge of concordant reflections bounded by $\mathrm{H} 2.5$ and $\mathrm{H} 3$ is morphologically consistent with the dipping and diffuse-stratification of Unit III. Horizontal reflections above H3 correspond to Unit IV. Weak mid-line Unit III reflectivity likely results from scattering by lithic breccias. Our comparison of Line 1 to the exposure demonstrates that GPR can adequately image the scour-and-fill feature in AD-3 and flow-unit contacts.

Line 5 is $\sim 350 \mathrm{~m}$ east of outcrop AD-3 (Figures 3.1c and 3.2c). Unlike the other lines described herein, Line 5 data were gained with AGC to suppress noise spikes relative to returns from geologic contacts. Water observed in a $7 \mathrm{~m}$ deep phreatic crater $50 \mathrm{~m}$ to the east (Figure 3.1c) corroborates WT at $1020 \mathrm{~m}$ elevation. Reflections below WT are not accurately interpretable for elevation. At the southern end, H2.5 descends northward at horizontal distance $150 \mathrm{~m}$, truncates $\mathrm{H} 2$, and continues to truncate lower reflections at $7^{\circ}$ dip for at least $12 \mathrm{~m}$ elevation between horizontal distances 200-300 m (T4b). H2.5 is not visible beneath WT between horizontal 
distances 300-400 m. A reflection below WT that appears beyond horizontal position 400 m suggests that H2.5 flattens. Along T4b, H2.5 separates lower, discontinuous and sub-parallel reflections from upper, irregular reflections.

Line 6 is east of and slightly oblique to Line 5 (Figure 3.3a). At the north-northeast end of the line, WT is located $\sim 5 \mathrm{~m}$ higher than in Line 5 (Figure 3.2c). Above WT, the amplitudes of south-dipping reflections increase across H1, which separates Units I and II. H2.5 extends southward to a truncation surface (T4a) that cuts $10 \mathrm{~m}$ of lower reflections at $5.1^{\circ}$ dip.

Neither Lines 4 nor 7 (Figure 3.3a and 3.3c) contain truncation surfaces that trace to T4. Similarities between T4a in Line 6 (Figure 3.3b), T4b in Line 5 (Figure 3.2c), T4c in AD-3 (Figure 3.2a), and T4c in Line 1 (Figure 3.2b) in apparent dip, relief, and adjacent radar-facies suggest that they are the same scour-and-fill feature. I interpret that lower and upper units separated by H2.5 correspond to Units II and IIIb, respectively. Prior to deposition of Unit III, PDCs eroded an asymmetrical channel at least $\sim 0.5 \mathrm{~km}$ long that initiated between Lines 6 and 7 . This channel ( $\mathrm{N}$ Channel) begins with a northwest trajectory and turns to the west, widens and deepens down-flow. The most abrupt increase in erosion occurred between Lines 6 and 7, where the truncation depth jumps from 0 to $10 \mathrm{~m}$. Erosion depth increases by $3 \mathrm{~m}$ between Lines 1 and 6 .

\subsubsection{S Channel}

I collected Line 3 alongside outcrop AD-2b (Figure 3.4) to trace stratigraphy from exposure to Lines 4, 6, and 7 (Figure 3.3). The adjacent stream is between 15-30 m below the top of the outcrop. Lahars eroded channels at the southern half of outcrop AD-2b [Brand et al., 2014]. The Unit II-III contact dips $\sim 5^{\circ}$ to the south, where Unit 
III is thickest $(\sim 10 \mathrm{~m})$. Unit III is diffusely stratified and separated into sub-flow units (Unit IIIa and Unit IIIb) by a repeated unit-contact. A thin lens of Unit IV mantles Unit IIIb.

In Line 3, WT follows the elevation of the adjacent stream (Figure 3.4b). The unit bounded by WT and H2 corresponds to Unit II in outcrop AD-2b (Figure 3.4a). At horizontal position $\sim 325 \mathrm{~m}$, lower reflections are truncated by a south-dipping portion of $\mathrm{H} 2(\mathrm{~T} 2 \mathrm{~d})$. At horizontal position $\sim 350 \mathrm{~m}, \mathrm{H} 2.5$ shallowly dips to the south, truncating Unit IIIa reflections (T3d). Chaotic, high-amplitude reflections at horizontal positions 400-600 m correlate with the lahar deposits and truncate both H2 and H2.5. H3 corresponds to Unit IV (Figure 3.4a).

Lines 4, 6, and 7 (Figure 3.3) are described simultaneously, making use of line crossings to correlate horizons from outcrop AD-2b and Line 3 (orange vertical lines in Figures 3.3 and 3.4). WT dips slightly to the north in Lines 4 and 6 (Figures 3.3a and 3.3b), and remains flat in Line 7 (Figure 3.3c) before disappearing to the north in all three lines. In the southern ends of Lines 4 and 6 (Figures 3.3a and 3.3b), H2 truncates reflections above WT for $\sim 13 \mathrm{~m}$ at $10.5^{\circ}$ dip in Line 6 (T1b) and $\sim 10 \mathrm{~m}$ at $3.3^{\circ}$ dip in Line 4 (T1a). Near the middle of all three lines, the dip of H2 reverses southward, to $3.6^{\circ}$ in Line 7 (Figure 3.3c) and $2.7^{\circ}$ in Lines 4 and 6 (Figures 3.3a and 3.3b), intermittently truncating lower reflections (T2a,b,c). At horizontal positions $175 \mathrm{~m}$ in Line 7 (Figure 3.3c), $250 \mathrm{~m}$ in Line 6 (Figure 3.3b), and $400 \mathrm{~m}$ in Line 4 (Figure 3.3a), H2.5 dips southward and truncates lower, coherent reflections (T3a,b,c). In Line 6 (Figure 3.3b), H2.5 becomes T4a, separating Units II and IIIb and truncating H2 (T4a). Reflections immediately beneath H2 correspond to Unit II. The coherent and sub-planar reflections of the unit beneath H2.5 are attributed to Unit IIIa, as in Line 3 (Figure 3.4b).Reflections above H2.5 correspond to Unit IIIb. 
In Lines 4 and 6 (Figures 3.3a and 3.3b), H3 begins to the south at the surface and descends parallel to H2. H3 eventually flattens within the depression bounded by T1 and T2, and dips parallel to T2, meeting the ground-surface to the north. In Line 7 (Figure 3.3c), H3 appears to the south, ascending from $1040 \mathrm{~m}$ elevation. Reflections immediately above H3 correspond to Unit IV in outcrop AD-2b and Line 3. H4 marks an upward transition from high to low amplitude reflections that roughly parallels the ground surface. I interpret $\mathrm{H} 4$ as the Unit IV-V contact from the mapped surface of Unit V, a $\sim 2-3 \mathrm{~m}$ thick pumice lobe deposit that mantles Unit IV (Figure 3.1b).

I interpret $\mathrm{T} 1$ and $\mathrm{T} 2$ as the boundaries of a second, unexposed channel complex (hereafter called S Channel), formed by multiple phases of erosion and deposition. The west-striking truncation boundaries show that Line 6 is closest to a $\mathrm{S}$ Channel cross-section (Figure 3.1c). Deep truncation of Unit II reflections by H2 suggests that the current responsible for deposition of Unit IIIa first eroded into Unit II, then deposited, resulting in the scour-and-fill. From superposition along H2.5 and

the repeated Unit III subunits between erosion of S Channel and N Channel, we interpret that $\mathrm{S}$ Channel formed prior to $\mathrm{N}$ Channel. The event that eroded $\mathrm{N}$ Channel coincides stratigraphically with erosion along T3 within S Channel. H2.5, H3, and H4 mimic the pooled morphology of H2, and Units IV and V are contained within the area of S Channel, suggesting that PDCs flowed through S Channel and were partially confined.

\subsection{Discussion}

Climactic PDCs from the 18 May 1980 eruption of MSH eroded two scour-and-fill features north-westward across the central pumice plain. The currents responsible 
for eroding the channels deposited part of their mass within the channels as Units IIIa and IIIb in S Channel and Unit IIIb in N Channel. The PDC scour-and-fill features are larger than any previously reported. N Channel is $\sim 12 \mathrm{~m}$ deep, $>200$ $\mathrm{m}$ wide, and at least $500 \mathrm{~m}$ long. The larger, S Channel is $\sim 15 \mathrm{~m}$ deep, $\sim 400 \mathrm{~m}$ wide, and at least $500 \mathrm{~m}$ long. From Line 6, the eroded cross-sectional area of $\mathrm{S}$ Channel is $\sim 3200 \mathrm{~m}^{2}$. If this area is extended over a half kilometer as the strike lines of S Channel suggest (Figure 3.1c), the total eroded volume is $\sim 1,600,000 \mathrm{~m}^{3}$. This volume is a small although significant percentage $(\sim 1.3 \%)$ of the total estimated volume of column-collapse PDCs deposited on 18 May 1980 (i.e., $~ 0.12 \mathrm{~km}^{3}$ ) [Rowley et al., 1981].

Evidence for substrate erosion is recognized in many PDC deposits, yet the causes and consequences of erosion are among the least understood aspects of PDC dynamics [e.g., Dufek, 2016]. Examples of erosion in PDC deposits include amalgamation and shear-mixing along flow-unit contacts [e.g., Branney and Kokelaar, 2002], identification of accidental components within PDC deposits entrained from up-flow exposures [e.g., Buesch, 1992; Calder et al., 2000; Bernard et al., 2014; Brand et al., 2016; Pollock et al., 2016; Roche et al., 2016], reduced thickness of tephra-fall deposits underlying PDC deposits [Scarpati and Perrotta, 2012], and channel-like scours carved into the substrate [e.g., Fisher, 1977; Kieffer and Sturtevant, 1988; Sparks et al., 1997; Cole et al., 1998; Brown and Branney, 2004; Brand and Clarke, 2009; Brand et al., 2014]. Fluidized and dry granular flow experiments demonstrate that erosion can be aided by vertical pore-pressure gradients [Roche et al., 2013] and/or by shear at the flow base [Rowley et al., 2011]. Field observations suggest erosive capacity is also affected by topographic conditions that increase shear or collisional stresses including: (1) propagation on steep slopes close to the substrate's angle of repose $\left(>25^{\circ}\right)$ [Cole 
et al., 1998; Bernard et al., 2014, Brand et al., 2016], (2) transitions from high to low slope [Scarpati and Perrotta, 2012], (3) irregular topography, such as debris avalanche hummocks [Pollock et al., 2016], or (4) channelized terrains, such as gullies along the flanks of volcanoes [Sparks et al., 1997; Cole et al., 1998].

No radargrams or outcrops show evidence of pre-PDC irregular topography (i.e., buried debris avalanche hummocks or bedrock) that could channelize or disrupt PDCs to initiate erosion of the channels. Scouring of both S and N Channels begin where PDCs turned from northward to northwestward and where the slope began to increase from $5^{\circ}$ to $\sim 12-15^{\circ}$ for $\mathrm{N}$ Channel and $\sim 10-15^{\circ}$ for $\mathrm{S}$ Channel. The increase from shallow to moderate slope may have influenced the location and initiation of erosion. Both channels are asymmetric, unexpectedly displaying greater erosional relief on their southern boundaries. This asymmetry implies that (1) the PDCs propagated oblique to the topographic gradient and were partially confined by the northwest facing slope, (2) more complete erosion occurred at the northern boundary, or (3) that flows began turning north at the location of our survey.

Erosion may be aided by the air retention of the substrate. Brand et al. [2014] provide evidence for the retention of gas between pore spaces after the PDCs came to rest, including: (1) soft sediment deformation due to loading of lithic blocks over finer-grained deposits; (2) a high proportion of fines in the deposits, which would have reduced deposit permeability and gas escape, (3) lack of distinct, well-developed grain fabric (typical of granular flow), even in the distal regions, suggesting interstitial gas buffered particle-particle interactions at the time of deposition, and (4) numerous secondary PDCs, which occurred along slopes of $\sim 5-6^{\circ}$ [Kuntz et al., 1990], reflecting high pore-pressure within the primary PDC deposits. Experimental studies of fluidized granular flows demonstrate that the head of a flow generates under-pressure 
that can be responsible for erosion via an upward pressure gradient [e.g., Roche, 2012; Roche et al., 2013]. Elevated pore-pressure in the substrate could increase erosion by strengthening the upward pressure gradient at the base of the PDCs. I suspect that an aerated substrate is also more susceptible to erosion via shear due to decreased friction between grains, thereby allowing substrate erosion on relatively shallow slopes $\left(\sim 5-15^{\circ}\right)$

It is also possible that the currents' internal conditions promoted erosion. Erosion occurs through the combined effects of basal stress imparted by the PDC that acts to mobilize the substrate, and the weak mechanical resistance of an unconsolidated and aerated substrate at a moderate slope angle $\left(5-15^{\circ}\right)$. The state of the PDCs (i.e., flow regime, velocity, concentration) is influenced by conditions at the vent, within the eruption column, and along the path of transport. Pulses of increased flux at the vent could produce PDCs with greater erosive capacity that coincide with flow-unit contacts. All truncation horizons discussed herein occur immediately before deposition of climactic flow-units. Thus, it is likely that the currents responsible for eroding $\mathrm{S}$ and $\mathrm{N}$ channels were more energetic than PDCs produced earlier in the eruption.

Our findings demonstrate that during sustained, waxing and waning eruptions that produce PDCs for several hours, cycles of deposition and erosion by PDCs modify the terrain encountered by subsequent flows [e.g., Cole et al., 1998]. The erosional process may be similar to seafloor erosion by turbidity currents that produces extensive submarine channels off continental shelves. Turbidity currents self-channelize either by lateral deposition of levees that constrict flows and promote downstream scouring [de Leeuw et al., 2016], or from broad scours that elongate and deepen through repeated passage of turbidity currents [Fildani et al., 2013]. The channels 
reported herein are morphologically similar to the incipient scours or broad megaflutes excavated from a single to few erosive flows [e.g., Elliott, 2000; Fildani et al., 2013], rather than the mature, sinuous, 100s of kilometers long and 100s of meters deep submarine canyons produced by numerous flows over many years [c.f., Clark and Pickering, 1996].

Turbidity currents with thicknesses between 1.3-5 times the channel depth are considered quasi-channelized, in which the fast-moving basal portion of the current is channelized while the overlying unconfined middle to top portion of the current is unconfined [Morhig and Buttles, 2007]. Lateral spreading is suppressed in quasichannelized currents, thereby preserving an axial zone of high flow energy. In our study, increased thicknesses of Units IIIa and IIIb within the channel axes suggest partial channelization of the PDCs responsible for their deposition. Repeated erosion and deposition of Unit III within the S channel boundary further demonstrates that the current responsible for eroding a channel can also deposit part of its mass within the channel. Units IV and V are contained within S Channel, suggesting a transition from quasi-channelization of PDCs that deposited Unit IIIB, to more complete channelization of the PDCs responsible for Units IV and V as the volume of the PDCs waned and the channel filled. Thus, our evidence suggests that the dimensions of the scours were sufficient to partially-channelize subsequent PDCs.

It is not possible to determine the effects of erosional self-channelization on the velocity and run-out distance of PDCs from our data. However, the combination of field, numerical, and experimental results provide insight into the influence of self-channelization on velocity and runout-distance. Brand et al. [2014] note an increase in the size and concentration of accidental blocks within $\mathrm{N}$ Channel relative to outside N Channel, suggesting increased carrying capacity in partially channelized 
flows. Simulations of PDCs propagating down slopes show that flows confined to sinuous or straight channels have increased flow velocity and run-out distance relative to the same flow conditions propagating across a smooth slope [Dufek, 2016]. Dynamically scaled turbidity current experiments reveal increased longitudinal flow velocities along the axis of confined flows, even in particularly shallow channels [de Leeuw et al., 2016]. Based on these previous works, we hypothesize that erosionally self-channelized PDCs exhibit increased flow runout distance and/or longitudinal velocity.

\subsection{Conclusion}

GPR imaging at MSH reveals the largest PDC scour-and-fill features reported to date, suggesting that concentrated, sustained PDCs are capable of erosional selfchannelization. The channels discovered herein demonstrate that (1) PDCs from eruptions sustained for several hours can produce large scours that alter topography and channelize subsequent flows in a manner analogous to incipient channels in submarine turbidity currents, and (2) a moderate topographic gradient, substrate properties, such as partial fluidization of fresh PDC deposits, and energetic pulses may facilitate substrate erosion. However, which variables have primary controls on erosion and the influence of self-channelization on flow mobility and run-out distance remain unclear. Future experimental and modeling efforts that investigate the causes and effects of erosional self-channelization would improve our understanding of volcanic hazards. 


\subsection{Supplementary Lines}

\subsubsection{Line 2}

Line 2 (Figure 3.5a) is oriented south to west, parallel to outcrop AD-2a (Figure 3.5b) and a talus slope to the north (Figure 3.5c). A large debris avalanche hummock, composed of pulverized and hydrothermally altered material from the pre-eruption norther edifice, is exposed at the south end of the outcrop (Figure 3.5b). A sharp-tomixed contact separates the debris avalanche hummock from PDC deposits attributed to Units III and IV [Brand et al., 2014]. Flow direction is considered a mixture of west

and north. Pollock et al. [2016] show that lithics within the PDC deposits originate from both the vent and from the debris avalanche hummock. A talus slope (Figure 3.5c) conceals stratigraphy immediately to the north of outcrop AD-2a and along the inferred trajectory of S Channel (Figure 3.1c).

Line 2 shows the reflective character of a debris avalanche deposit and reveals nature of strata hidden by the talus slope (Figure 3.5c). Line 2 is described with five horizons. Deep reflectivity at the southern end of the line is faint, suggesting signal attenuation or a lack of reflective boundaries. Above, H1, an undulating reflection which descends to the north matches the position of the contact between the debris avalanche hummock and PDC deposits (Figure 3.5b). A deep, faint second horizon at the far north end of Line 2 corresponds to the depth of the Unit I-II contact $(\mathrm{H} 1)$ in Line 1 (Figure Figure 3.5b). Reflections above $\mathrm{H} 1$ at mid-line are relatively low frequency and sub-planar, as is seen Unit II in Line 1. H2 is flat lying and separates the basal unit of low frequency reflections from higher frequency, irregular unit. At midline, H2.5 truncates lower reflections (T1d) and conforms to H2, separating lower wavy and coherent reflections from upper chaotic and faint reflections. H2.5 eventually 
diverges from H2 150 m to the north of the T1d. The two units separated by H2.5

correspond stratigraphically to Units IIIa and IIIb, as seen in Line 3. Therefore, T1d is a westward extension of S Channel, where after deposition of Unit IIIa, PDCs continued to erode beyond the initial scour at the Unit II-IIIa contact (Figure 3.1c). Finally, H3 separates lower, chaotic reflections from wavy reflections that extend across the majority of the line. These shallow, wavy reflections are attributed to Unit $\mathrm{IV}$, given the unit's corresponding position in outcrop AD-2a.

\subsubsection{Line 8}

Line 8 is oriented southeast to northwest and crosses Line 7 (Figure 3.6). At the northwest end, WT is relatively flat and isolated among incoherent reflections. H1 dips southward, 10 $\mathrm{m}$ above WT, and marks a transition from incoherent to wavy and sub-planar reflections. H2 marks a transition from high-amplitude to low amplitude reflectivity with increasing elevation between horizontal positions $\sim 550 \mathrm{~m}$ and $650 \mathrm{~m}$. Along H2.5, between horizontal positions of $\sim 200 \mathrm{~m}$ and $400 \mathrm{~m}$, reflectivity transitions from sub-parallel to wavy and irregular. We attribute reflections immediately above H2.5 to Unit IIIb, by superposition. Higher amplitude reflections in the very near surface between horizontal positions of $400 \mathrm{~m}$ and $800 \mathrm{~m}$ mantle reflections immediately above H1-2.5. A similar high-amplitude reflection, H3, exists above and to the southeast of H2.5, meeting the north-dipping slope of the pumice plain in a similar nature as Unit IV in Lines 4, 6, and 7 (Figure 3.3). The unit above H3, between horizontal positions 400-800 m matches the distribution of near-surface Unit IV deposits (Figure 3.1b). Near the southeast end of the line, H3 truncates 10 $\mathrm{m}$ of lower, Unit IIIb reflections. Line 8 does not show truncation horizons within Unit III as seen in Lines 4, 6, and 7 (Figure 3.3). Assuming Unit IV PDCs propagated 
to the northwest, this suggests after the inception and evolution of S Channel, later flows continued to erode and reshape the pumice plain along the channel trajectory. H4, at the southeast end separates a sub-planar, discontinuous reflection from Unit IV reflection. These near-surface reflections match the extent of Unit $\mathrm{V}$ deposits (Figure 3.1b).

\subsubsection{Line 9}

Line 9 (Figure 3.7) was collected with goal of imaging the down-flow evolution of lithic levees exposed in outcrop D-4 [Brand et al., 2014]. H2 at $1083 \mathrm{~m}$ elevation separates deep wavy and faint reflections from sub-planar and discontinuous reflections above. The unit becomes more coherent from west to east between 200 and $300 \mathrm{~m}$, then fades to coherent and wavy reflections. H3 separates the unit of sub-planar reflections from shallow and wavy reflectivity at $1090 \mathrm{~m}$ elevation. Using the Descriptions and unit thicknesses in Brand et al. [2014], we attribute H2 to the Unit II-III contact, and H3, to the Unit III-IV contact. The radargram shows no clear evidence of lithic levees; therefore we are unable to track the lithic levees with $50 \mathrm{MHz}$ GPR. Higher frequency antennas (i.e., $100 \mathrm{MHz}$ ) or seismic tomography may more effectively image lithic breccias.

\subsection{Figures}




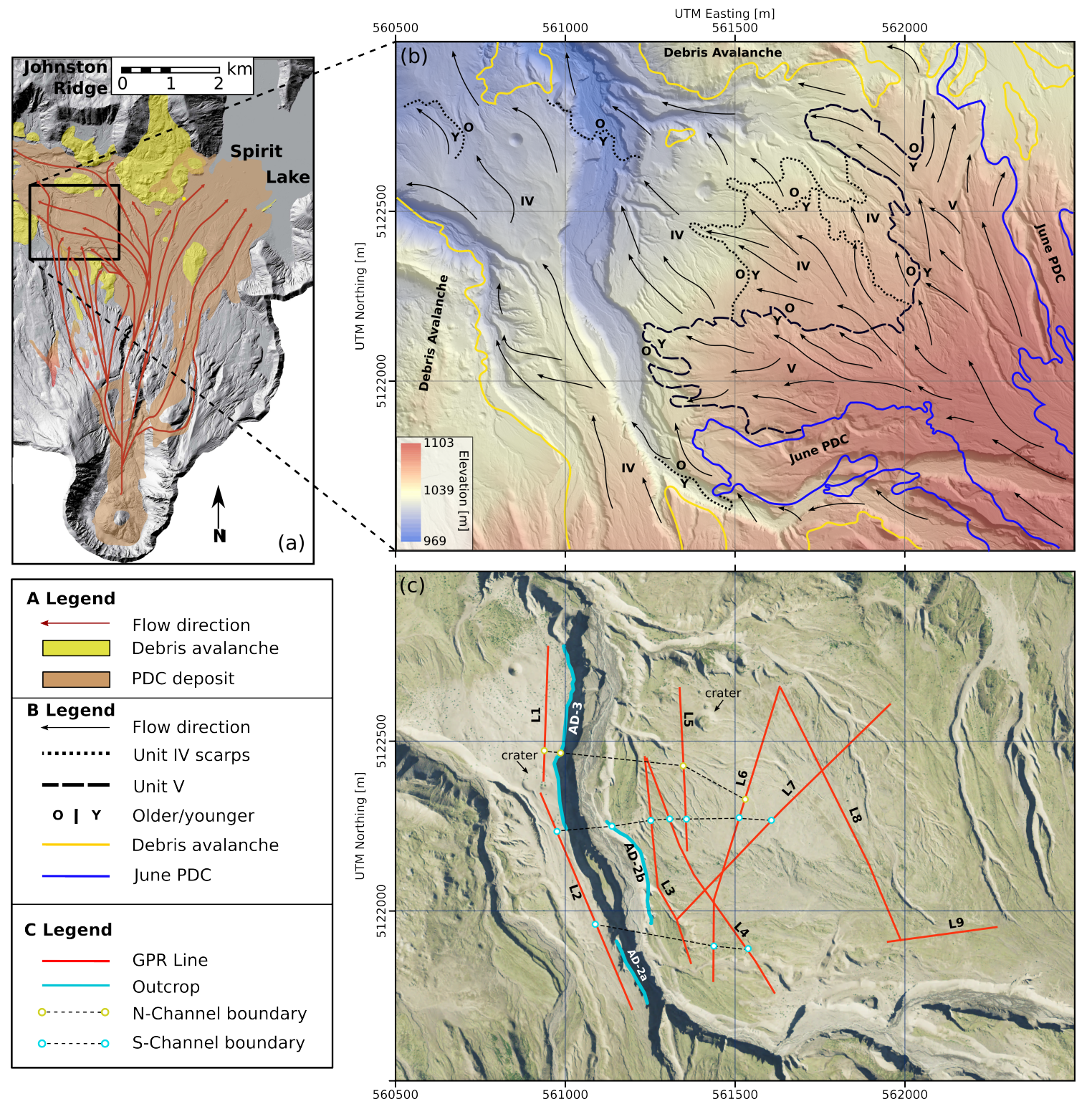

Figure 3.1: Maps of the study site show debris avalanche and PDC deposits, and the survey design. Site maps (b and c) have identical coordinates. (a) Digital elevation model of the northern slope of MSH with debris avalanche hummock locations and major PDC trajectories [Brand et al., 2014]. (b) Combined map of elevation and surficial PDC units from 1980 [Kuntz et al., 1990]. Flow directions are derived from the surface morphology; lower unit flow directions may deviate significantly. (c) Map of GPR lines, outcrops, and subsurface channel boundaries. 
(a)

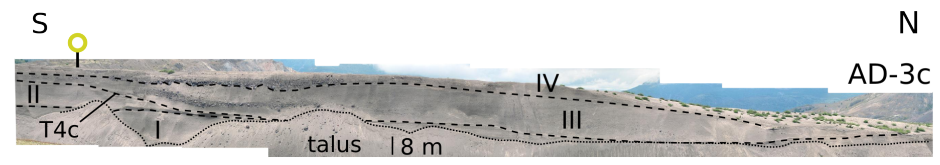

$\mathrm{N}$

$A D-3 C$

\begin{tabular}{|ccc|}
\hline$\#$ (e.g. I,II) & Flow-unit \\
\hline- & - & Flow-unit horizon \\
\hline$\cdots \cdots \cdots \cdots \cdots$ & Water-table horizon \\
\hline \multicolumn{1}{|c|}{ I } & Line crossing \\
\hline I & i & N, S Channel Boundary \\
\hline
\end{tabular}

(b)

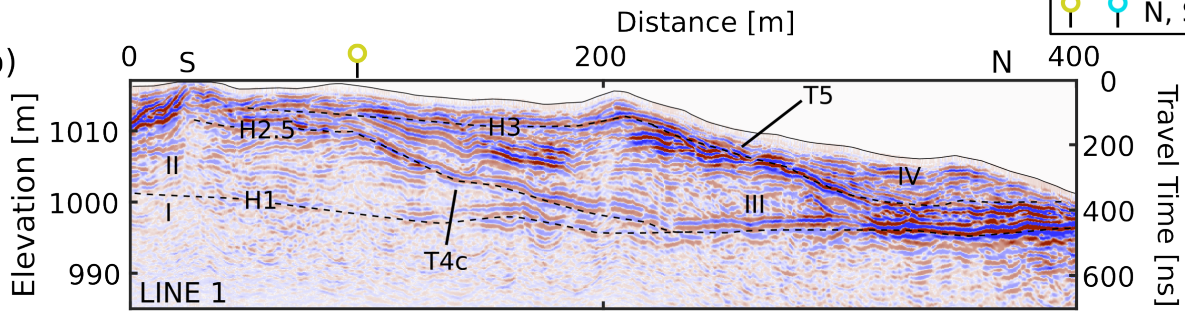

(c)

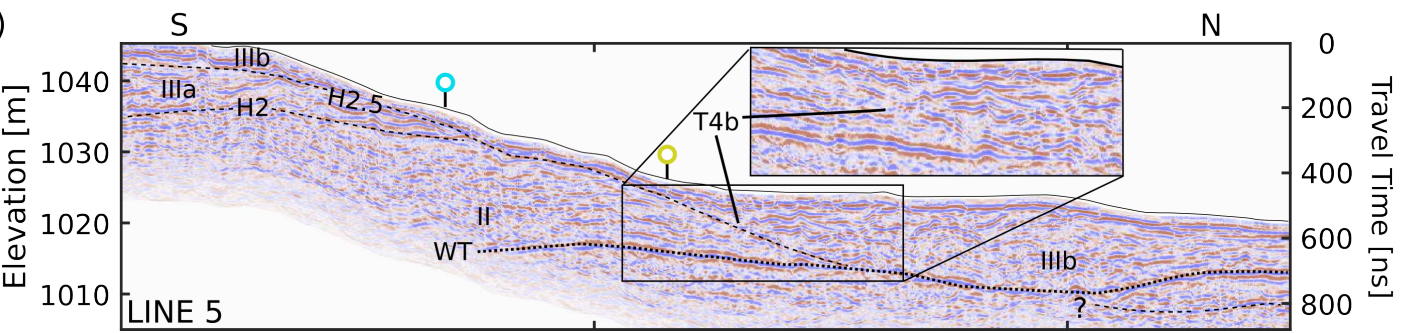

Figure 3.2: Radargram and outcrop locations are shown in Figure 3.1. Sub-sections of Figures 3.2-3.4 are generally presented in the up-flow direction, from northwest to southeast. The scour-and-fill exposed in outcrop AD-3 (a) is validated in Line 1 (b) and traced up-flow (c). Channel boundaries are defined by the locations of truncation horizons. T4 is the southern boundary of $\mathrm{N}$ Channel. (a) Photograph of outcrop AD-3, 180 m wide. (b) Radargram of Line 1. (c) Radargram of Line 5. Note 3 times vertical length exaggeration on all radargrams. 

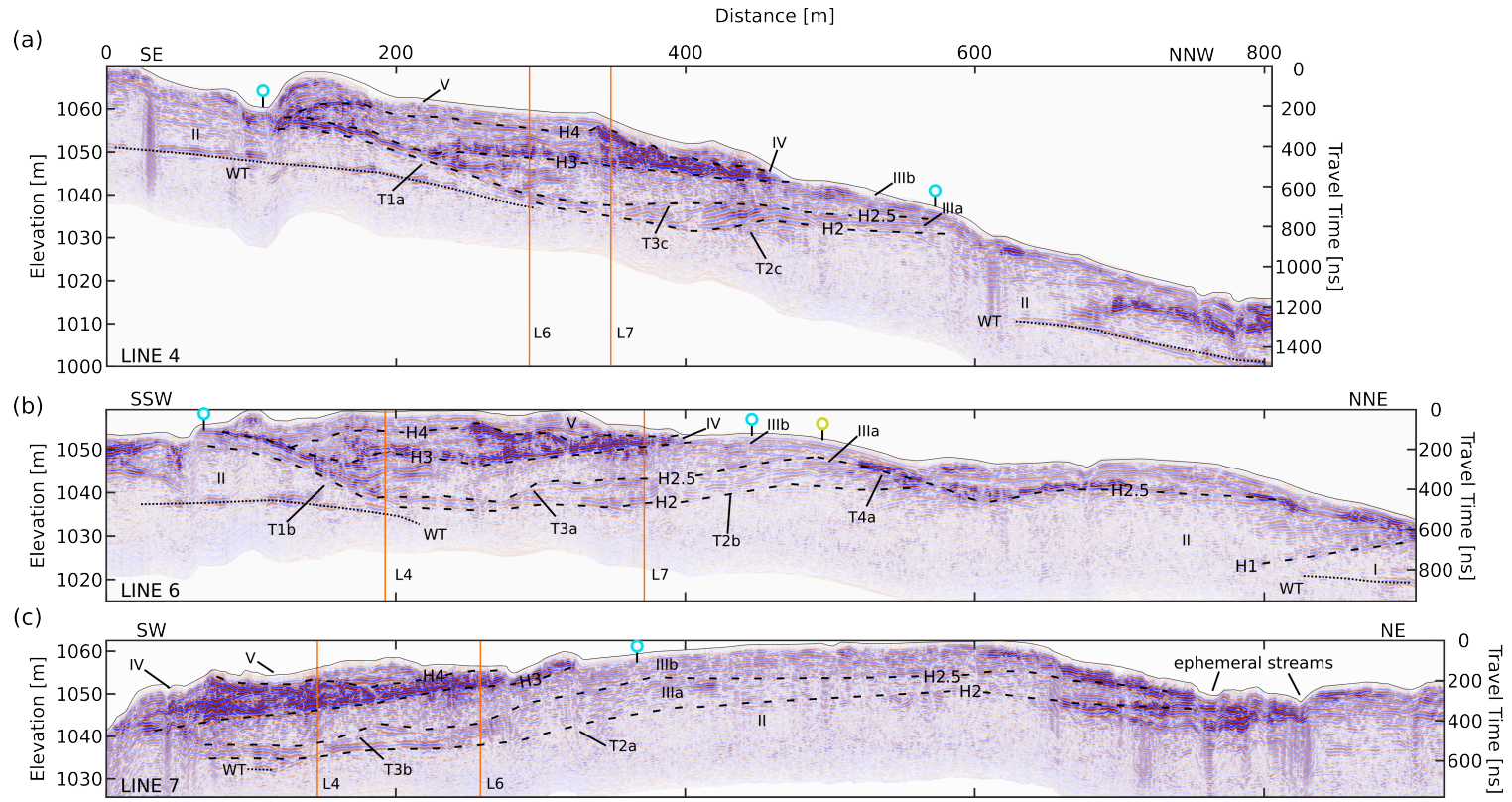

Figure 3.3: Three cross-lines show S Channel and the point of inception of $\mathrm{N}$ Channel (exposed scour-and-fill at outcrop AD-3) between Lines 6 and 7. N Channel does not appear in Lines 4 or 7. (a) Radargram of Line 4. (b) Radargram of Line 6. (c) Radargram of Line 7. Line crossings are marked by orange lines. 


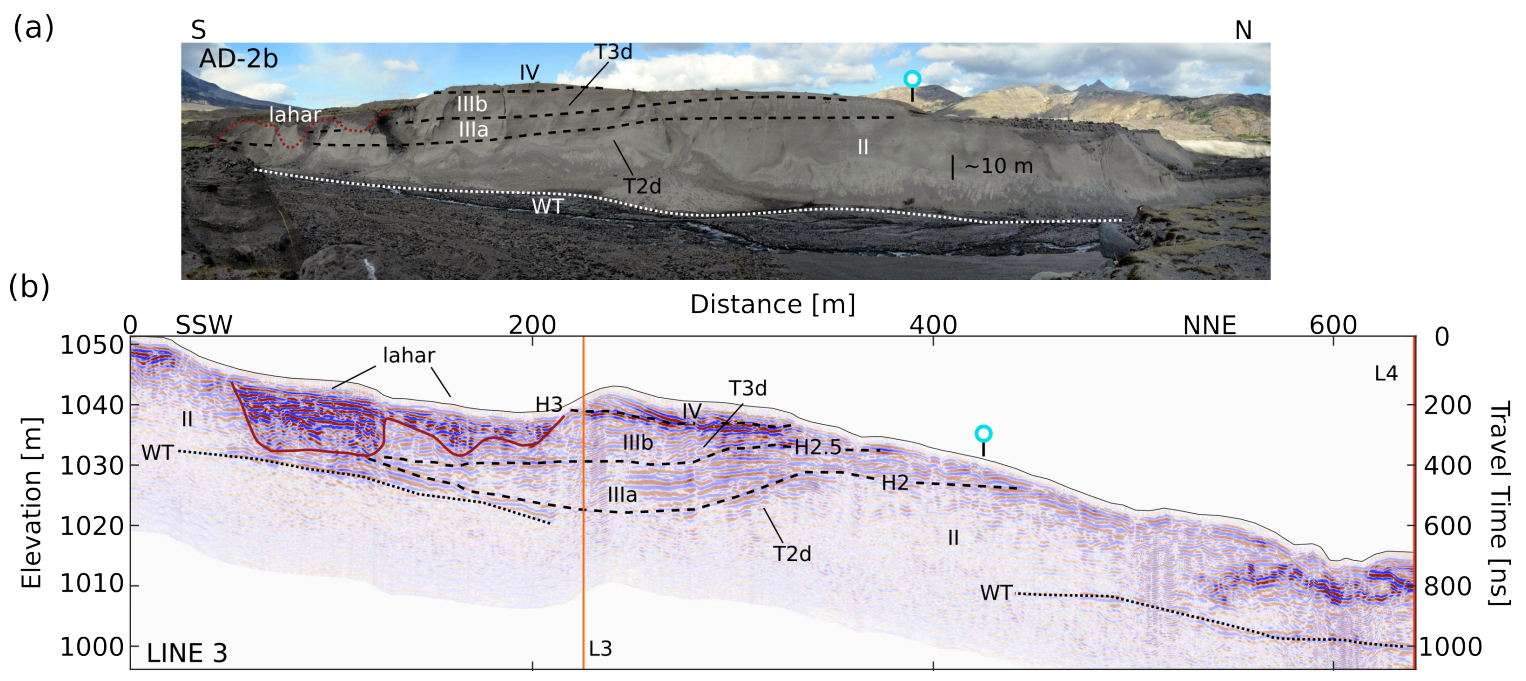

Figure 3.4: $\mathrm{S}$ Channel is exposed at outcrop AD-2b, where Line 3 is used to correlate reflectivity within Figure 3.3 to mapped stratigraphy. Lahar erosion to the south obscures the southern boundary of S Channel.(a) Panorama of outcrop AD-2b with corresponding flow units. Note that east and west directions are flipped to aid in comparison with all radargrams. (b) Radargram of Line 3.

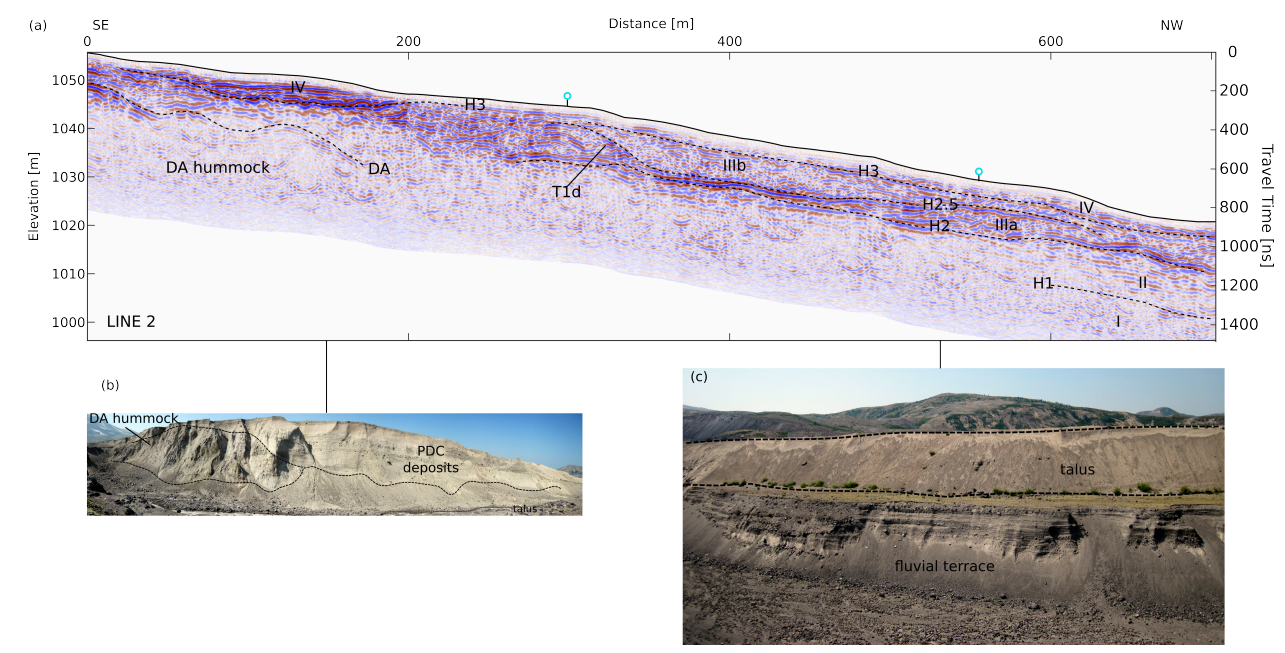

Figure 3.5: Line 2 confirms the GPR reflectivity of an exposed debris avalanche hummock and reveals scouring down-flow from S Channel. (a) Radargram of Line 2. (b) The debris avalanche hummock reflection is corroborated at outcrop AD-2a. (c) Slumping sediments prevent stratigraphic verification of the northern half of the radargram and T1c. 


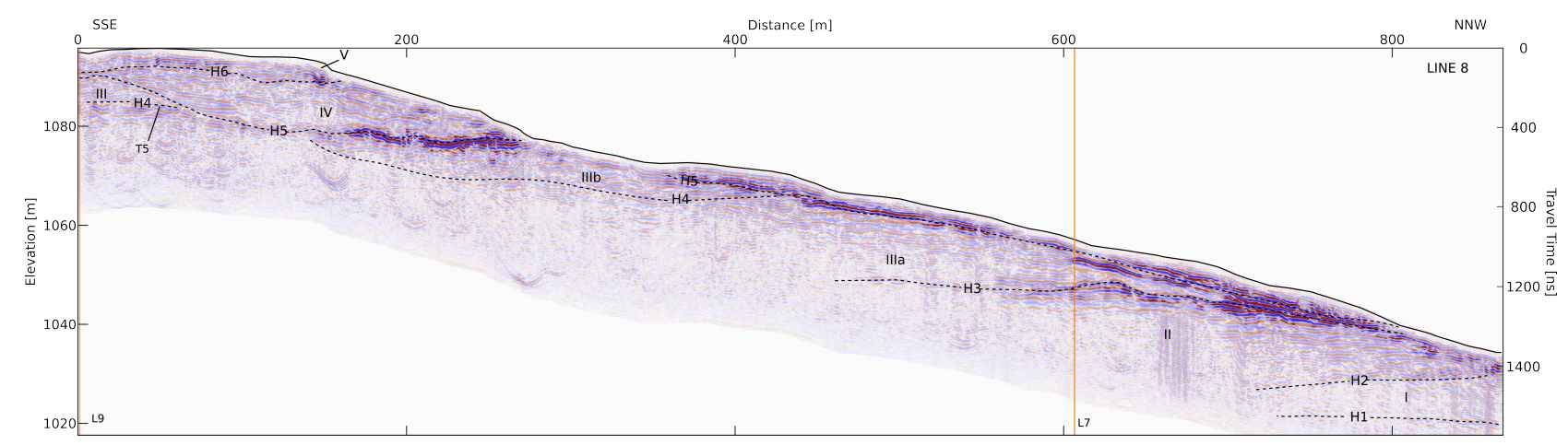

Figure 3.6: Radargram of Line 8. Note the Units II-V are exposed along the surface of the ground and truncation of Unit III by Unit IV at $60 \mathrm{~m}$ (T5) may represent scouring up-flow from $\mathrm{S}$ Channel. $\mathrm{V}: \mathrm{H}$ is $3: 1$ for all radargrams. Line 8 crosses Line 7 along the orange line.

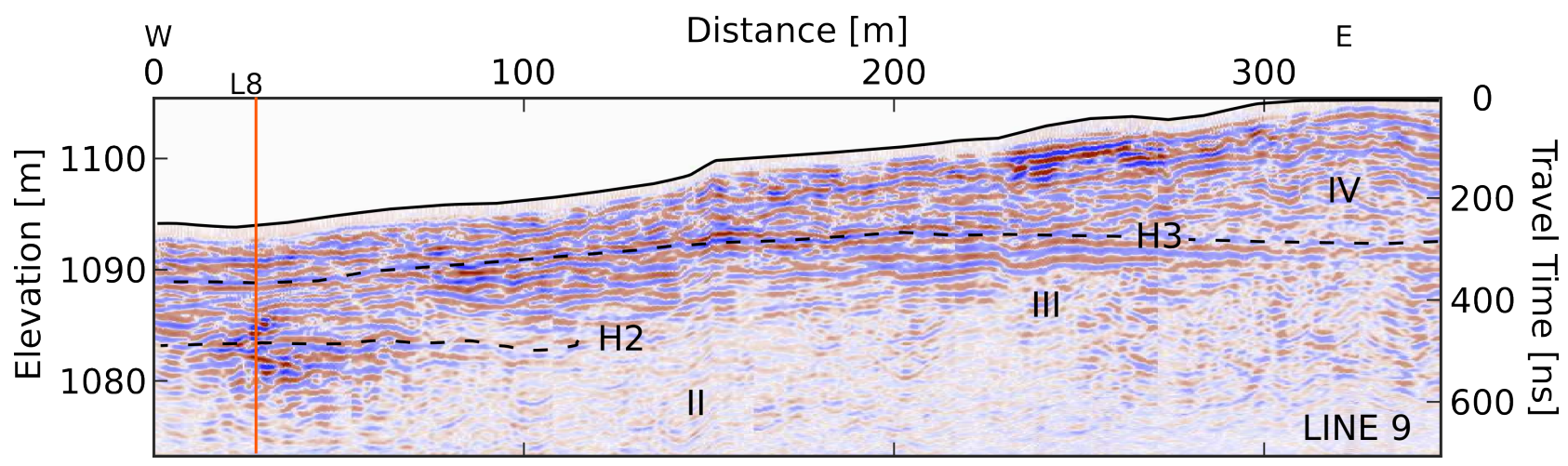

Figure 3.7: Radargram one Line 9 with cross-point to Line 8 marked in orange. Flow direction is left and slightly into the page. 
(a) S N
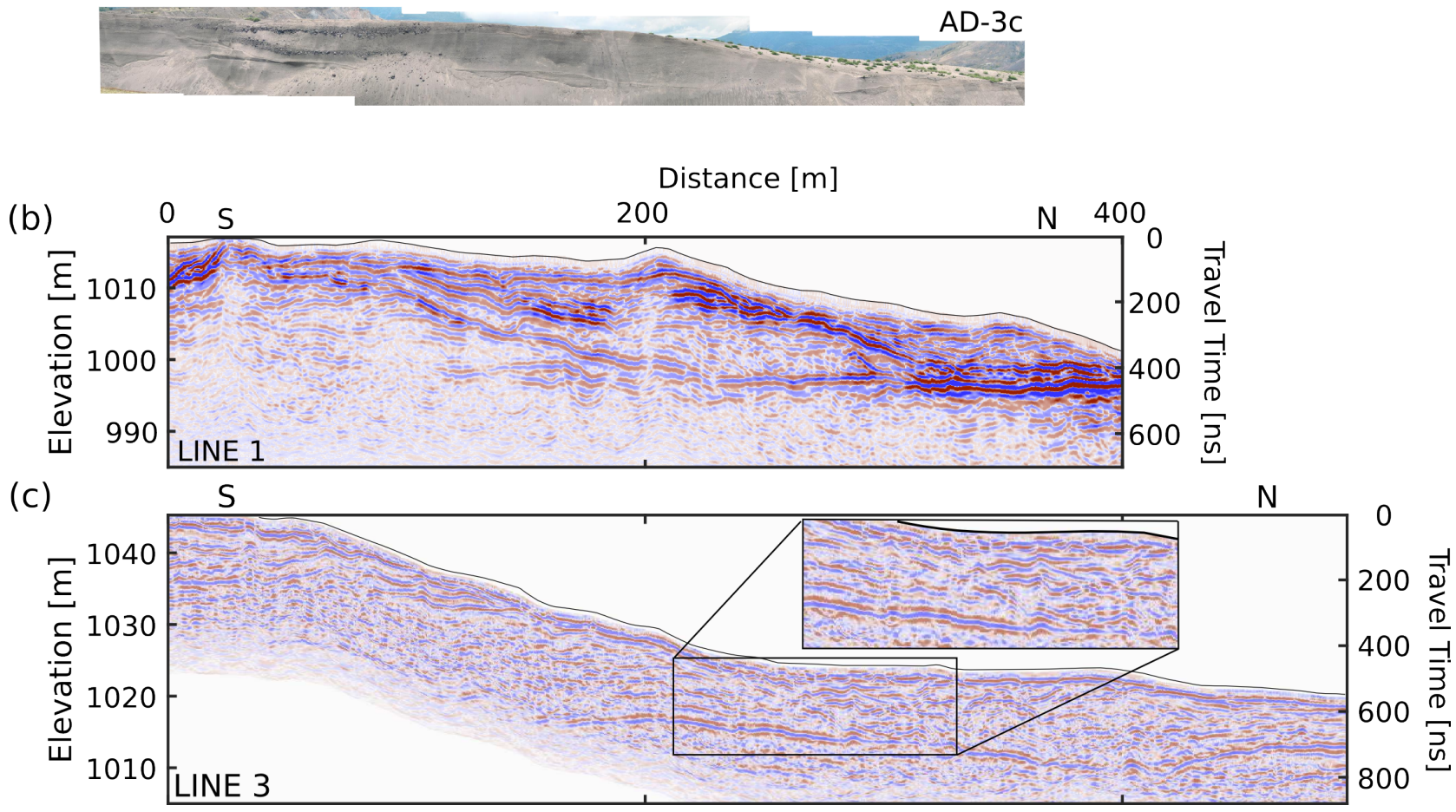

Figure 3.8: Figure 3.2 without interpretations. 


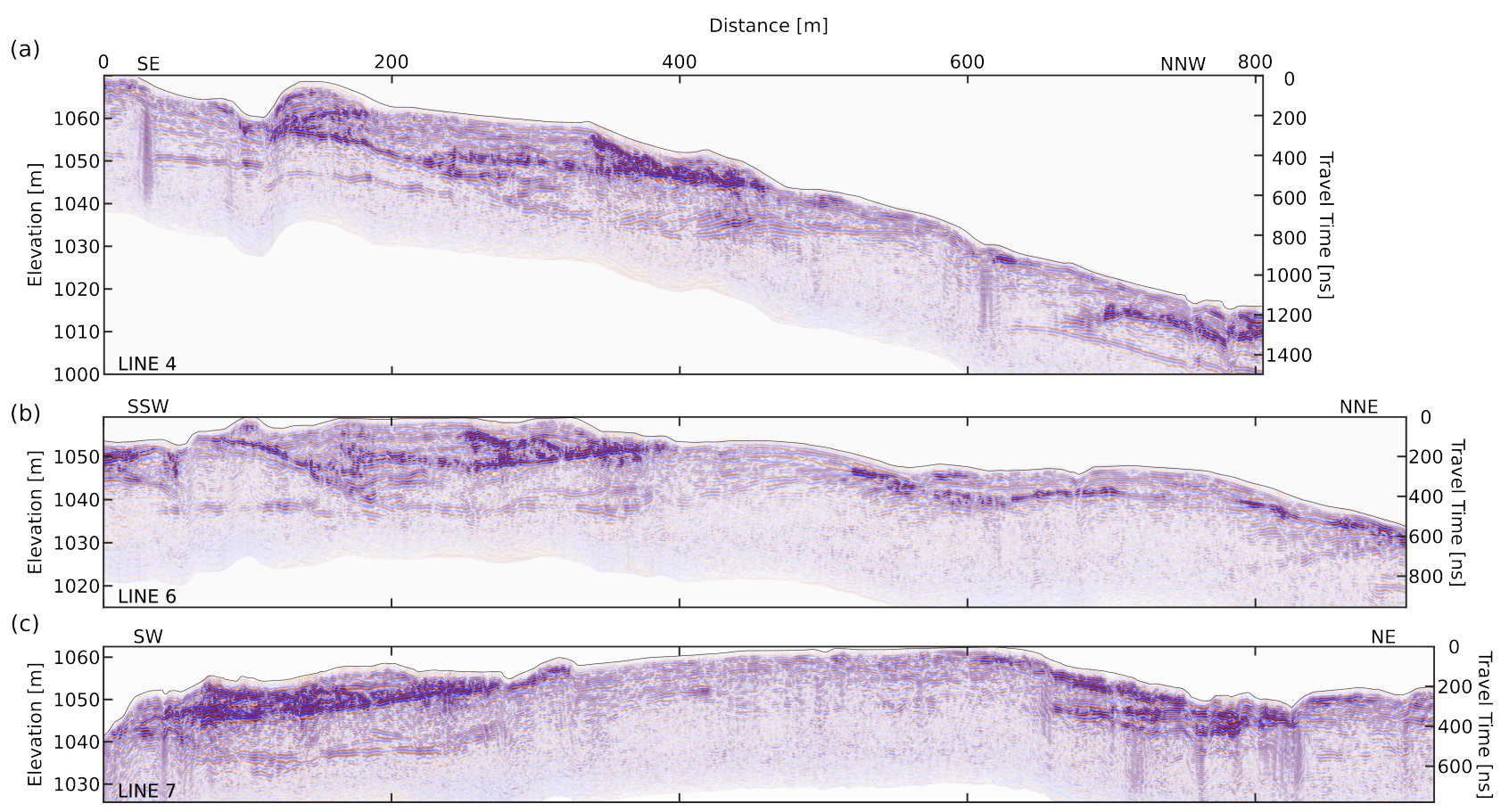

Figure 3.9: Figure 3.3 without interpretations.

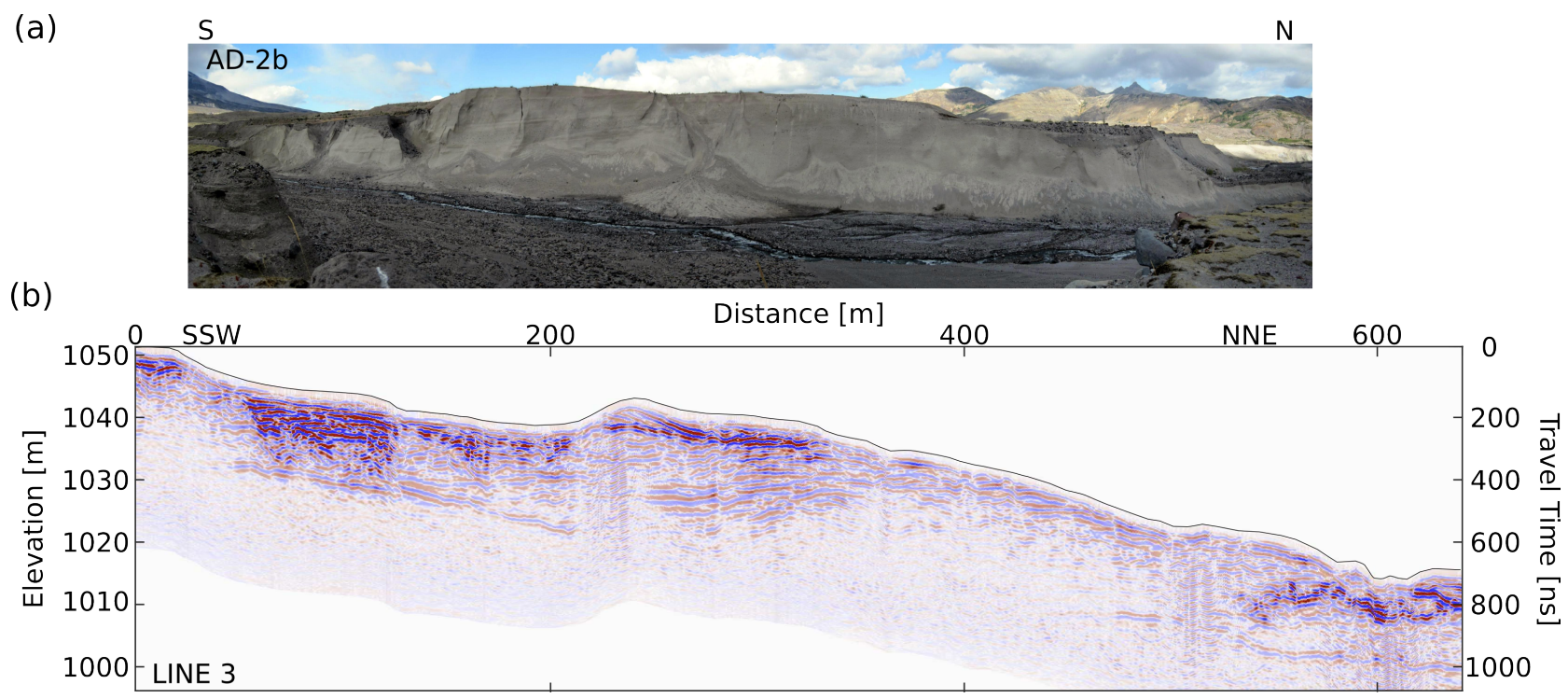

Figure 3.10: Figure 3.4 without interpretations. 


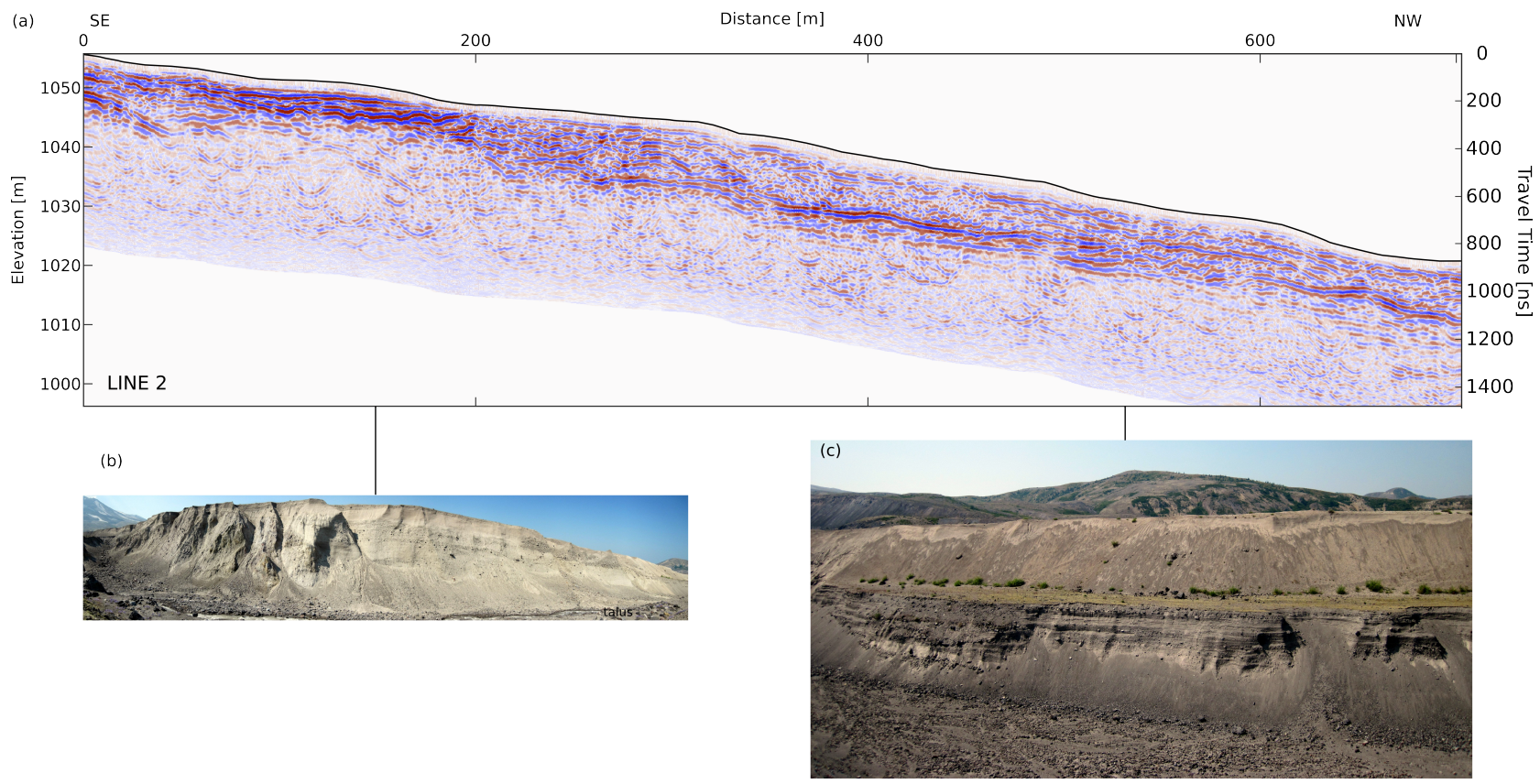

Figure 3.11: Figure 3.5 without interpretations.

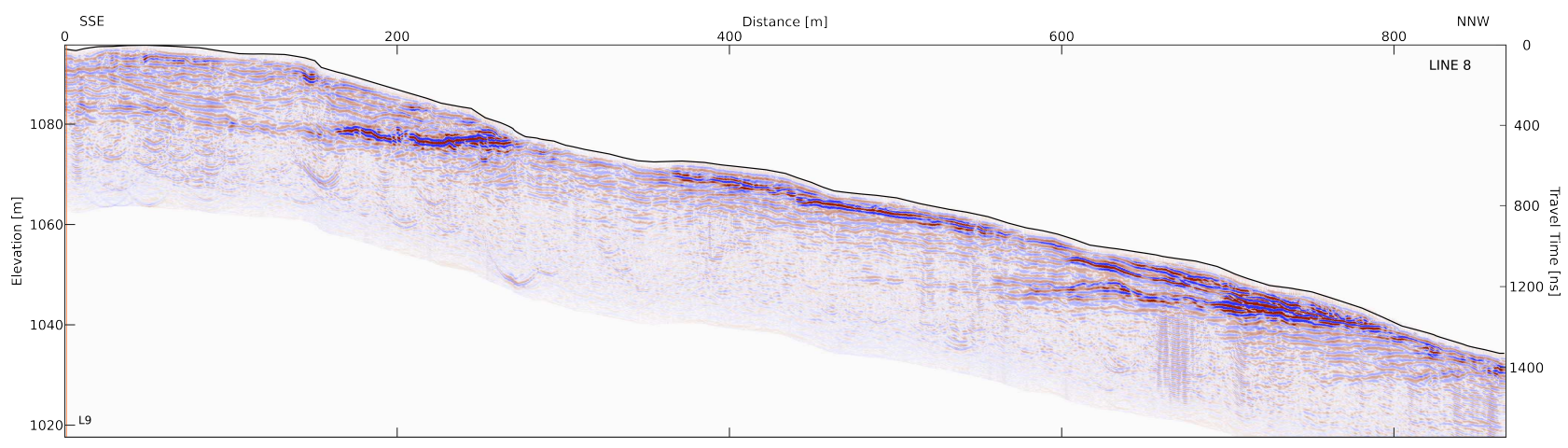

Figure 3.12: Figure 3.6 without interpretations. 


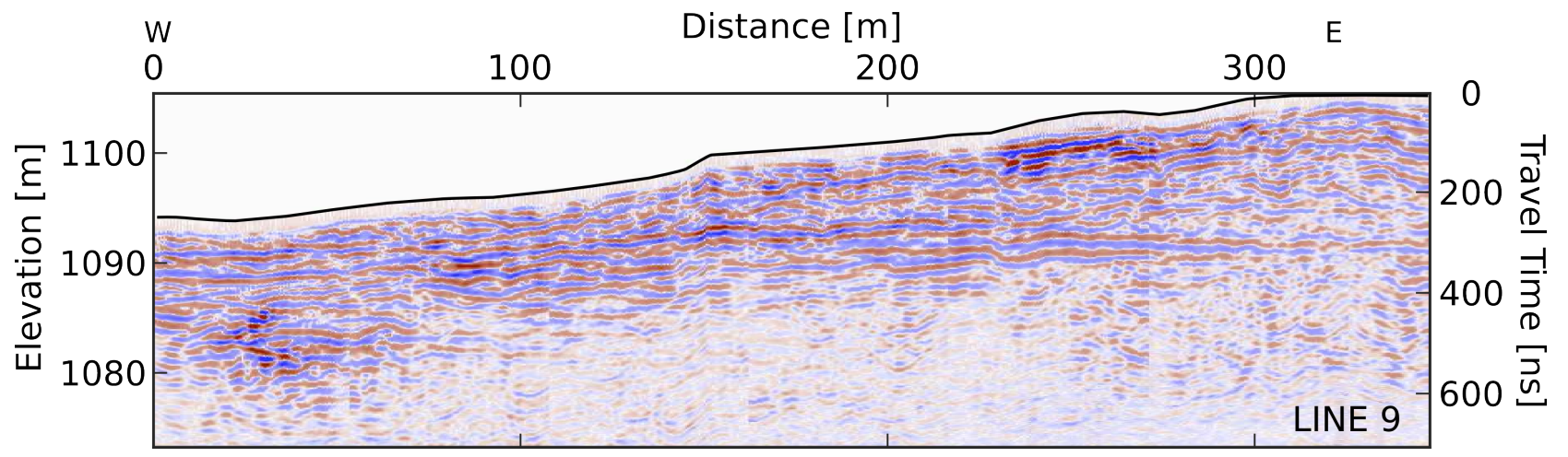

Figure 3.13: Figure 3.7 without interpretations. 


\section{CHAPTER 4}

\section{CONCLUSIONS}

This thesis demonstrates that GPR and active-source seismic imaging are robust techniques for geophysical measurement and geologic interpretation in pyroclastic deposits.

In the first study, In situ constraints on porosity and water-saturation of pyroclastic deposits from electromagnetic and seismic velocities, joint petrophysical modeling of seismic and electromagnetic velocities in unconsolidated pyroclastic deposits reveals the dependence of active seismic and GPR measurements on both two-phase porosity (vesicularity and intergranular porosity) and water-saturation. Coincident active-source seismic and GPR surveys demonstrate that seismic velocities are more predictive of porosity, whereas $V_{E M}$ relates more to volumetric water-content. Seismic velocities are increased in zones with lower porosity and relatively poor-sorting (i.e., breccias). Despite total deposit porosities between $0.72-0.83$, seismic and electromagnetic velocities of pyroclastic deposits are consistent with well-sorted beach sand or alluvial conglomerates at partial saturation. Seismic velocities in uniquely high porosity pyroclastic deposits are elevated by the high-critical porosity of pumice, which results in a rigid matrix at vesicularities $<0.8$.

In the second study, Evidence of erosional self-channelization of pyroclastic density currents revealed by ground-penetrating radar imaging at Mount St. Helens, Wash- 
ington (USA), GPR imaging of the central pumice plain at MSH reveals the largest PDC scour-and-fill features reported to date, suggesting that concentrated PDCs are capable of erosional self-channelization. These channels demonstrate that (1) large PDCs from eruptions sustained for several hours can produce large-scale scours that alter topography and channelize subsequent flows in a manner analogous to incipient channels in submarine turbidity currents, and (2) a moderate topographic gradient, substrate properties, such as partial fluidization of fresh PDC deposits, and the intrinsic state of PDCs may facilitate substrate erosion. However, it is unclear which variables have first-order controls on erosion from field studies alone. Erosional self-channelization may have significant effects on flow mobility and run-out. Thus, experimental and modeling efforts should investigate the causes and effects of erosion and self-channelization to improve our understanding of volcanic hazards.

The studies within this thesis add to the growing body of research that applies exploration geophysics to investigate volcanic problems. Chapter 2 demonstrates the comparative utilities of GPR and seismic imaging, and the petrophysical inversion provides new means to separate the effects of rock properties and effective stress from seismic and electromagnetic measurements. Our findings in Chapter 3 are new evidence for the process of erosional self-channelization in PDCs, which may significantly increase expected flow run-out distance. Future studies could investigate this process with analog experiments and numerical models to better understand the physics of self-channelization. Ultimately, these contributions improve both the methods to investigate pyroclastic deposits and our understanding of PDC dynamics. 


\section{REFERENCES}

[1] Bachrach, R., J. Dvorkin, and A. Nur (2000), Seismic velocities and Poisson's ratio of shallow unconsolidated sands, Geophysics, 65(2), 559-564, doi: 10.1190/1.1444751.

[2] Bais, G., P. Bruno, V. Di Fiore, and A. Rapolla (2003), Characterization of shallow volcanoclastic deposits by turning ray seismic tomography: an application to the Naples urban area, J. App. Geophys., 52(1), 11-21, doi: 10.1016/S09269851(02)00230-6.

[3] Barrash, W., and T. Clemo (2002), Hierarchical geostatistics and multifacies systems: Boise hydrogeophysical research site, Boise, Idaho, /textitWater Resour. Res., 38(10), 14-1-14-18, doi: 10.1029/2002WR001436.

[4] Bass, J. D. (1995), Elasticity of minerals, glasses, and melts, in Mineral Physics and Crystallography: A Handbook of Physical Constants, AGU Ref. Shelf, vol. 2, edited by T. J. Ahrens, pp. 45-63, Washington, D. C., doi: 10.1029/RF002p0045.

[5] Beard, D. C., and P. K. Weyl (1973), Influence of texture on porosity and permeability of unconsolidated sand, AAPG Bull., 572, 349-369.

[6] Beaver, C. L., A. E. Williams, E. A. Atekwana,F. M. Mewafy, G. Abdel Aal, L. D. Slater, and S. Rossbach, S. (2016), Microbial communities associated with zones of elevated magnetic susceptibility in hydrocarbon-contaminated sediments, Geomicrobiol. J., 33(5), 441-452, doi:10.1080/01490451.2015.1049676.

[7] Benage, M. C., J. Dufek, and P. A. Mothes (2016), Quantifying entrainment in pyroclastic density currents from the Tungurahua eruption, Ecuador: Integrating field proxies with numerical simulations, Geophys. Res. Lett., 43, 6932-6941, doi:10.1002/2016GL069527.

[8] Bernard, J., K. Kelfoun, J. L. Le Pennec, and S. V. Vargas (2014), Pyroclastic flow erosion and bulking processes: comparing field-based vs. modeling results at Tungurahua volcano, Ecuador, Bull. Volcanol., 76(9), 1-16, doi:10.1007/s00445014-0858-y. 
[9] Biot, M. A. (1956), Theory of propagation of elastic waves in a fluid saturated porous solid Part I: Low frequency range, J. Acoust. Soc. Am., 28, 168-178, doi: 10.1121/1.1908239.

[10] Bouvet de Maisonneuve, C., O. Bachmann, and A. Burgisser (2009), Characterization of juvenile pyroclasts from the Kos Plateau Tuff (Aegean Arc): Insights into the eruptive dynamics of a large rhyolitic eruption, Bull. Volcanol., 71(6), 643-658, doi: 10.1007/s00445-008-0250-x.

[11] Bradford, J. H. (2006), Applying reflection tomography in the postmigration domain to multifold ground-penetrating radar data, Geophysics, 71(1), K1-K8, doi: $10.1190 / 1.2159051$.

[12] Bradford, J. H. (2008), Measuring water content heterogeneity using multifold GPR with reflection tomography, Vadose Zone J., 7(1), 184-193, doi: 10.2136/vzj2006.0160.

[13] Bradford, J. H., and J. T. Harper (2005), Wave field migration as a tool for estimating spatially continuous radar velocity and water-content in glaciers, Geophys. Res. Lett., 32, 1-4, doi:10.1029/2004GL021770.

[14] Bradford, J. H., W. P. Clement, and W. Barrash (2009), Estimating porosity with groundpenetrating radar reflection tomography: A controlled 3D experiment at the Boise Hydrogeophysical Research Site, Water Resour. Res., 45, W00D26, doi: 10.1029/2008WR006960.

[15] Bradford, J. H., E. L. Babcock, H. P. Marshall, and D. F. Dickins (2015), Targeted reflection-waveform inversion of experimental ground-penetrating radar data for quantification of oil spills under sea ice, Geophysics, 81(1), WA59-WA70, doi: 10.1190/geo2015-0170.1.

[16] Brand, B. D., S. Bendaña, S. Self, and N. Pollock (2016), Topographic controls on pyroclastic density current dynamics: Insight from 18 May 1980 deposits at Mount St. Helens, Washington (USA), J. Volcanol. Geotherm. Res., 321, 1-17, doi:10.1016/j.jvolgeores.2016.04.018.

[17] Brand, B. D., and A. B. Clarke (2009), The architecture, eruptive history, and evolution of the Table Rock Complex, Oregon: from a Surtseyan to an energetic maar eruption, J. Volcanol. Geotherm. Res., 180(2), 203-224, doi:10.1016/j.jvolgeores.2008.10.011.

[18] Brand, B. D., C. Mackaman-Lofland, N. M. Pollock, S. Bendaña, B. Dawson, and P. Wichgers (2014), Dynamics of pyroclastic density currents: Conditions that promote substrate erosion and self-channelization-Mount St 
Helens, Washington (USA), J. Volcanol. Geotherm. Res., 276, 189-214, doi:10.1016/j.jvolgeores.2014.01.007.

[19] Branney, M. J., and B. P. Kokelaar (2002), Pyroclastic Density Currents and the Sedimentation of Ignimbrites, vol. 27, Geol. Soc. London, U. K.

[20] Breard, E. C., G. Lube, J. R. Jones, J. Dufek, S. J. Cronin, G. A. Valentine, and A. Moebis (2016), Coupling of turbulent and non-turbulent flow regimes within pyroclastic density currents, Nature, 9, doi:10.1038/ngeo2794.

[21] Bristow, C. S., S. D. Bailey, and N. Lancaster (2000), The sedimentary structure of linear sand dunes, Nature, 406, 56-59.

[22] Brown, R. J., and M. J. Branney (2004), Bypassing and diachronous deposition from density currents: Evidence from a giant regressive bed form in the Poris ignimbrite, Tenerife, Canary Islands, Geology, 32(5), 445-448, doi:10.1130/G20188.1.

[23] Bruno, P. P. G. (2015), High-resolution seismic imaging in complex environments: A comparison among common- reflection-surface stack, common-midpoint stack, and prestack depth migration at the Ilva-Bagnoli brownfield site, Campi Flegrei, Italy, Geophysics, 80(6), B203-B214, doi:10.1190/geo2014-0488.1.

[24] Bruno, P. P. G., and A. Castiello (2009), High resolution onshore seismic imaging of complex volcanic structures: An example from Vulcano Island, Italy, $J$. Geophys, Res., 114(B12), 1-12, doi:10.1029/2008JB005998.

[25] Buesch, D.C. (1992), Incorporation and redistribution of locally derived lithic fragments within a pyroclastic flow, Geol. Soc. Am. Bull., 104(9), 1193-1207, doi:10.1130/0016-7606.

[26] Cagnoli, B., and J. K. Russell (2000), Imaging the subsurface stratigraphy in the Ubehebe hydrovolcanic field (Death Valley, California), using ground penetrating radar, J. Volcanol. Geotherm. Res., 96, 45-56 doi:10.1016/S0377-0273(99)001420 .

[27] Cagnoli, B., and T. J. Ulrych (2001), Ground penetrating radar images of unexposed climbing dune-forms in the Ubehebe hydrovolcanic field (Death Valley, California), J. Volcanol. Geotherm. Res., 109(4), 279-298, doi:10.1016/S03770273(01)00196-2.

[28] Calder, E. S., R. S. J. Sparks, and M. C. Gardeweg (2000), Erosion, transport and segregation of pumice and lithic clasts in pyroclastic flows inferred from ignimbrite at Lascar Volcano, Chile, J. Volcanol. Geotherm. Res., 104(1-4), 201-235, doi:10.1016/S0377-0273(00)00207-9. 
[29] Cassidy, N. J., E. S. Calder, A. Pavez, and L. Wooller (2009), GPR-derived facies architectures: a new perspective on mapping pyroclastic flow deposits, in Studies in Volcanology: The Legacy of George Walker, edited by T. Thordarson, S. Self, L. G., S. K. Rowland, and A. Hoskuldsson, pp. 181-210, Special Publications of IAVCEI.

[30] Chedeville, C., and O. Roche (2015), Influence of slope angle on pore pressure generation and kinematics of pyroclastic flows: insights from laboratory experiments, Bull. Volcanol., 77(11), 1-13, doi:10.1007/s00445-015-0981-4.

[31] Clark, J. D., and K. T. Pickering (1996), Submarine Channels: Processes and Architecture, 231 pp., Vallis Press, London.

[32] Clement, W. P., M. D. Knoll, L. M. Liberty, P. R. Donaldson, P. Michaels, W. Barrash, and J. R. Pelton (1999), Geophysical surveys across the Boise Hydrogeophysical Research Site to determine geophysical parameters of a shallow, alluvial aquifer, paper presented at SAGEEP99, The Symposium on the Application of Geophysics to Engineering and Environmental Problems, Environ. and Eng. Geophys. Soc., Oakland, Calif.

[33] Cole, P. D., E. S. Calder, T. H. Druitt, R. Hoblitt, R. Robertson, R. S. J. Sparks, and S. R. Young (1998), Pyroclastic flows generated by gravitational instability of the 1996-97 lava dome of Soufriere Hills volcano, Monserrat, Geophys. Res. Lett., 25(18), 3425-3428.

[34] Courtland, L. M., S. E. Kruse, C. B. Connor, L. J. Connor, I. P. Savov, and K. T. Martin (2012), GPR investigation of tephra fallout, Cerro Negro volcano, Nicaragua: a method for constraining parameters used in tephra sedimentation models, Bull. Volcanol., 74(6), 1409-1424, doi:10.1007/s00445-012-0603-3.

[35] de Leeuw, J., J. T. Eggenhuisen, and M. J. Cartigny (2016), Morphodynamics of submarine channel inception revealed by new experimental approach, Nat. Commun., 7, 10886, doi:10.1038/ncomms10886.

[36] Dufek, J. (2016), The fluid mechanics of pyroclastic density currents, Annu. Rev. Fluid Mech., 48(1), 459-485, doi:10.1146/annurev-fluid-122414-034252.

[37] Dufek, J., J. Wexler, and M. Manga (2009), Transport capacity of pyroclastic density currents: Experiments and models of substrate-flow interaction, $J$. Geophys. Res., 114, B11203, doi:10.1029/2008JB006216.

[38] Elliott, T. (2000), Megaflute erosion surfaces and the initiation of turbidite channels, Geology, 28(2), 119-122, doi:10.1130/00917613(2000)28<119:MESATI >2.0.CO;2. 
[39] Félix, G., and N. Thomas (2004), Relation between dry granular flow regimes and morphology of deposits: formation of leves in pyroclastic deposits, Earth Planet. Sci. Lett., 221(1), 197-213, doi:10.1016/S0012-821X(04)00111-6.

[40] Fildani, A., S. M. Hubbard, J. A. Covault, K. L. Maier, B. W. Romans, M. Traer, and J. C. Rowland (2013), Erosion at inception of deep-sea channels, Mar. Pet. Geol., 41, 48-61, doi:10.1016/j.marpetgeo.2012.03.006.

[41] Fisher, R. V. (1977), Erosion by volcanic base-surge density currents: Ushaped channels, Geol. Soc. Am. Bull., 88(9), 1287-1297, doi:10.1130/00167606(1977)88<1287:EBVBDC $>2.0$. CO;2.

[42] Gase, A., J. H. Bradford, and B. D. Brand (2015), Ground-penetrating radar and active seismic investigation of stratigraphically verified pyroclastic deposits. Abstract NS41A-1916 presented at 2015 Fall Meeting, AGU, San Francisco, Calif., 14-18 Dec.

[43] Gase, A. C., B. D. Brand, and J. H. Bradford (2017), Evidence of erosional self-channelization of pyroclastic density currents revealed by ground-penetrating radar imaging at Mount St. Helens, Washington (USA), Geophys. Res. Lett., 44, doi: 10.1002/2016GL072178.

[44] Gassmann, F. (1951), Elastic waves through a packing of spheres, Geophysics, 16, 673-685.

[45] Girolami, L., T. H. Druitt, O. Roche, and Z. Khrabrykh (2008), Propagation and hindered settling of laboratory ash flows, J. Geophys. Res., 113(B2), 1-13, doi:10.1029/2007JB005074.

[46] Giustiniani, M., F. Accaino, S. Picotti, and U. Tinivella (2008), Characterization of the shallow aquifers by highresolution seismic data, Geophys. Prospect., 56(5), 655-666, doi:10.1111/j.1365-2478.2008.00705.x.

[47] Gomez, C., F. Lavigne, N. Lespinasse, D. S. Hadmoko, and P. Wassmer (2008), Longitudinal structure of pyroclastic-flow deposits, revealed by GPR survey, at Merapi Volcano, Java, Indonesia, J. Volcanol. Geotherm. Res., 176(4), 439-447, doi:10.1016/j.jvolgeores.2008.04.012.

[48] Greaves, R. J., D. P. Lesmes, J. M. Lee, and M. N. Toksoz (1996), Velocity variations and water content estimated from multi-offset, ground-penetrating radar, Geophysics, 61(3), 683-695, doi: 10.1190/1.1443996.

[49] Gribler, G., L. M. Liberty, T. D. Mikesell, and P. Michaels (2016), Isolating retrograde and prograde Rayleigh-wave modes using a polarity mute, Geophysics, 81(5) V379-V385, doi: 10.1190/geo2015-0683.1. 
[50] Helgerud, M. B., J. Dvorkin, A. Nur, A. Sakai, and T. Collett (1999), Elasticwave velocity in marine sediments with gas hydrates: Effective medium modeling, Geophys. Res. Lett., 26(13), 2021-2024, doi: 10.1029/1999GL900421.

[51] Hill, R. (1952), The elastic behavior of crystalline aggregate, Proc. Phys. Soc. London, A65, 349-354.

[52] Holbrook, W. S., C. S. Riebe, M. L. Elwaseif, J. Hayes, K. L. BaslerReeder, D. Harry, A. Malazian, A. Dosseto, P. C. Hartsough, and J. W. Hopmans (2014), Geophysical constraints on deep weathering and water storage potential in the Southern Sierra Critical Zone Observatory, Earth Surf. Process. Landf., 39(3), 366-380, doi: 10.1002/esp.3502.

[53] Huisman, J. A., S. S. Hubbard, J. D. Redman, and A. P. Annan (2003), Measuring soil water content with ground penetrating radar, Vadose Zone J., 2(4), 476-491, doi: 10.2136/vzj2003.4760.

[54] Jessop, D. E., K. Kelfoun, P. Labazuy, A. Mangeney, O. Roche, J. L. Tillier, and G. Thibault (2012), LiDAR derived morphology of the 1993 Lascar pyroclastic flow deposits, and implication for flow dynamics and rheology, J. Volcanol. Geotherm. Res., 245, 81-97, doi:10.1016/j.jvolgeores.2012.06.030.

[55] Kelfoun, K., P. Samaniego, P. Palacios, and D. Barba (2009), Testing the suitability of frictional behaviour for pyroclastic flow simulation by comparison with a well-constrained eruption at Tungurahua volcano (Ecuador), Bull. Volcanol., 71(9), 1057-1075, doi:10.1007/s00445-009-0286-6.

[56] Kieffer, S. W., and B. Sturtevant (1988), Erosional furrows formed during the lateral blast at Mount St. Helens, May 18, 1980, J. Geophys. Res., 93(B12), 14793-14816, doi:10.1029/JB093iB12p14793.

[57] Kiser, E., I. Palomeras, A. Levander, C. Zelt, S. Harder, B. Schmandt, S. Hansen, K. Creager, and C. Ulberg (2016), Magma reservoirs from the upper crust to the Moho inferred from high-resolution Vp and Vs models beneath Mount St. Helens, Washington State, USA, Geology, 44(6), 411-414, doi:10.1130/G37591.1.

[58] Klug, C., and K. V. Cashman (1994), Vesiculation of May 18, 1980, Mount St. Helens magma, Geology, 22(5), 468-472, doi: 10.1130/00917613(1994)022;0468:VOMMSH $; 2.3 . C O ; 2$.

[59] Kokelaar, B. P., R. L. Graham, J. M. N. T. Gray, and J. W. Vallance (2014), Fine-grained linings of leveed channels facilitate runout of granular flows, Earth Planet. Sci. Lett., 385, 172-180, doi:10.1016/j.epsl.2013.10.043. 
[60] Kuntz, M. A., P. D. Rowley, N. S. MacLeod, R. L. Reynolds, L. A. McBroome, A. M. Kaplan, and D. J. Lidke (1981), Petrography and particle-size distribution of pyroclastic-flow, ash-cloud, and surge deposits, U. S. Geol. Surv. Bull., 1250, 525-539.

[61] Kuntz, M. A., P. D. Rowley, and N. S. MacLeod, (1990), Geologic map of pyroclastic-flow and related deposits of the 1980 eruptions of Mount St. Helens, Washington, U.S. Geol. Surv. Misc. Geol. Invest. Map, I-1950, U.S. Geol. Surv., Reston, Va.

[62] Lawyer, L. C., C. C. Bates, and R. B. Rice (2001), Geophysics in the affairs of mankind: A personalized history of exploration geophysics, No. 10, SEG Books, U.S.

[63] Manville, V., J. D. L. White, B. F. Houghton, and C. J. N. Wilson (1998), The saturation behaviour of pumice and some sedimentological implications, Sediment. Geol., 119(1-2), 5-16, doi: 10.1016/S0037-0738(98)00057-8.

[64] Mavko, G., and T. Mukerji (1998), Bounds on low-frequency seismic velocities in partially saturated rocks, Geophysics, 63(3), 918-924, doi: 10.1190/1.1444402.

[65] Mavko, G., T. Mukerji, and J. Dvorkin, (1998) The Rock Physics Handbook, Cambridge Univ. Press, New York.

[66] Miller, C. R., P. S. Routh, T. R. Brosten, and J. P. McNamara (2008), Application of time-lapse ERT imaging to watershed characterization, Geophysics, 73(3), 7-17, doi:10.1190/1.2907156.

[67] Mindlin, R. D. (1949), Compliance of elastic bodies in contact, J. App. Mech., 16, 259-268.

[68] Mohrig, D., and J. Buttles (2007), Deep turbidity currents in shallow channels, Geology, 35(2), 155-158, doi:10.1130/G22716A.1.

[69] Nagaoka, Y., K. Nishida, Y. Aoki, M. Takeo, and T. Ohminato (2012), Seismic imaging of magma chamber beneath an active volcano, Earth Planet. Sci. Lett., 333-334, 1-8 doi:10.1016/j.epsl.2012.03.034.

[70] Nur, A., G. Mavko, J. Dvorkin, and D. Galmudi (1998), Critical porosity: A key to relating physical properties to porosity in rocks, The Leading Edge, 17(3), 357-362, doi: 10.1190/1.1437977.

[71] Pasquet, S., W. S. Holbrook, B. J. Carr, and K. W. W. Sims (2016), Geophysical imaging of shallow degassing in a Yellowstone hydrothermal system, Geophys. Res. Lett., 43(23), 12,027-12,035, doi: 10.1002/2016GL071306. 
[72] Pittari, A., R. A. F. Cas, C. J. Edgar, H. J. Nichols, J. A. Wolff, and J. Mart (2006), The influence of palaeotopography on facies architecture and pyroclastic flow processes of a lithic-rich ignimbrite in a high gradient setting: The Abrigo Ignimbrite, Tenerife, Canary Islands, J. Volcanol. Geotherm. Res., 152(3-4), 273315, doi:10.1016/j.jvolgeores.2005.10.007.

[73] Pollock, N. M., B. D. Brand, and O. Roche (2016), The controls and consequences of substrate entrainment by pyroclastic density currents at Mount St Helens, Washington (USA), J. Volcanol. Geotherm. Res., 325, 135-147, doi:10.1016/j.jvolgeores.2016.06.012.

[74] Pouliquen, O., J. Delour, and S. B. Savage (1997), Fingering in granular flows, Nature, 386, 816-817, doi:10.1038/386816a0.

[75] Roche, O. (2012), Depositional processes and gas pore pressure in pyroclastic flows: an experimental perspective, Bull. Volcanol., 74(8), 1807-1820, doi:10.1007/s00445-012-0639-4.

[76] Roche, O., Y. Niño, A. Mangeney, B. Brand, N. Pollock, and G. A. Valentine (2013), Dynamic pore-pressure variations induce substrate erosion by pyroclastic flows, Geology, 41(10), 1107-1110, doi:10.1130/G34668.1.

[77] Roche, O., D. C. Buesch, and G. A. Valentine (2016), Slow-moving and fartravelled dense pyroclastic flows during the Peach Spring super-eruption, Nat. Commun., 7, 10890, doi:10.1038/ncomms10890.

[78] Rogers, J. J. W., and W. B. Head (1961), Relationships between porosity, media size, and sorting coefficients of synthetic sands, J. Sediment. Petrol., 31, 467-470.

[79] Rowley, P. J., P. Kokelaar, M. Menzies, and D. Waltham (2011), Shearderived mixing in dense granular flows, J. Sediment. Res., 81, 874-884, doi:10.2110/jsr.2011.72.

[80] Rozar, E. J. (2015), Defining Antecedent Topography at Coral Pink Sand Dunes, Kane County, Utah: The Influence of Structural Controls on Dune-field Boundary Conditions and Holocene Landscape Evolution, Masters Thesis, Boise State University.

[81] Russell, J. K., and M. V. Stasiuk (1997), Characterization of volcanic deposits with ground-penetrating radar, Bull. Volcanol., 58(7), 515527, doi:10.1007/s004450050159.

[82] Rust, A. C., J. K. Russell, and R. J. Knight (1999), Dielectric constant as a predictor of porosity in dry volcanic rocks, J. Volcanol. Geotherm. Res., 91(1), 79-96. 
[83] Rust, A. C., and J. K. Russell (2000), Detection of welding in pyroclastic flows with ground penetrating radar: insights from field and forward modeling data, J. Volcanol. Geotherm. Res., 95(1), 23-34.

[84] Rust, A. C., and J. K. Russell (2001), Mapping porosity variation in a welded pyroclastic deposit with signal and velocity patterns from ground-penetrating radar surveys, Bull. Volcanol., 62(6-7), 457-463.

[85] Santamarina, J. C., V. Rinaldi, D. Fratta, K. Klein, Y. H. Wang, G. C. Cho, and G. Cascante (2005), A survey of elastic and electromagnetic properties of near-surface soils, in Near-Surface Geophysics, edited by D. K. Butler, pp. 71-87, Soc. of Explor. Geophys., Tulsa, Okla.

[86] Scarpati, C., and A. Perrotta (2012), Erosional characteristics and behavior of large pyroclastic density currents, Geology, 40(11), 1035-1038, doi:10.1130/G33380.1.

[87] Small, C., and T. Naumann (2001), The global distribution of human population and recent volcanism, Environ. Hazards, 3, 93-109.

[88] Sparks, R. S. J., M. C. Gardeweg, E. S. Calder, and S. J. Matthews (1997), Erosion by pyroclastic flows on Lascar Volcano, Chile, Bull. Volcanol., 58(7), 557-565, doi:10.1007/s004450050162.

[89] Sparks R.S.J., Aspinall W.P., Crosweller H.S., Hincks T.K. (2013), Risk and uncertainty assessment of volcanic hazards, in Hill L., Rougier J., Sparks R.S.J., eds., Assessment of Risk and Uncertainty for Natural Hazards: Cambridge, Cambridge University Press.

[90] Topp, G. C., J. L. Davis, A. P. Annan (1980), Electromagnetic determination of soil water content: measurements in coaxial transmission lines, Water Resour. Res., 16(3), 574-582, doi: 10.1029/WR016i003p00574.

[91] Van Dam, R. L., and W. Schlager (2000), Identifying causes of groundpenetrating radar reflections using timedomain reflectometry and sedimentological analyses, Sedimentology, 47(2), 435-449, doi: 10.1046/j.1365-3091.2000.00304.x.

[92] Venzke, E., R. W. Wunderman, L. McClelland, T. Simkin, J. F. Luhr, L. Siebert, and G. Mayberry (2002), Global Volcanism, 1968 to the Present, Digital Inf. Ser., GVP-4, Global Volcanism Program, Smithson. Inst., Washington, D. C. (Available at http://www.volcano.si.edu/gvp/reports/).

[93] Walton, K. (1987), The effective elastic moduli of a random packing of spheres, J. Mech. Phys. Solids, 35, 213-226. 
[94] Wharton, R. P., G. A. Hazen, R. N. Rau, and D. L. Best (1980), Electromagnetic propagation logging: advances in technique and interpretation, paper presented at the 55th Annual Fall Technical Conference and Exhibition, Soc. Petrol. Eng., paper 9267, Dallas, TX.

[95] Whitham, A. G., and R. S. J. Sparks (1986), Pumice, Bull. Volcanol., 48(4), 209-223.

[96] Wilson, L., and J. W. Head (1981), Morphology and rheology of pyroclastic flows and their deposits, and guidelines for future observations, U.S. Geol. Surv. Bull., 1250, 513-524.

[97] Witham, C. S. (2005), Volcanic disasters and incidents: A new database, J. Volcanol. Geotherm. Res., 148(3-4), 191-233, doi:10.1016/j.jvolgeores.2005.04.017.

[98] Wohletz, K., and G. Heiken (1992), Volcanology and Geothermal Energy, Berkeley: University of California Press, U.S.

[99] Wynn, J., A. Mosbrucker, H. Pierce, and K. Spicer (2016), Where is the Hot Rock and Where is the Ground Water Using CSAMT to Map Beneath and Around Mount St. Helens, J. Environ. Eng. Geophys., 21(2), 79-87, doi:10.2113/JEEG21.2.79.

[100] Zimmer, M. A., M. Prasad, G. Mavko, and A. Nur (2007), Seismic velocities of unconsolidated sands: Part 1 Pressure trends from 0.1 to $20 \mathrm{MPa}$, Geophysics, 72(1), E1-E13, doi: 10.1190/1.2399459. 